\title{
Thematic teaching and student engagement in a non-academic Year 12 mathematics course
}

\author{
David Charles Hay Pomeroy
}

A three paper thesis submitted in partial fulfilment of the requirements for the degree of Master of Education

Victoria University of Wellington

May 2011 



\begin{abstract}
The recently revised New Zealand Curriculum (Ministry of Education, 2007) encourages mathematics teachers to engage their students through the use of meaningful contexts for learning. One approach to making contexts for mathematics more meaningful is to explore a single context over a series of lessons, an approach known as thematic teaching. Prior studies of thematic mathematics teaching have failed to reach a consensus on the relationship between thematic teaching and student outcomes such as achievement and attitude toward learning.

This study used a pragmatic, mixed methods design to examine the relationship between thematic teaching and student engagement with two classes of lowachieving senior students in a New Zealand secondary school. It examined which student characteristics appeared to be related to whether students engaged with thematic teaching, and the reason students gave for their preferred teaching styles. Students experienced four thematic lessons with the theme of the human settlement of the Pacific Islands and four non-thematic lessons during a coordinate geometry topic. Each student's engagement was assessed every lesson using questionnaires and observations, and students were interviewed in order to elicit their views on thematic teaching.
\end{abstract}

Collectively, no difference was found between student engagement in thematic and non-thematic teaching. However, many individual students found either thematic or non-thematic teaching more engaging. English language learners tended to prefer non-thematic teaching, some reporting that they found the theme an unhelpful complication. There is preliminary evidence that Pakeha students may engage with thematic teaching to a greater extent than Pasifika students. Students did not engage in learning when they did not understand the mathematical content, even when they were interested in the theme.

The study augments the thematic mathematics teaching literature by examining variability in the apparent effects of thematic teaching, and articulating students' experiences of thematic teaching. It gives guarded support for the current policy emphasis on teaching mathematics contextually and reveals some potential pitfalls associated with teaching mathematics thematically. 


\section{Acknowledgements}

I wish to acknowledge the support of my supervisor, Robin Averill, for her dedicated and astute support throughout the research process. With her keen intellect, warm humour, and genuine desire to see greater equity in mathematics classrooms, she is has been not only an outstanding supervisor but an inspiration in terms of what an educational academic can do to enhance practice in their field. She is always encouraging, honest, and constructive in the feedback she provides. Matt McCrudden and Flaviu Hodis provided valuable methodological advice.

This study would not have been possible without the willing support and cooperation of the participating students and teachers from Parkville College (a pseudonym). To preserve anonymity, they cannot be identified by name.

Liz Hay was my keen-eyed proof-reader. Alix Klein went the extra mile to provide excellent and timely administrative support in a busy postgraduate office. Sheila Law manages an enviable office complex for research students, which greatly enhanced the sometimes daunting journey of completing thesis research. The cleaners and ground staff at the Karori Campus, Victoria University of Wellington provided a beautiful study environment.

Finally Rachel Catherine Hay Pomeroy, who became my wife shortly after the submission of my first draft, provided invaluable personal support, encouragement, and companionship. Thank you. 


\section{Table of Contents}

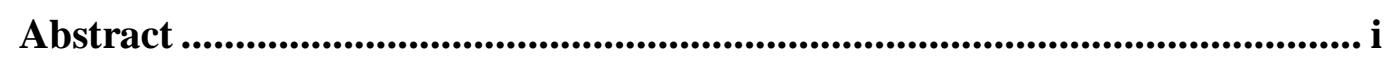

Acknowledgements................................................................................. ii

Tables...................................................................................................... vii

Figures ........................................................................................ viii

Abbreviations ......................................................................................................... ix

Chapter 1: Introduction........................................................................................... 1

1.1 Secondary mathematics pathways in New Zealand............................... 3

1.2 New directions in New Zealand education policy ................................ 4

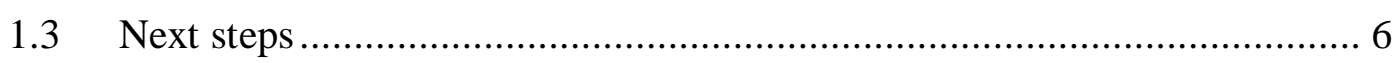

Chapter 2: Review of literature .......................................................................... 7

2.1 Context and thematic teaching ........................................................ 7

2.1.1 Definitions: Context and thematic teaching ................................... 8

2.1.2 Implementation of thematic teaching .........................................10

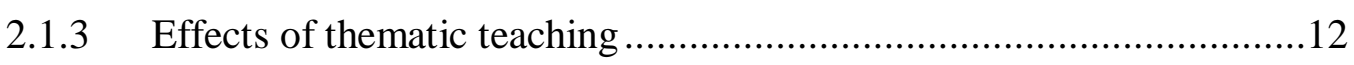

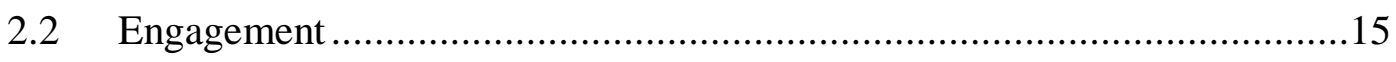

2.2.1 Engagement in literature ......................................................... 16

2.2.2 Substantive importance of engagement ........................................17

2.2.3 Measurability of engagement ................................................ 18

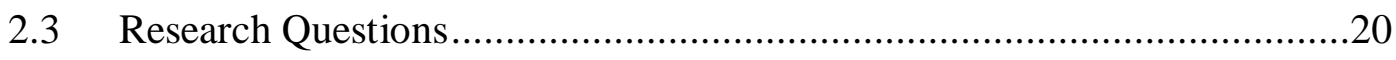

Chapter 3: Methods ..................................................................................22

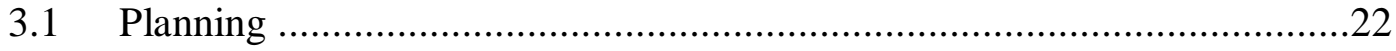

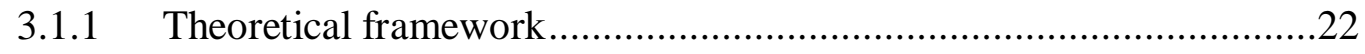

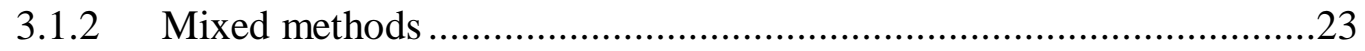

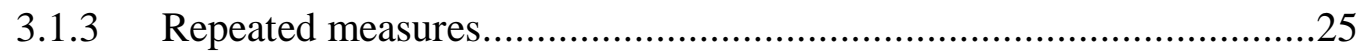

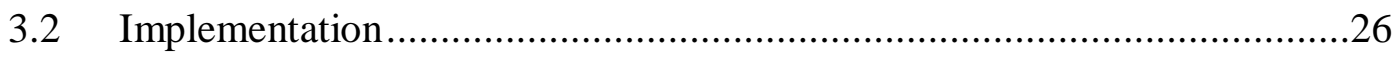

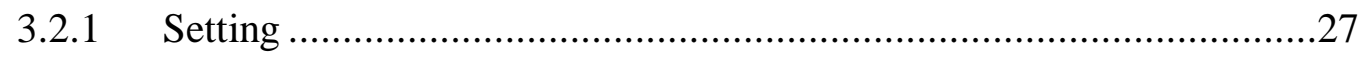




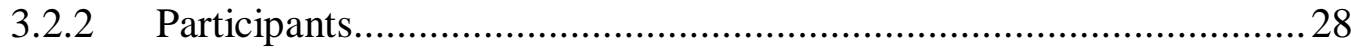

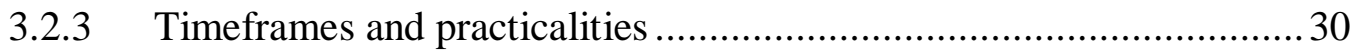

3.2.4 Thematic and non-thematic teaching ............................................. 33

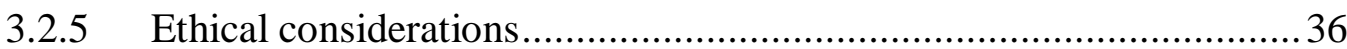

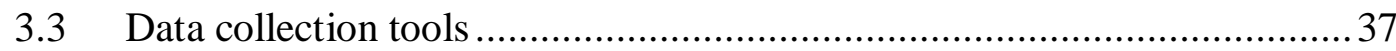

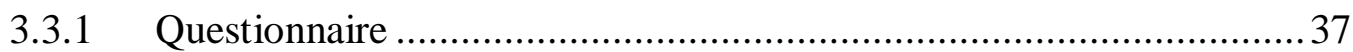

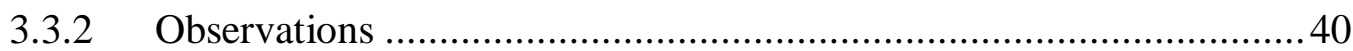

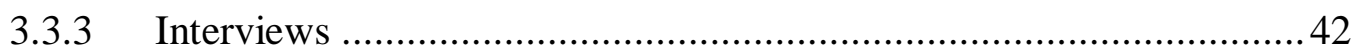

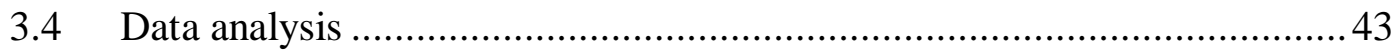

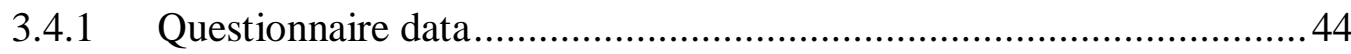

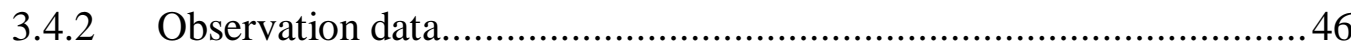

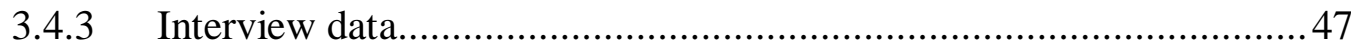

3.4.4 Data reliability and coverage …............................................. 47

Chapter 4: Results and analysis ..............................................................49

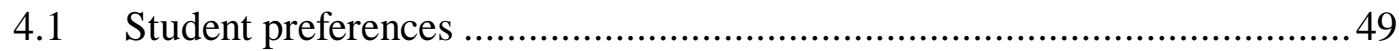

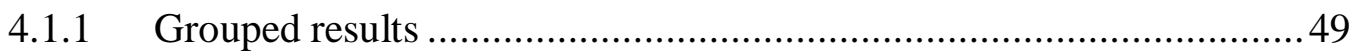

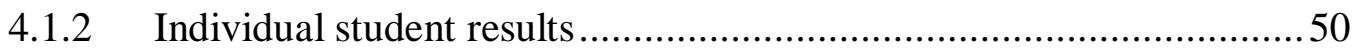

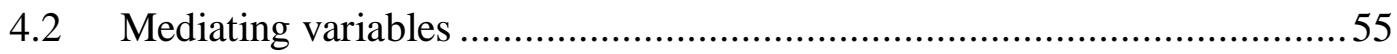

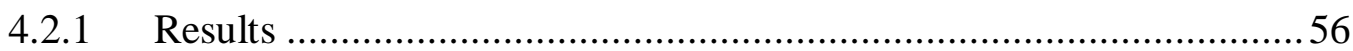

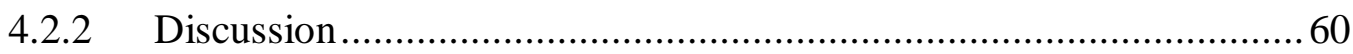

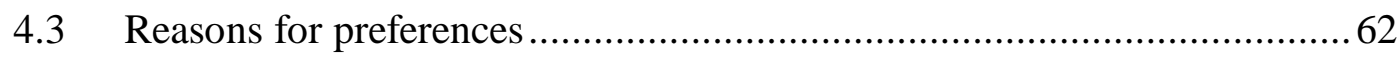

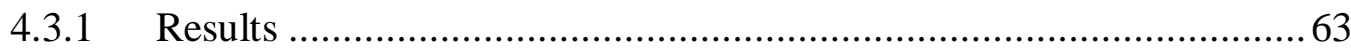

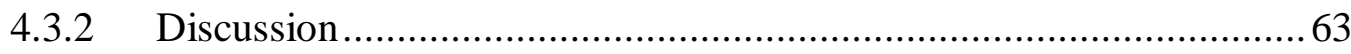

Chapter 5: Conclusions ...........................................................................66

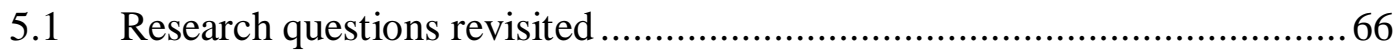

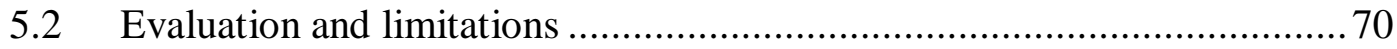


5.2.1 Theoretical framework

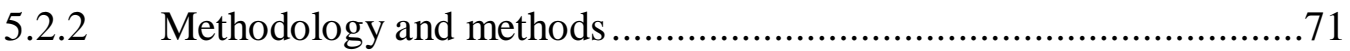

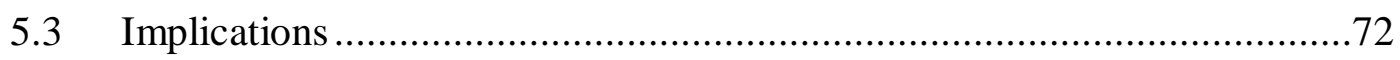

5.3.1 Implications for teaching practice .......................................... 73

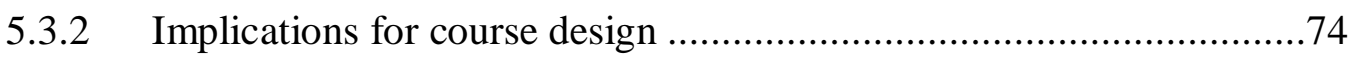

5.3.3 Implications for policy and curriculum ..................................... 74

5.3.4 Implications for future research ................................................. 75

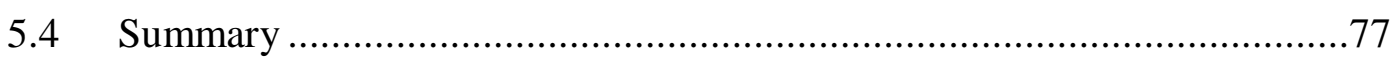

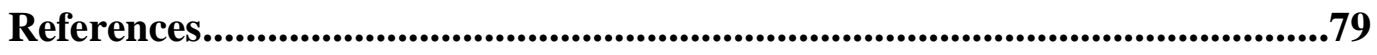

Appendices ......................................................................................................................84

Appendix A. Reports of the implementation of thematic teaching ...................84

Appendix B. Studies of the effects of thematic teaching ..............................86

Appendix C. Engagement questionnaire ............................................. 89

Appendix D. Observation schedule Version 2 .......................................... 91

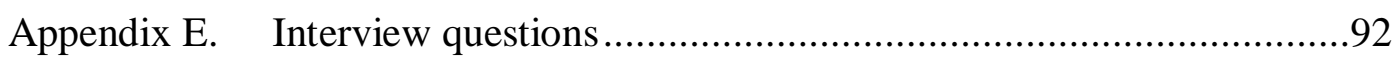

Appendix F. Sample thematic worksheet ................................................93

Appendix G. Thematic worksheet for Lesson 1 ...........................................95

Appendix H. Student information letter ................................................ 98

Appendix I. Student consent form ................................................... 100

Appendix J. Validation of self-report questionnaire .................................101

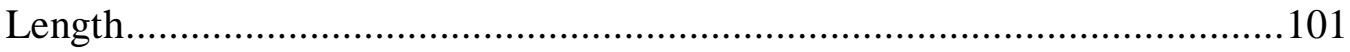

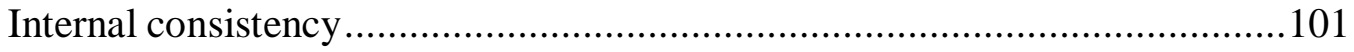

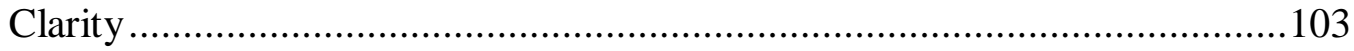

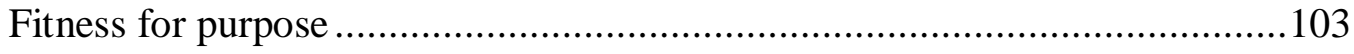

Appendix K. Observation schedule Version 1 ......................................... 105

Appendix L. Page 1 of thematic revision sheet ...........................................107 
Appendix M. Page 1 of non-thematic revision sheet.................................... 108

Appendix N. Inter-item correlations for engagement questionnaire ...............109

Appendix O. Item statistics for engagement questionnaire ........................... 110 


\section{Tables}

Table 1. School Criteria and Parkville College ...................................................27

Table 2. Interpretation of TPI Values ...........................................................45

Table 3. Distribution of Student Preferences .........................................................52

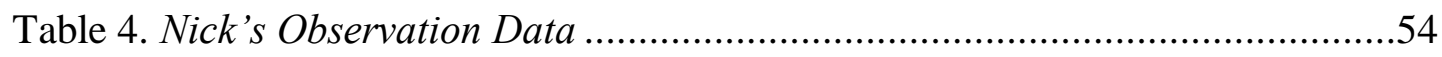

Table 5. Preference Distributions by Class Membership .....................................56

Table 6. Preference Distributions by ELL status ...............................................57

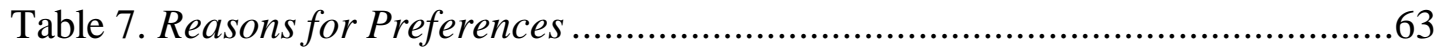




\section{Figures}

Figure 1. Simplified diagram of counterbalanced, repeated measures design ..........25

Figure 2. Participant and school ethnic profiles ................................................29

Figure 3. Design of experimental phase .......................................................... 32

Figure 4. Item 1 in the engagement questionnaire ............................................ 44

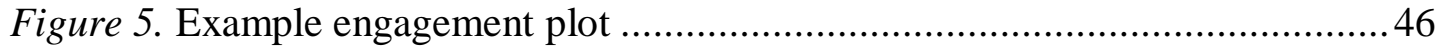

Figure 6. Number of lessons students were present in class ...............................48

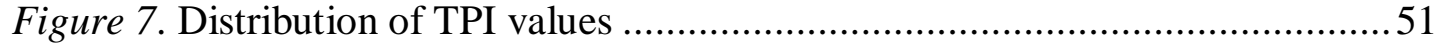

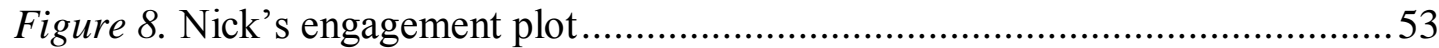

Figure 9. Effects of class membership and ELL status on TPI …........................58

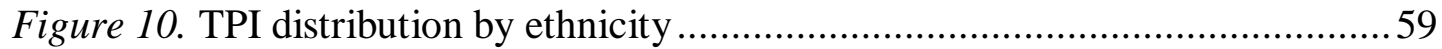

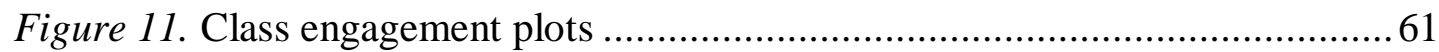




\section{Abbreviations}

EI Engagement Index

ELL English Language Learner

TPI Thematic Preference Index

NCEA National Certificate of Educational Achievement

NZQA New Zealand Qualifications Authority 



\section{Chapter 1: Introduction}

Prior to embarking on the study which culminated in this thesis, I taught mathematics at a large, coeducational secondary school in suburban New Zealand. During this time I joined the generations of mathematics teachers who have been asked, "what is the point of learning this?", "how is this going to help me in real life?", and "when am I ever going to use Pythagoras' Theorem?" My impression was that many students struggled to connect the content of mathematics lessons in any meaningful way to the world outside the classroom, and viewed mathematics as a hoop to jump through in order to achieve school success. In my experience this attitude towards mathematics learning was evident in the preoccupation of many senior students with the gaining of credits towards their school qualifications rather than with the value of mathematics learning for its own sake or its practical utility.

One strategy by which I attempted to enhance the relevance of mathematics to students was to embed learning in a single real-world context for several consecutive lessons, thereby providing an extended illustration of the mathematics of that realworld context. This approach to teaching is sometimes called thematic teaching (Handal \& Bobis, 2004), and the context a theme, because the context is a common feature of a number of individual learning tasks. My most successful attempt at teaching thematically occurred during 2008, using the theme of the Beijing Olympic Games. Activities included constructing graphs of medal tallies, calculating mean speeds in races of various distances, and measuring time and distance in our own athletic events, drawing in mathematical content from a range of mathematical areas. The lessons had the uniting theme of the Beijing Olympics rather than covering skills, strategies, and understandings drawn from a single mathematical content domain. My impression was that students found the Olympics topic highly engaging, and there are individual lessons of which I still carry fond memories.

This thesis describes a study in which I returned to the school setting as a researcher to evaluate the effectiveness of thematic teaching with two classes of low-achieving senior mathematics students. As a teacher my intuition was that thematic teaching engaged students more fully in learning mathematics than the more traditional non- 
thematic methods that I usually employed. Approaching thematic teaching as a researcher enabled me to explore the influence of thematic teaching as a nonteaching observer, informed by extensive literature on thematic teaching and engagement ${ }^{1}$, and equipped with a variety of methods for monitoring students' engagement. The following paragraphs sketch an outline of the structure of this fivechapter thesis.

Chapter One outlines some typical features of teaching in mathematics courses intended for less mathematically capable senior students in New Zealand, with particular attention to the extent to which mathematics is embedded in real-world contexts. Two potential catalysts for change in teaching practice are then examined: the recently revised New Zealand Curriculum (Ministry of Education, 2007) and the national review of standards against which students can be assessed. Overall, the chapter outlines the status quo of senior mathematics teaching in New Zealand and suggests that a shift towards a more thematic approach could enhance students' engagement and therefore merits further investigation.

Chapter Two summarises some existing knowledge and debate relevant to thematic teaching of mathematics to senior secondary students in New Zealand. The literature reviewed includes prior studies of the effects of thematic teaching, and literature concerning the learning of mathematics and its relationship to student engagement. In Chapter Two it is argued that, taken together, prior studies produce no definite conclusion regarding the benefits of thematic teaching; instead it seems that thematic teaching can enhance learning, but that this effect is inconsistent across students. The existing literature leaves us with question regarding why some students and not others benefit from thematic teaching, and this question is adopted as the primary focus of the empirical component of the study. Chapter Two concludes with the specific research questions to be addressed in the empirical component of this study.

Chapter Three describes the planning and implementation of the empirical study on which this thesis is based. Two teachers of lower-ability senior mathematics classes agreed to teach four consecutive lessons of a coordinate geometry topic thematically,

\footnotetext{
${ }^{1}$ The term engagement is formally defined in Section 2.2.1.
} 
using the theme of the indigenous settlement of the Pacific Islands. For both classes, student engagement in learning was assessed during four thematic lessons and four non-thematic lessons, using classroom observations and student questionnaires. Both teachers and many of the students were also interviewed to elicit their views and experiences of thematic teaching. In Chapter Four the questionnaire, observation, and interview data are analysed using a mixed methods approach to identify individual students' preferences for thematic or non-thematic teaching.

Chapter Five summarises the key outcomes of the study and how they contribute to the broader field of literature concerning thematic teaching. Suggestions are made for further research which could build on the results of the current study, and implications of the study for policy, course design and teaching practice are discussed.

\subsection{Secondary mathematics pathways in New Zealand}

This section describes those aspects of the New Zealand education system that must be understood in order to appreciate what it means to be in a non-academic ${ }^{2}$ senior $^{2}$ mathematics course. It also describes the typical circumstances that lead students to enter such courses.

New Zealand secondary schooling consists of up to five years of study, normally starting at age twelve in Year 9. In New Zealand Years 9 and 10 are generally referred to as junior secondary school and Years 11 to 13 as senior secondary school. New Zealand's main secondary school qualifications are the National Certificates of Educational Achievement (NCEAs), which can be gained at three levels. Typically students sit assessments towards their NCEA Level One certificate in Year 11, their NCEA Level Two certificate in Year 12 and their NCEA Level Three certificate in Year 13, although many leave school after gaining only a Level One or Two certificate. Students sit a combination of internal assessments, administered by schools throughout the year, and external assessments, national examinations which students sit at the end of the year. Each assessment corresponds to Level One, Two, or Three of NCEA and contributes a given number of credits, towards the

${ }^{2}$ The term non-academic is adopted here as it was used by teachers at the school where the study took place. 
corresponding certificate. Most mathematics assessments have a credit value of two to four and most senior students have the opportunity to gain up to 24 mathematics credits per year towards the eighty required for each certificate. The standards assessed are either Achievement Standards, which may be graded Not Achieved (no credits gained), or Achieved, Merit, or Excellence (passing grades), or Unit Standards which may only be graded Not Achieved or Achieved (NZQA, 2010a).

The NCEA system enables schools to allocate students into mathematics courses based on their ability and prior achievement, choosing standards deemed by teachers to be most appropriate for the students in that class. Typically, students who have gained poor results in Year 10 proceed to a non-academic Year 11 course designed for less able students and often consisting entirely of internally assessed work. These students, should they choose to take mathematics in Year 12, will proceed to a similar course, which may assess them against Level 1 and Level 2 standards. Nonacademic courses do not aim to prepare students adequately for the mathematically challenging NCEA Level Three courses Calculus or Statistics and Modelling. There is significant overlap between the mathematical content of some Achievement Standards and Unit Standards, however, the most straightforward Unit Standards are less challenging than the Achievement Standards that pertain to the same mathematical content area, especially in Number. Thus the non-academic courses tend to be assessed primarily with Unit Standards.

\subsection{New directions in New Zealand education policy}

New Zealand schools are currently in the process of implementing a recently revised New Zealand Curriculum (Ministry of Education, 2007), which has a strong focus on the central importance of student engagement. In mathematics, the curriculum explicitly links student engagement with the use of meaningful contexts. Every mathematics Achievement Objective is prefixed with: 
"In a range of meaningful contexts, students will be engaged in thinking mathematically and statistically. They will solve problems and model situations ${ }^{3}$..." (Ministry of Education, 2007, non-numbered foldout pages).

As such, meaningful contexts and being engaged in thinking mathematically and statistically are both centrally embedded in New Zealand's official policy on teaching and learning mathematics in schools. For teachers, this emphasis raises the question of what makes a context meaningful, and how best to facilitate engagement in mathematical and statistical thinking ${ }^{4}$. Thematic teaching uses a single real-world context over a series of lessons and has the potential to help make contexts meaningful to students, thereby increasing their engagement in mathematical thinking (Chapter 2). Furthermore, the New Zealand Curriculum (Ministry of Education, 2007) provides some guidance for teachers seeking to choose appropriate and meaningful themes or contexts for learning mathematics: "Mathematicians ... create models to represent both real-life and hypothetical situations. These situations are drawn from a wide range of social, cultural, scientific, technological, health, environmental, and economic contexts" (Ministry of Education, 2007, p. 26). Thus the current study addresses an issue that is pertinent to the practice of teachers attempting to implement the New Zealand Curriculum in the mathematics classroom.

A further reason for the timeliness of the topic is that all Unit Standards which are linked to the New Zealand Curriculum (Ministry of Education, 2007) at Curriculum Level Six and above will be deregistered as part of a standards review ${ }^{5}$ (NZQA, 2009). All NCEA Level Two mathematics Unit Standards will be removed, since they are linked to the New Zealand Curriculum at Level Seven. Thus school curriculum leaders designing non-academic Year 12 courses will need to assess students against the revised Level Two Achievement Standards if they wish to offer any credits at Level Two. Non-academic Year 11 courses will not need such

\footnotetext{
${ }^{3}$ This is followed by specific objectives such as "...relate rate of change to the gradient of a graph".

${ }^{4}$ This thesis will not distinguish between mathematical thinking and statistical thinking.

${ }^{5}$ At the time of the study, NZQA was in the process of reviewing all accredited standards used for assessment in secondary schools. There are plans for significant changes in mathematics standards, including the complete removal of many Unit Standards. For an explanation of Unit Standards and Achievement standards, see New Zealand Qualifications Authority website (NZQA, 2010a).
} 
extensive revision as some of the Unit Standards currently offered in these courses will remain available and Year 13 non-academic courses tend to have low numbers and high rates of attrition throughout the year. The major revision that Year 12 courses will require is an ideal opportunity to integrate thematic teaching into course plans, should it have a positive impact on engagement.

\subsection{Next steps}

This chapter has described the circumstances that can lead to classes of senior mathematics classes which have high concentrations of poorly motivated students with histories of failure in mathematics. At the same time, a revised national curriculum is advocating an approach to teaching and learning in which the relevance of learning is clear, and where mathematics learning in particular is meaningfully linked to a range of contexts. Thematic teaching is one way to show the real-world applications of mathematics, which could perhaps make the subject more relevant to students and increase their engagement with learning. In order to formulate research questions which will form the basis for a fruitful and original study, it is necessary to investigate what is already known about the effect of thematic teaching in mathematics. These questions will also be more precise in their focus if the terms thematic teaching and engagement, introduced and briefly described in this introductory chapter, are further refined. Chapter Two reviews prior studies of thematic teaching so as to move beyond the anecdotal discussion of thematic teaching presented so far. It also probes in more depth what is meant by engagement, and why engagement could prove informative as an outcome variable. Chapter Two will lead to research questions which, whilst they have their genesis in my personal teaching experience, have been refined and informed by the work of prior educational research. 


\section{Chapter 2: Review of literature}

Broadly stated, the educational problem that this study seeks to address is that some senior students in non-academic mathematics classes are not fully engaged in learning. I have recounted teaching experiences that led me to question whether the sustained use of a single context (i.e. thematic teaching) could give students more meaningful learning experiences than piecemeal use of multiple, unrelated contexts, or no context at all. However, prior to posing research questions, it is necessary to take into account relevant literature, in addition to the personal experiences and policy documents alluded to in Chapter One.

The goals of this chapter are:

- to review prior studies of the effects of thematic teaching and summarise areas of consensus and dispute with respect to the effect of thematic teaching on student engagement (Section 2.1);

- to examine and more clearly define what is meant by engagement, and to evaluate the substantive importance and practical feasibility of using engagement as an outcome variable (Section 2.2) and;

- to pose clearly defined and testable research questions of substantive educational interest (Section 2.3).

\subsection{Context and thematic teaching}

Whilst many factors such as students' family lives, work obligations, and leisure pursuits influence their engagement (Fredricks, Blumenfeld, \& Paris, 2004; Yair, 2000), this study focuses on the influence of thematic mathematics teaching on engagement. The review of the thematic mathematics teaching literature is reported in three subsections:

- clarification of how the terms context and thematic teaching have been used in prior literature and how they will be used in this thesis (Section 2.1.1); 
- description of various approaches to thematic teaching recorded in the literature, especially those relating to mathematics (Section 2.1.2); and

- summary of existing empirical findings and theoretical predictions concerning the effects of thematic teaching, especially in mathematics (Section 2.1.3).

\subsubsection{Definitions: Context and thematic teaching}

\section{$\underline{\text { Context }}$}

The term context has a range of specific meanings such as the socio-political context of a national education system or aspects of the school context in which a student learns. For clarity, within this thesis context only refers to the context of a mathematical task, the "social, cultural, scientific, technological, health, environmental, and economic contexts" referred to in the New Zealand Curriculum (Ministry of Education, 2007). The context may be a real or imagined event, process or object that forms the narrative basis of one or more mathematical tasks, often referred to as word problems in New Zealand schools. Numerous studies have used context in this sense (e.g., Chronaki, 2000; Lam, 2007; Saenz, 2009), and commonly used synonyms include "everyday life" (Saenz, 2009, p. 126), "real world" (Ching, 2009, p. 420), and "real" problems (Lam, 2007, p. 274), although contexts may also be imaginative or fictional (Beaton, 2004; Nicol \& Crespo, 2005).

Thematic teaching is teaching in which a single context or a group of closely related contexts forms the basis of a unit of learning Handal and Bobis (2004). A theme can be conceived as a context in which a variety of learning experiences are situated over an extended period of time (e.g., Lam, 2007; Lipson, Valencia, Wixson, \& Peters, 1993). Thus the difference between thematic teaching of mathematics and using contextual problems is that the same broad context is used in many problems, often over a series of lessons. Some authors further clarify the meaning of thematic teaching by contrasting thematic teaching with the fragmented, piecemeal approach that textbooks often bring to the contexts of word problems (Handal \& Bobis, 2004; Saenz, 2009). 
Roth (1996) wrote an insightful philosophical analysis of the context of mathematical problems, providing three overlapping senses in which context can be understood. Two of these provide a theoretical framework for predicting and interpreting the impact of various contexts on learning in the classroom. Firstly, context can refer to "all additional knowledge necessary to understand the mathematical problem" (Roth, 1996, p. 491). This definition is theoretically useful because context includes what is explicitly stated in a problem and what is implied but not stated. Not all students will form the same interpretations of what knowledge is implied, therefore the context as it is actually construed by each student may vary, depending on factors such as the student's background knowledge, experiences, and level of reading comprehension (Ajideh, 2003).

Secondly, context can refer to a phenomenon, such as an Olympic sprint race, that can be expressed mathematically and hence can be used in word problems. This definition of context as a phenomenon that students experience provides a theoretical link between context and engagement. Roth explains that

when students meaningfully appropriate [mathematics] by engaging with the phenomenon, the latter can be considered that context which elaborates the meaning [of the mathematics]. (Roth, 1996, p. 491).

Framing context as a phenomenon that students need to engage with in order to "meaningfully appropriate" mathematics (Roth, 1996, p. 491) highlights the importance of student engagement with the context in learning mathematics.

Roth's (1996) perspectives provide a student-centred way of framing context in mathematics problems. A context is determined partly by the interpretive lens of each student and is not entirely circumscribed by the author of the problem. Nor is a context defined simply by an objective description of some real-world or imagined situation; it is experienced by students and gives meaning to the associated mathematics to the extent that students engage with that experience. Roth's (1996) theoretical standpoint on the context of mathematics problems has two implications for the interpretation of thematic teaching studies. 
Firstly, not all phenomena are equally engaging (Boaler, 1993) so the effects of thematic teaching may vary between studies depending on how engaging the chosen theme is. Therefore one must be wary of extrapolating results from a study in which a specific theme was used, to apply to thematic teaching in general; it may not be valid to generalise results across different themes. Secondly, students can be expected to differ in terms of the extent to which they engage with a particular theme, because students have different interests and prior knowledge (Beswick, 2011). Therefore it is reasonable to expect variation between students' levels of engagement with thematic teaching, so it may not be valid to generalise across students, even within the same theme.

The value of teaching mathematics contextually has been subject to discussion for some time (e.g., Boaler, 1993; Chronaki, 2000; Ross, McCormick, \& Krisak, 1986), with authors warning that teaching mathematics in context will not automatically or necessarily improve student achievement or engagement. For example, Boaler (1993, p. 17) claimed that even when mathematics is taught in a realistic context, students still perceive it as "school mathematics" rather than treating problems as they would outside the classroom. In a recent review of evidence for the benefits of contextualised mathematics tasks, Beswick concludes that "the available evidence suggests that context problems provide no simple answers to the problems of student engagement" (Beswick, 2011, p. 381).

\subsubsection{Implementation of thematic teaching}

A range of educational research databases was searched in order to find studies reporting different ways in which thematic teaching had been implemented. My own thematic teaching was improvised in an ad hoc manner, so this stage of the literature review aimed to provide a more comprehensive overview of possibilities for implementation. The Introduction and Literature Review of Handal and Bobis' (2004) article on teachers' views of the barriers to implementation of thematic teaching provided an informative review of the field of thematic teaching in mathematics, which many of the more recent articles referred to. Appendix A summarises a variety of empirical studies which describe the implementation of 
thematic teaching. Many of these studies also reported effects of thematic teaching, and the effects are discussed in Section 2.1.3. A diverse selection of these studies, chosen to illustrate the broad range of thematic interventions, participant, and settings, is summarised below.

The articles reviewed (Appendix A) described a wide range of themes. Some themes, such as Harry Potter (Beaton, 2004), were fictional whilst others, such as business education (Olicker, 2005), were more practical. Some studies of thematic mathematics teaching used data gathered on a practical field trip as the basis for later work in the classroom. For example, Roth (1996) conducted classroom-based activities based on biological data gathered outside the classroom, and Perry and Howard (2008) took predominantly Australian Aboriginal students to a local site of cultural and historical significance and based mathematical learning tasks on this experience. Eight years prior to my own thematic topic based on the Beijing Olympics, Anderson and Schaffner (2000) published a series of resources they had used to teach mathematics based on an Olympic theme during the 2000 Sydney Olympic Games.

Much of the literature on thematic teaching relates to themes used simultaneously across several subject areas, often referred to as integrated learning (e.g., Beaton, 2004; Ching, 2009; Leonard, 2004; Lipson, et al., 1993; Loughran, 2005). For example, Beaton (2004) designed and taught a Year 6 Canadian class an integrated topic which combined mathematics, science, and English, based on the theme of Harry Potter. The author describes how the engaging fantasy theme made "subjects that might seem ordinary in the course of the curriculum take on a new dimension" (Beaton, 2004, p. 16).

Other studies describe thematic teaching within a single subject area such as English (Lipson, et al., 1993), technology (Ching, 2009), science (McCarthy, 2005), or mathematics (e.g., Henderson \& Landesman, 1992; Roth, 1996; Taylor, 1999). These studies examined the relationship between thematic teaching and variables such as achievement, motivation, and behaviour. Participants ranged from primary to tertiary students and had a wide range of academic abilities. Although all of these studies described the teaching implementation as thematic, the interventions often included 
simultaneous, far-reaching modifications to teaching practice, such as increased practical work (McCarthy, 2005) or interaction with technology (Ching, 2009; Taylor, 1999), and practical field trips (Perry \& Howard, 2008; Roth, 1996).

\subsubsection{Effects of thematic teaching}

This section of the literature review examines prior studies that contribute to knowledge about the effects of thematic teaching. Studies included describe the implementation of a thematic teaching intervention in a school or adult education setting and report on one or more outcome (dependent) variables, such as achievement, attitude towards mathematics, or behaviour. The studies can be considered evaluation studies of thematic teaching (Johnson \& Christensen, 2008) because they attempt to ascertain the effect of thematic teaching on some outcome variable of substantive educational importance.

An illustrative sample of the studies reviewed is included in Appendix B and summarised below. Studies were chosen to demonstrate the range of settings, participants, methodologies and findings that were present in the literature that was reviewed. Studies were conducted in the US, UK, Canada, Australia, Taiwan, and Singapore. No New Zealand studies were found which directly addressed the effects of thematic teaching. The participants ranged from primary to adult students, although the most frequently studied age group was Year 7 to Year 10 (ages $10-$ 14). Few studies included senior secondary school students over the age of 15 . Two US studies and one Australian study had a specific focus on students who were not achieving good results in mathematics (Henderson \& Landesman, 1992; McCarthy, 2005; Perry \& Howard, 2008). Henderson and Landesman's (1992) study of junior secondary Australian Aboriginal students with mathematical tasks related to a field trip to a site of local cultural significance reported increased engagement in learning based on teacher and parent interviews. The US studies both reported some academic gains as a result of thematic interventions, but no improvement in behaviour (McCarthy, 2005) or attitude towards mathematics (Henderson \& Landesman, 1992).

A variety of qualitative, quantitative and mixed methodologies was employed in the studies reviewed, and the methodologies determined the nature of the findings that 
each study was able to generate. The quasi-experimental and correlational studies that gathered quantitative achievement data from large numbers of students and used the thematic intervention for at least one year had the greatest statistical power in terms of establishing a relationship between thematic teaching and the outcome variable or variables (Johnson \& Christensen, 2008). Of these studies, Ching's (2009) study of Taiwanese primary students' achievement after a year of a computerbased thematic teaching programme had mixed results; some year groups showed small increases in mathematics achievement after one year relative to students who had received non-thematic teaching, whilst other year groups showed small decreases in achievement, and some showed no difference at all. Henderson and Landesman's (1992) US study of at-risk middle-school students of Mexican descent showed that a year of thematic teaching improved these students' achievement in mathematics but had no effect on their attitudes towards mathematics. The most positive result obtained in a large-scale study comes from Taylor's (1999) UK study of Year 7-8 students, which reported a significant positive correlation between time spent on a computer-based thematic learning programme and achievement at the end of one year, after controlling for start-of-year achievement. Taken together, the studies present an inconclusive picture of the effects of thematic teaching on student achievement. Furthermore, the nature of the thematic intervention in each case is multi-layered, with any effect of thematic teaching, as defined in the current study, confounded by increased use of computer technology (Ching, 2009; Taylor, 1999) or cooperative learning groups and practical tasks (Henderson \& Landesman, 1992).

Studies with smaller sample sizes, when taken together, present a similarly disparate set of findings. For example, Leonard's (2004) US study of Year 7 students reported that a thematic programme which integrated mathematics, English and mathematics around the theme of architecture improved students' motivation, time on task, and attitude towards mathematics. The following year, Olicker's (2005) US study of Year 10 students reported that a thematic mathematics intervention using the theme of business education resulted in no improvement in academic performance. In summary, the studies reviewed (Appendix B), when taken together, are inconclusive with respect to the effect of thematic teaching on student achievement and attitude 
towards mathematics, with positive and neutral (but not negative) effects reported for both achievement and attitude towards mathematics.

Two of the Australian studies reviewed (Perry \& Howard, 2008; Wilson, 2009) had samples which included senior secondary students; these studies were also the only ones to include student engagement as an outcome variable. Both studies reported increased student engagement as a result of thematic mathematics teaching. However, in both studies the evidence of increased engagement came solely from debrief interviews with teachers, rather than from direct observations of or reports from students, and should be interpreted cautiously.

Before summarising what can be concluded about the effects of thematic teaching from the existing literature, recall the discussion of Roth's (1996) theorising of context; critically, that Roth's view implies that thematic teaching will not have uniform effects across all students or all themes. Hence this summary does not seek to form a general conclusion about the effects of all thematic teaching, for there may be none.

Prior studies have suggested that thematic teaching can have a positive effect on students' mathematical achievement, but that it does not always do so. Furthermore, they have shown that thematic teaching can improve students' attitudes towards mathematics but that, again, this is not always the case. The two reviewed studies that report on student engagement as an outcome variable claim that, in teachers' opinions, thematic teaching improved student engagement. Thus it is unclear whether one should expect thematic teaching to affect the achievement or attitudes towards mathematics of New Zealand senior secondary students in non-academic classes. There is some evidence that thematic teaching could have a positive effect on students' engagement, but this is based on teachers' impressions in two overseas studies and should be treated as a tentative indication only.

The question of whether thematic teaching is likely to increase the engagement of senior students in New Zealand secondary schools is not yet satisfactorily addressed in existing literature, because:

- no identified studies have attempted directly to measure engagement; 
- no New Zealand studies have specifically addressed the effects of thematic teaching in mathematics; and

- few related studies have had senior secondary student participants.

The lack of literature concerning the potential benefits of thematic teaching has been raised in two recent summary articles. In a synthesis of three meta-analyses of instructional variables which enhance achievement and engagement in science and mathematics, Ruthven (2011) highlighted the need for more research related to contextual factors in mathematics teaching. Furthermore, Beswick's (2011) review of evidence for the benefits of contextual instruction in mathematics suggests that the impact of contextual teaching on engagement is complex, subject to multiple confounding variables, and would benefit from further research.

\subsection{Engagement}

The reviewed reports of studies which evaluate the merit of thematic teaching (Section 2.1.3) tended to use achievement, rather than engagement, as their primary indicator of success. The substantive question in studies which included a specific pedagogical intervention was often, do students in the intervention group achieve better test results than students in the control group? If the answer to this question was yes, then the intervention was recommended for implementation. Implicit in this line of reasoning is the assumption that achievement in standardised tests is the best indicator of educational success. The current section investigates the suitability of student engagement as an outcome variable in a study which aims to evaluate the effectiveness of a thematic teaching intervention. The section will be structured in three parts:

- clarifying how the term engagement is used in existing educational literature, and how it will be used in this study (Section 2.2.1);

- investigating the educational importance of engagement and thereby evaluating the substantive value of using engagement as an outcome variable (Section 2.2.2); and 
- investigating the practical feasibility of using engagement as an outcome variable (Section 2.2.3).

\subsubsection{Engagement in literature}

Engagement is a multi-dimensional concept which has been defined in a variety of ways. In a widely cited meta-analysis of studies of engagement in education, Fredricks, Blumenfeld, and Paris (2004) argue that the wide range of uses of the term engagement make it problematic to measure and define. Yet they opine that it is an educationally useful meta-construct, and will become more useful as the relationships within its dimensions are further elucidated.

This thesis follows Fredricks et al (2004) and others (e.g., Martin \& Marsh, 2006; Symonds, Lawson, \& Robinson, 2008) in describing engagement as having three dimensions: cognitive, emotional, and behavioural engagement. Cognitive engagement includes the psychological effort of concentrating and the use of cognitive problem-solving strategies (Helme \& Clarke, 2001). Emotional engagement includes excitement about learning and a sense of motivation. Behavioural engagement is characterised by time on task, attendance, cooperation, asking questions and other directly observable student behaviours. There is a significant overlap between the cognitive, emotional, and behavioural dimensions of engagement (Fredricks, et al., 2004). A smile following success could be interpreted as emotional or behavioural; verbalising a problem-solving strategy could be behavioural or cognitive. There is also significant overlap between engagement dimensions and other well-documented constructs, such as the overlap between cognitive engagement and self-efficacy, emotional engagement and motivation, or behavioural engagement and task-avoidance (Fredricks, et al., 2004).

A further distinction within engagement is substantive engagement, a durable, proactive approach to learning versus procedural engagement, the extent to which a student is actively involved in a particular task at a given point in time (Fredricks, et al., 2004). Substantive engagement is quite stable over short time periods, whereas procedural engagement can vary within a lesson from one activity to the next. A teacher might comment that a student 'seemed really engaged today', as a result of 
an interesting lesson or being in a good mood; this would refer to procedural engagement. They might also comment that some students 'are not engaging in their studies' on a long term basis, referring to substantive engagement. The following two subsections examine firstly the substantive importance then the practical measurability of engagement. These considerations will determine which dimensions of engagement will be the focus of this study.

\subsubsection{Substantive importance of engagement}

Many of the studies reviewed (e.g., Ching, 2009; Henderson \& Landesman, 1992) used achievement of students in mathematics assessments as their primary indicator of the success of the thematic intervention. However, using achievement data as the sole measure of an intervention's success can be misleading. Ruthven (2011) points out that reforms in the English secondary mathematics have coincided with an increase and student achievement and a marked decline in student attitudes towards mathematics. Therefore, this section explores views of the aims of education in order to suggest that engagement is also a valid indicator of successful education. If this is the case, then examining the relationship between student engagement and thematic teaching could add a new and valuable dimension to knowledge about thematic teaching.

Manu'atu (2009) has explored values held in pre-colonial Tongan education and argues strongly for their contemporary relevance not only for Tongan students but for others of diverse cultural backgrounds. In particular, she describes the Tongan concept of malei, which refers to a sense of group energy and purpose alongside coherence and clarity of content; a sense of strength and purpose within a framework that makes sense. When malei is present in a lesson, Manu'atu believes that Tongan students feel that they can connect to what they are learning, that they are on a collective voyage of discovery. This Tongan notion provides one criterion for evaluating whether a lesson is successful. Malei shares with engagement cognitive, emotional, and behavioural dimensions of involvement in learning. The presence of malei can vary from one lesson to the next, so it is most closely comparable to procedural, rather than substantive, engagement. 
Noddings (2003) proposes that happiness should be a primary aim of education, and that an important goal of each lesson should be that students enjoy it. This in no sense negates the importance of learning; in fact Noddings claims that students learn more effectively when they are happy in class. Yet she holds the axiological standpoint that students being happy at school is a worthy aim for its own sake, not merely because happiness may facilitate students achieving high test scores. Students who are emotionally engaged in their learning will be happy learners (Fredricks, et al., 2004). Therefore, if happiness is taken to be a valid aim of education, then it is educationally meaningful to measure the extent to which thematic teaching affects students' emotional engagement with learning. Manu'atu's (2009) and Noddings' (2003) philosophies of education both value the process as well as the outcomes of learning, and the New Zealand Curriculum (Ministry of Education, 2007) places high importance on student engagement in learning (see Section 1.2). The above examples suggest that engagement can sit alongside achievement as a substantively important measure of effective education.

Fredricks, et al, (2004) argue that the multidimensionality of engagement makes it educationally useful, despite also complicating its definition and measurement. Engagement incorporates cognitive, emotional, and behavioural elements of the student experience of learning, enabling researchers to analyse pedagogical processes more robustly than could be the case if only one of these dimensions was included in the analysis. Measuring student engagement could facilitate a rich description of any effects of thematic teaching, helping to explain the inconsistency in the findings of prior studies. Therefore, it was decided that cognitive, emotional, and behavioural dimensions of engagement would all be included in the study. Given the short timeframe available for the empirical phase of the study, it was also decided to focus exclusively on procedural engagement, as little variability in substantive engagement could be expected over the course of a short thematic intervention (Fredricks, et al., 2004).

\subsubsection{Measurability of engagement}

Prior to framing research questions concerned with the effects of thematic teaching on engagement it is necessary to establish whether it is practically feasible to make 
valid and reliable assessments of students' engagement in learning. A full explanation of how engagement was measured is included later (Section 3.3). Fredricks, et al (2004) describe a wide range of tools for the measurement of cognitive, emotional, and behavioural engagement. Many of these tools (e.g., Kong, Wong, \& Lam, 2003; Martin \& Marsh, 2006) are self-report questionnaires which can be adapted to specific age-groups and subjects, so there is potential to modify some of these tools to evaluate the engagement of senior secondary school students in mathematics. A difficulty with these self-report questionnaires is that they are designed to measure long-term, substantive engagement, not procedural engagement. Therefore they are not suited to evaluating changes in students' procedural engagement over the short time frame available in the current study. No questionnaires were identified which specifically measured procedural engagement, but some items in the questionnaires reviewed were able to be adapted for a questionnaire focusing on procedural engagement. Developing this questionnaire (Section 3.3.1) would add to the workload of the study, but would also contribute a new and qualitatively different measurement tool to the existing stock of engagement self-report questionnaires.

Helme and Clark (2001) developed a list of observable behaviours and interview response patterns which can be used to assess procedural cognitive engagement in mathematics. They argue that the fine-grained analysis made possible by direct classroom observation gives a more detailed and accurate description of student engagement than self-report questionnaires can. Behaviours indicating cognitive engagement included verbalising thinking, asking questions, and completing peer utterances; in interviews, student claims to have learned new material or detailed recollections of parts of the lesson provided evidence of cognitive engagement. As Helme and Clark (2001) pointed out, very few studies have attempted to measure engagement by direct observation, and most rely on self-report by students, or on teachers' assessments of overall levels of class engagement. Hence there are few precedents for a study measuring engagement by observations or interviews, but there is reason to expect that observations and interviews could provide complementary measures of engagement alongside self-report questionnaires. 
In summary, there is evidence in the reviewed literature that engagement can be measured through self-report questionnaires, classroom observations, and student interviews. However, any self-report questionnaire would need to be significantly adapted to focus on procedural engagement (Section 3.3.1), and there are few prior exemplars of measuring engagement via observations (Section 3.3.2) or interviews (Section 3.3.3). Hence any measurement tools adapted for use in the current study would require a substantial phase for piloting and improving tools before commencing the study proper.

\subsection{Research Questions}

Chapter One developed the objective of examining the relationship between thematic teaching and student engagement in mathematical thinking. The presence or absence, magnitude, and nature of this relationship will have direct implications for classroom practice, and could inform the planning of secondary mathematics departments looking to implement the New Zealand Curriculum (Ministry of Education, 2007) more fully. The review of literature conducted in this chapter has shown that a number of studies of thematic teaching have had inconclusive or conflicting results in terms of the effects of thematic teaching (Section 2.1). Furthermore, Roth's (1996) analysis of mathematical contexts provides a theoretical rationale for expecting that thematic teaching will have different effects depending on the theme and the background of the students. Given this uncertainty about whether thematic teaching can be expected to have any consistent effects across students or themes, it seems unproductive to pose research questions about the consistent effects of thematic teaching. It would be more illuminating to go beyond a simple question of whether one should retain or reject a hypothesis that thematic teaching is unrelated to student engagement. If the effects of thematic teaching vary, it will be more useful to know which students benefit from a thematic approach and which do not, as well as any particular aspects of thematic teaching students find beneficial or detrimental to their learning.

A single study is insufficient basis for making decisive recommendations on the value of thematic teaching for all Year 12 students in non-academic classes in New Zealand, let alone for other students. However, by explaining in detail how students 
experienced one variant of thematic teaching, it will be possible to make tentative suggestions for what might constitute effective use of context with similar students. Therefore the following three research questions are posed:

(1) What relationship, if any, does thematic teaching have to the procedural engagement of students in a non-academic Year 12 mathematics course?

If thematic teaching does appear to be related to the engagement of some students, the following two questions will also be addressed:

(2) Which student characteristics (e.g., ethnicity, English language proficiency, interest in the theme) are related to students' preferences for thematic or nonthematic teaching?

(3) What reasons do students give for their preferences for thematic or nonthematic teaching?

The current study aims to broaden the literature on empirical studies of thematic teaching in mathematics by focusing on a little-researched age group. Empirical studies of thematic teaching tended to focus on primary (e.g., Beaton, 2004; Leonard, 2004), intermediate (e.g., Henderson \& Landesman, 1992) and junior secondary (e.g., Olicker, 2005) students. Findings from studies with younger students may not generalise to senior secondary students. It is quite plausible, for instance, that students approaching the end of their schooling are more focused on gaining qualifications than simply enjoying learning, so they may perceive thematic teaching as a distraction or a waste of time. The current study may also supplement existing literature by suggesting factors that may account for the inconsistent results of prior studies. Finally, this study may contribute methodologically to literature on the measurement of engagement by providing an exemplar of the measurement of specifically procedural engagement. 


\section{Chapter 3: Methods}

This chapter describes the planning and implementation of the empirical phase of the study. Section 3.1 describes how a pragmatic research paradigm was used to generate a specific mixed-methods study design in order to address the research questions. Section 3.2 reports details of study implementation including the school setting, the study participants, the way in which thematic teaching was carried out, and ethical considerations. Section 3.3 describes the measurement of student procedural engagement from tool design and piloting to data processing. Section 3.4 outlines how engagement data was collated and summarised.

\subsection{Planning}

This section describes the methodological process whereby the research questions were used to generate a specific plan for the empirical study. The theoretical lens used to frame the questions and design methods was pragmatic (Section 3.1.1), drawing on the strengths of the postpositivist and social constructivist methodological traditions. The research questions require measures of student engagement (quantitative) and reasons for preferences (qualitative), so a mixed methods design was developed (Section 3.1.2). Given the focus of the study on detecting changes in procedural engagement over short periods of time, a repeated measures design was deemed most suitable for the requirements of the study (3.1.3).

\subsubsection{Theoretical framework}

This study utilises the strengths that both the postpositivist and social constructivist worldviews bring to educational enquiry. According to postpositivism, knowledge is stable and external to the knower, whereas social constructivism views knowledge as a product of social processes and thus particular to the social dynamics in which knowledge is generated (Scott \& Usher, 1999). Postpositivism often underpins quantitative research methodologies, and social constructivism qualitative methodologies (Johnson \& Christensen, 2008). Both of these paradigms help to frame particular facets of the research questions in ways which make them open to meaningful empirical enquiry. 
The research questions probe the nature of the relationship between thematic teaching and procedural engagement. In order for this relationship to be meaningful, one must assume that thematic teaching really is different from non-thematic teaching, and that engagement is a real, measurable state which may be present in students to a variable extent. Because of the postpositivist assumption that knowledge is external and not merely constructed by the researcher, measured changes in engagement can be interpreted as conveying substantive information about students, and not simply reporting the perceptions of the researcher. In short, postpositivism provides the epistemological basis for supposing that there is a difference between thematic teaching and non-thematic teaching and that engagement can be measured.

As discussed in Chapter 2, there is no clear consensus about the effect of thematic teaching on engagement, despite a number of studies having been conducted on the topic. This lack of consistency led to the current study focusing on variability between students in the relationship between engagement and thematic teaching (Research Question 2) and reasons for this variability (Research Question 3). Social constructivism provides a framework in which it is expected that participants' engagement will depend on a complex array of social factors, including their relationship with the teacher and their peers, their prior experience of learning mathematics, and their familiarity with contexts used (Ajideh, 2003; Beswick, 2011). When learning is viewed from a social constructivist perspective, it makes sense to ask questions about inconsistencies as well as patterns.

The use of postpositivist and social constructivist paradigms in a single study can be seen as adopting a pragmatic paradigm, because all available means are used to answer the research questions (Cherryholmes, 1992). Furthermore, since postpositivist and social constructivist frameworks often underpin quantitative and qualitative methods respectively, studies that draw pragmatically on both frameworks tend to combine quantitative and qualitative methods using mixed methods designs (Creswell \& Plano Clark, 2007; Feilzer, 2010).

\subsubsection{Mixed methods}


This study adopted a pragmatic, mixed methods approach, assessing engagement using quantitative self-report questionnaires, and qualitative classroom observations and interviews (Section 2.2.3). One purpose of the mixed-methods design was to measure engagement with greater validity, by triangulating multiple measures of engagement (Creswell \& Plano Clark, 2007). Questionnaires provided the students' reported experiences and the observations gave an external observer's perspective. Together these facilitated analysis of differences in engagement between thematic and non-thematic lessons. The students' and teachers' qualitative, verbal responses provided further sources of evidence to confirm or contest any conclusion based on quantitative findings. Furthermore, the qualitative data made the quantitative data more substantively interpretable by situating it in a specific social setting which had been observed by the interviewer and described by students in their own words (Creswell \& Plano Clark, 2007). The inclusion of qualitative methods enabled the study to investigate reasons behind any quantitative results.

All questionnaires, observation notes, and interviews were recorded such that the researcher could identify the particular student who provided the data (individual tagging) and the lesson during which the data was collected (temporal tagging). Individual tagging of data facilitated analysis of individual students' patterns of engagement, enabling the effect of thematic teaching on engagement to be analysed at the level of the group and the individual. Individual tagging enabled student variables, such as gender, ethnicity, and English language proficiency to be analysed in terms of whether they were related to students' preferences for thematic or nonthematic teaching.

Despite their utility, quantitative self-report questionnaires have a predetermined range of responses and therefore do not allow the students to fully express their views on and experiences of thematic teaching. The interviews allowed students to explain more freely their experiences of thematic teaching and to give explanations that the researcher may not previously have considered. Utilising mixed methods enabled the study to combine conclusions about the effects of thematic teaching on procedural engagement with students' and teachers' insider views on the mechanism of effects. 


\subsubsection{Repeated measures}

This study used a repeated measures design with counterbalancing (see Johnson \& Christensen, 2008, pp. 320-321). Repeated measures refers to the fact that each student's engagement was measured every lesson by means of a questionnaire and observations (Figure 1). Counterbalancing refers to the fact that students did not all experience thematic and non-thematic teaching in the same order; some received thematic teaching first, and others non-thematic teaching (Ellis, 1999). Whilst only one of the reviewed studies utilised a repeated measures design (Mulcahy \& Krezmien, 2009), another methodological precedent for the design was located within the social sciences literature (Singh, et al., 2004). A counterbalanced design required the participation of at least two classes, so that the teaching conditions could be presented in a different order for each class. This design was chosen in order to ascertain whether students' levels of procedural engagement varied systematically between thematic and non-thematic lessons.

\begin{tabular}{|l|l|l|l|l|l|l|l|l|}
\hline Lesson & 1 & 2 & 3 & 4 & 5 & 6 & 7 & 8 \\
\hline Class A & \multicolumn{3}{|c|}{ Lessons 1 - 4: Thematic teaching } & Lessons 5 - 8: Non-thematic teaching \\
\hline Class B & Lessons 1 - 4: Non-thematic teaching & Lessons 5 - 8: Thematic teaching \\
\hline $\begin{array}{r}\text { Repeated } \\
\text { measures }\end{array}$ & \multicolumn{4}{|c|}{$\begin{array}{r}\text { Students complete engagement questionnaire each lesson. } \\
\text { Students observed to assess engagement each lesson. }\end{array}$} \\
\hline
\end{tabular}

Figure 1. Simplified diagram of counterbalanced, repeated measures design

Given that procedural engagement is fluid and can change from one lesson to the next (Fredricks, et al., 2004), a design that assesses engagement every lesson provides rich and detailed data about trends or patterns in procedural engagement. In any given lesson, engagement is influenced by a wide range of factors including not only the style of teaching, but also influences from students' home environments and other events that may recently have taken place outside the classroom (Beswick, 2011; Yair, 2000). Therefore measuring engagement over multiple thematic and nonthematic lessons reduced the extent to which these external factors could have confounded the relationship between thematic teaching and engagement (Johnson \& Christensen, 2008), enhancing the internal validity of the conclusions. 
Another advantage of the repeated measures design was that there was no 'experimental' and 'control' group; the engagement of all students was monitored during thematic and non-thematic lessons. Statistically this had the effect of doubling the sample size, because all students experienced thematic and non-thematic teaching (Johnson \& Christensen, 2008). Not only was each 'group' larger, but the two groups also consisted of the same participants, taught by the same teachers. This eliminated some sources of bias such as differences between the teaching styles of the two teachers, which would have been very problematic in a design which compared two classes.

Counterbalancing was intended to reduce the bias that could have been caused by sequencing effects, such as systematic changes in responses to the engagement questionnaire as a result of completing it multiple times. Counterbalancing was also intended to reduce the bias which could have been introduced by history effects, which are effects of external events that influence engagement but are not measured as part of the study design (Johnson \& Christensen, 2008). For example, suppose that the first four lessons were more interesting than the latter ones because of differences in the mathematical content. This bias would be reduced by counterbalancing because it would make thematic teaching appear more interesting for Class A and non-thematic teaching appear more interesting for Class B, so the effects of this bias would to some extent be cancelled out. An important caveat applying to the benefits of counterbalancing is that they only apply when making group comparisons of engagement between the two teaching conditions. Counterbalancing does nothing to ameliorate the confounding impact of sequencing or history effects on the results when they are analysed at the level of the individual student.

\subsection{Implementation}

This major section of the Methods chapter relates how the empirical component of the study was conducted. It describes:

- The school setting (Section 3.2.1),

- the students and teachers who participated in the study (Section 3.2.2), 
- sequencing and timeframes (Section 3.2.3),

- how thematic teaching was implemented in the study (Section 3.2.5), and

- how ethical considerations were taken into account (Section 3.2.5),

\subsubsection{Setting}

Owing to a prior connection to Parkville College I was known by a number of students and staff, and was familiar with many aspects of the school, making it a convenient setting for the study. Table 1 lists criteria for the participant school, and shows how Parkville College met the criteria. Parkville College was very suitable for the study, so no additional schools were contacted.

Table 1. School Criteria and Parkville College

\begin{tabular}{|c|c|c|}
\hline $\begin{array}{l}\text { Criterion for } \\
\text { study school } \\
\text { suitability }\end{array}$ & Reason for criterion & $\begin{array}{l}\text { Extent to which Parkville } \\
\text { College met criterion }\end{array}$ \\
\hline $\begin{array}{l}\text { Participant classes } \\
\text { co-educational and } \\
\text { multi-ethnic. }\end{array}$ & $\begin{array}{l}\text { Gender and ethnicity can be analysed } \\
\text { as potential variables mediating the } \\
\text { effect of thematic teaching on } \\
\text { engagement. }\end{array}$ & $\begin{array}{l}\text { Both genders and a variety of } \\
\text { ethnicities were strongly } \\
\text { represented in the Math } 203 \\
\text { classes (see 3.2.2) }\end{array}$ \\
\hline $\begin{array}{l}\text { At least } 15 \\
\text { students per class } \\
\text { (sample size } \geq 30 \text { ) }\end{array}$ & $\begin{array}{l}\text { Statistical techniques used in the } \\
\text { quantitative analysis are more robust } \\
\text { with a larger sample sizes (Johnson } \\
\text { \& Christensen, 2008) }\end{array}$ & Sample size of 47 \\
\hline
\end{tabular}

Parkville College is a large, co-educational, high decile ${ }^{6}$, state secondary school in suburban New Zealand. It offers non-academic mathematics courses at Years 11, 12 and 13. Students are allocated into the Year 11 non-academic course (Math 103) based on their teacher recommendations and grades from Year 10. Typically these students will have received a high proportion of Not Achieved grades on school

\footnotetext{
${ }^{6}$ A high decile school is one in which many students have high socio-economic status families.
} 
mathematics assessments in Year 10. Students who enter the Year 12 non-academic course (Math 203) are predominantly those who took Math 103 the previous year, although there are some who showed particularly poor performance in a Year 11 academic mathematics course and some who choose to repeat Math 203 as Year 13 students.

As a result of the above selection process, most students in Math 203 had experienced failure in school mathematics. As junior students, or in some cases in Year 11, they had received a high proportion of Not Achieved grades and had been performing near the bottom of their class. In the year this study took place there were two classes taking the course Math 203, which is assessed with NCEA Level 1 and Level 2 Unit Standards and two NCEA Level 2 Achievement Standards. Math 203 included significantly less formal algebra and graphing than other Year 12 courses, and no calculus.

\subsubsection{Participants}

The participants were the students and teachers of the two Math 203 classes at Parkville College.

\section{Teachers}

\section{Tony Munns}

Tony and his wife emigrated from England two years prior to the study. Tony was in his fifties, identified as "White European" and had been teaching mathematics for 13 years, 11 of which were in the United Kingdom. Before moving to New Zealand he was Head of Mathematics at a boys' grammar school. Prior to training as a teacher he had over 20 years' experience in the British military, in engineering and operations roles. He is the coordinator of the Math 203 course.

\section{Chris Daniels}

Chris was in his first year of teaching, having graduated with a secondary teaching diploma at the end of the year preceding the study. He was in his late twenties and 
identified as New Zealand European. He had trained to teach mathematics and history and was teaching mathematics full-time at Parkville College, the first school in which he had been employed.

\section{$\underline{\text { Students }}$}

The 47 students in the two study classes came from a broad range of socio-economic, ethnic, and linguistic backgrounds. Compared with the school as a whole, the participant classes included a high proportion of English Language Learners (ELLs) (21\% c.f. $7 \%)$ and students who qualified for reader/writer assistance during assessments (19\% c.f. 10\%) (Assistant Principal, personal communication, September 10, 2010). The ethnic profile of the participant classes also differed from that of the whole school, most notably by including more Pasifika and South East Asian students and fewer NZ European/Pakeha students (Figure 2). There were 22 female and 25 male students.

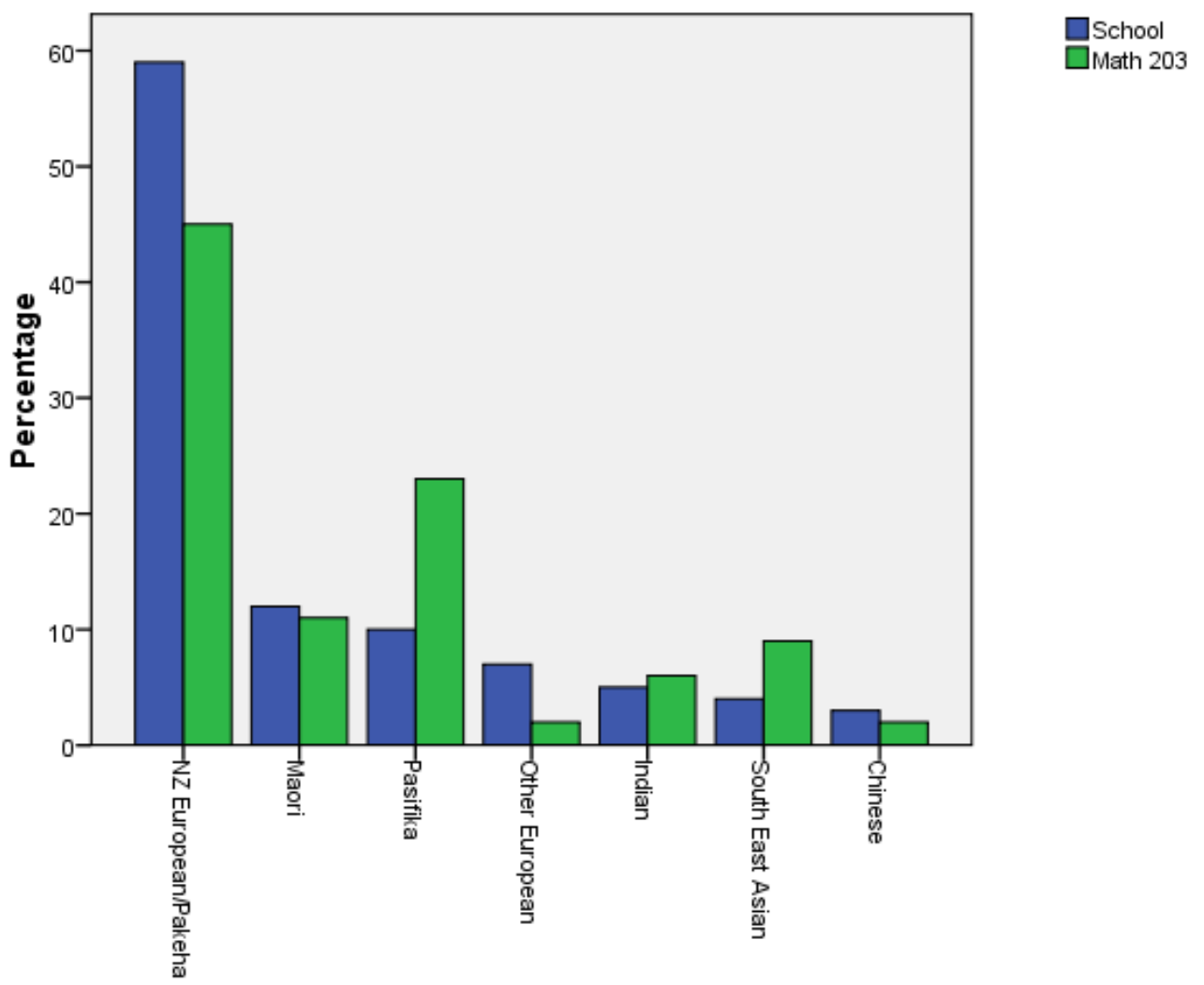

Ethnicity

Figure 2. Participant and school ethnic profiles 
There were forty Year 12 students and seven Year 13 students, six of whom were in Chris' class. The Year 13 students were mostly repeating Math 203 for a second year, although one student was doing Math 203 in Year 13 because he had elected not to take any mathematics course in Year 12.

\subsubsection{Timeframes and practicalities}

The study had three broad phases: planning, pilot, and experimental. The planning phase involved liaising with Parkville College staff, particularly Tony and Chris, in order to negotiate a mutually agreeable plan for conducting the research. The pilot phase involved using draft versions of the engagement questionnaire, observation schedule, and interview protocol with non-participant students, then refining these drafts in an iterative manner until a satisfactory and usable tool was developed. The experimental phase was a three-week period during which Tony and Chris taught thematically and non-thematically with their Math 203 classes and data was gathered from students and teachers. Relevant details of each phase are described below.

\section{Planning Phase}

I formally approached the Principal and Head of Department (HOD) Mathematics with a description of my proposed research. I briefed Tony and Chris on the proposed study and they were both enthusiastic about the value of the research and willing to participate by trialling thematic teaching with their Math 203 classes. We agreed that the pilot phase should take place in Term Two and the experimental phase early in Term Three as this was mutually convenient. I obtained class rolls, teacher timetables, a list of assessments already completed in Math 203 that year, and a school events calendar.

Tony and Chris had significant input into the choice of the mathematical content and theme for the experimental phase. In terms of mathematical content, we agreed to use Coordinate Geometry which lends itself well to either thematic or non-thematic teaching. At the end of the thematic topic, students would be assessed against Unit Standard 5245: Solve Coordinate Geometry Problems (NZQA, 2010b). 
Following the planning phase meetings, I consulted the school calendar and the Deputy Principal to check for events which might interfere with the experimental phase. Factors such as teacher workload in relation to report writing and disruptive events such as vaccinations and sports exchanges were taken into account when proposing specific dates for the experimental phase.

\section{Pilot Phase}

During the pilot phase draft versions of the engagement questionnaire (Appendix C), observation schedule (Appendix D), and interview script (Appendix E) were tested and refined (Section 3.3). The purpose of this pilot was twofold; to practise the skills involved in collecting data and to trial and improve the data gathering tools. This phase took place on three days over the period of a week, late in Term Two.

\section{Experimental Phase}

The experimental phase consisted of sixteen lessons, eight with each class, and student and teacher interviews conducted outside of class time. The content and context of each lesson, and the sequencing of experimental interventions and measurements, are shown in Figure 3. 


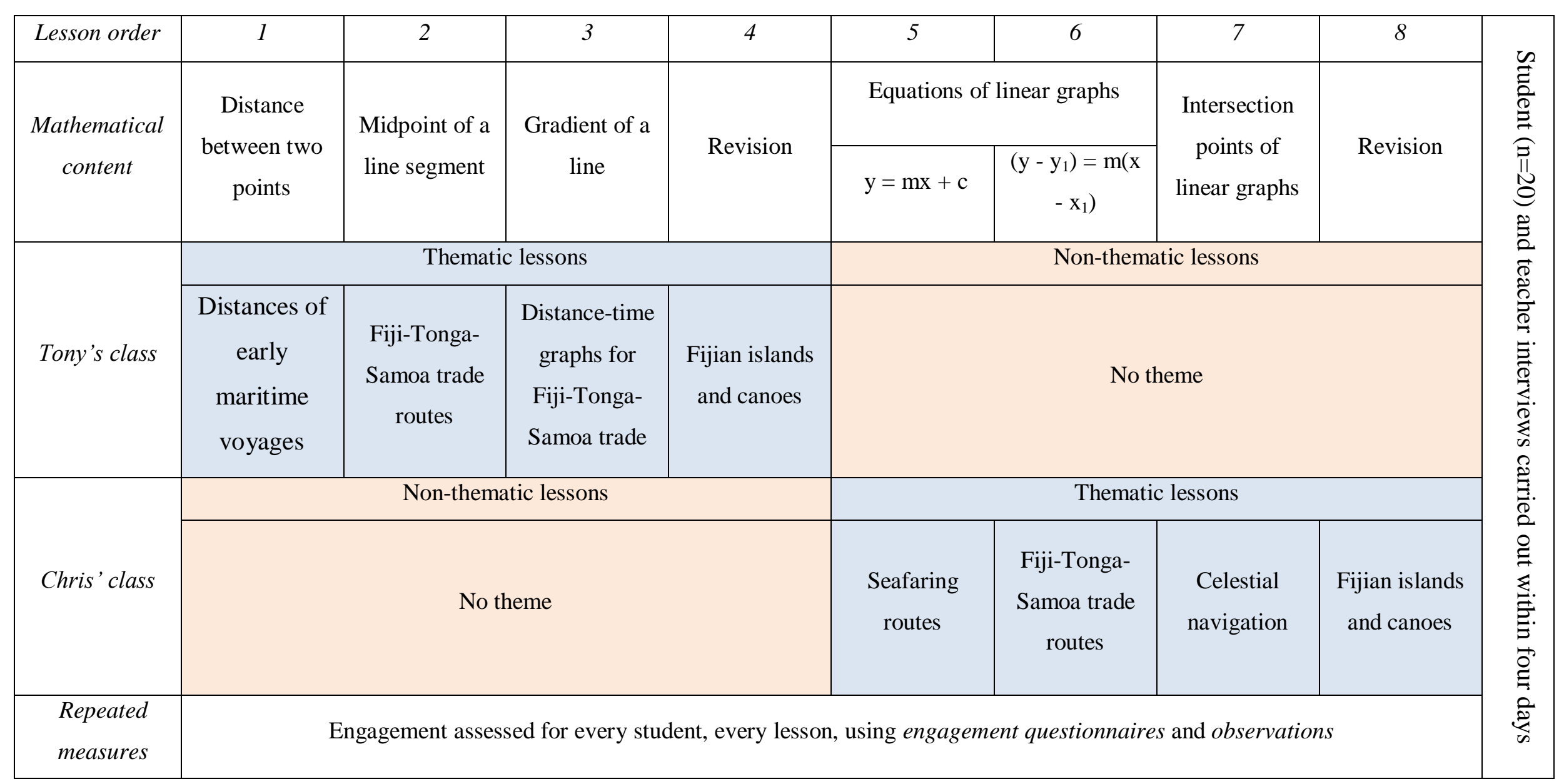

Figure 3. Design of experimental phase 


\subsubsection{Thematic and non-thematic teaching}

Tony and Chris were both enthusiastic about implementing thematic teaching in their classrooms. However, they required some preparation in order to implement thematic teaching in a manner that would lend validity to the study. The two key components of this preparation were establishing expectations for the implementation of thematic teaching and the provision of teaching resources.

\section{Teacher preparation}

Thematic teaching has been defined and implemented in a variety of ways in prior studies (Section 2.1.2) and this study focuses on thematic teaching as the sustained use of a single context over a series of lessons. In order to evaluate the impact of thematic teaching it was necessary to keep other aspects of teaching as similar as possible between the thematic and non-thematic lessons. This narrow focus in terms of the implementation of thematic teaching meant that teachers could put their energy into making a single change to their practice. Lessons of both teachers were observed during the planning phase with the intention that thematic teaching could be integrated smoothly with their usual classroom routines.

I presented myself to Tony and Chris as someone with a strong interest in thematic teaching and with the time and resources to support them as they trialled thematic teaching in their classrooms, not as an expert thematic teacher. I made it clear to them that they did not need to change any of their classroom routines or expectations for the study. Thus the three of us collaboratively decided on the theme the human settlement of the Pacific Islands. This theme was chosen because there were a number of Pasifika students in both classes and because the distances and directions involved in ocean navigation provided a clear link between the theme and coordinate geometry. The book Vaka Moana (Howe, 2006) was an important resource that the teachers and I used to broaden our knowledge of the human settlement of the Pacific Islands. Whilst I developed the majority of the teaching resources, both teachers had input into which aspects of the theme should be emphasised in connection to particular mathematical achievement objectives. Thus the planning phase consisted of discussions in which the teachers and I negotiated how thematic teaching could be implemented within the teachers' existing classroom routines. For the non-thematic 
lessons, it was agreed that the teachers would plan and teach their lessons as usual, without the consistent use of any one context.

The planning phase lesson observations showed that both Tony and Chris followed some common classroom routines. Both started their lessons with questions on the whiteboard or overhead projector to revise learning from previous lessons. Both made use of the textbook Further Units in Maths (Siber, 2004) alongside worksheets and examples written on the whiteboard as learning tasks. Whilst Tony tended to spend more time than Chris teaching from the front of the classroom, both teachers appeared confident when presenting new material. Both teachers had their classroom physically arranged with the desks in rows facing the front of the room, and neither has fixed seating plans, although sometimes students were asked to shift seats for behaviour management.

\section{$\underline{\text { Resource development }}$}

Thematic resources were required to replace the usual non-thematic starter questions, textbooks, and worksheets. I was unable to locate any pre-existing resources which explored the content of coordinate geometry within the theme of the human settlement of the Pacific Islands, so I developed the required resources myself (see sample worksheet, Appendix F). PowerPoint presentations were used in place of starter questions written on the whiteboard, and thematic worksheets were produced to be used in place of the textbook. In most cases non-thematic resources were also produced in order to make the two teaching conditions as similar as possible in terms of factors other than the theme. Whilst the use of PowerPoint presentations and worksheets was a departure from the teachers' usual practice of writing starter questions on the whiteboard and working from the textbook, it was necessary in order to make the two teaching conditions comparable.

The first lesson of the topic is now briefly described to illustrate what was actually taking place in the classroom during the thematic and non-thematic lessons. The mathematical content of the first lesson was using Pythagoras' Theorem to find the distance between two points on a plane ${ }^{7}$. Chris taught this lesson non-thematically,

\footnotetext{
${ }^{7}$ The shortest distance between a pair of points with coordinates $\left(x_{1}, y_{1}\right)$ and $\left(x_{2}, y_{2}\right)$ is given by distance $=\sqrt{\left(x_{2}-x_{1}\right)^{2}+\left(y_{2}-y_{1}\right)^{2}}$.
} 
referring to various contexts but also not focusing on one particular theme. Tony, who taught the first lesson thematically, began the lesson by introducing the theme and discussing theories of the origins of indigenous Pacific peoples with reference to a map from Vaka Moana (Howe, 2006). He then demonstrated how to use Pythagoras' Theorem to find the distance between two points on a grid and used this to find the distance of one ocean voyage. The students then completed a worksheet (Appendix $\mathrm{G}$ ) which required them to find the distances of various voyages that took place during the settlement of the Pacific Islands, using a grid superimposed on the migration map. Some students went on to calculate the approximate time these voyages might have taken to complete.

I observed all thematic and non-thematic lessons during the experimental phase and thus I was able to monitor the extent to which thematic and non-thematic teaching was implemented as planned. Deviations from planned practice and other qualitative observations of interest were recorded in field notes. There were a number of phases within the planned thematic lessons of both classes during which the teachers focused on the mathematical content with only minimal reference to the theme. However, by and large the teachers implemented thematic teaching as planned during the scheduled thematic lessons, and made only rare references to the theme during non-thematic lessons.

By being present in the classroom I was able to assess factors other than the teaching condition that seemed to affect student engagement. For example, during one of Chris' non-thematic lessons, the classroom was unusually quiet and more of the students were on-task than usual. I asked some students why they thought the class was working so well, and without exception they attributed it to the absence from class of a small number of disruptive students: "it's "cos the noisy people are away". During one thematic lesson, Tony announced shortly after the start of the lesson "I'm grumpy today" and was not as tolerant or patient as usual with his students. It seemed to me that students responded to Tony's attitude with less willingness to listen than usual, despite the thematic content of the lesson. During one of Chris' lessons the students seemed quite unsettled, and when I enquired about this afterwards Chris informed me that there had been an unpleasant altercation between students during the lunch break directly prior to the lesson, and he speculated that the 
altercation might have influenced the students' engagement with learning mathematics. The above factors illustrate the complex set of factors which may have influenced student engagement and made the results of the study less interpretable because any relationship between thematic teaching and engagement could be masked or exaggerated by extraneous influences such as these.

\subsubsection{Ethical considerations}

This study adhered to the ethical guidelines of both the Victoria University of Wellington Human Ethics Committee and the New Zealand Association of Research in Education (NZARE). The Principal, the two teachers, and all participating students were given details of the proposed study by means of information letters (Appendix H) and personal discussion before they were asked to fill in consent forms (Appendix I). Participants were informed that neither they nor their school would be named in any publication, and pseudonyms have been used in this report. Students were also informed that data would not be collected anonymously. Analysis of individual preferences required that the students put their initials on all engagement questionnaires, and it would not have been possible to collect observation or interview data anonymously. Students were assured that their responses would be kept confidential, including from their teachers.

A significant ethical consideration for this study was that the experimental phase involved deviating from the teaching programme that the students would otherwise have experienced. However, the potential negative impact of the intervention was ameliorated by providing the teachers with adequate preparation for thematic teaching, providing quality teaching resources for thematic and non-thematic teaching, and aligning the thematic topic with the mathematical content of an NCEA Unit Standard so that the learning could contribute towards the students' formal qualifications. The disruption caused by the repeated administration of the questionnaire was minimised by keeping the questionnaire very short, and the classroom observations were quiet and unobtrusive. Interviews were scheduled for 
lunchtimes and study periods ${ }^{8}$ so that they did not remove students from planned learning activities.

\subsection{Data collection tools}

The mixed methods design used in this study employed a quantitative self-report questionnaire and classroom observations to monitor the procedural engagement of students, and interviews to ascertain students' and teachers' views on thematic teaching. This section reports how the questionnaire, the observation schedule, and the interview protocol were developed, piloted, and implemented. Within the postpositivist paradigm, this section focuses on the measurement of the dependent variable, procedural engagement.

\subsubsection{Questionnaire}

The engagement questionnaire (Appendix C) was developed specifically for the current study, and the validity of the study's conclusions are contingent on the validity of the questionnaire as an indicator of procedural engagement. Therefore a full evaluation of the validity of the current study requires a detailed account of the process of developing the engagement questionnaire. However, a large section within the main report on the validation of the questionnaire would take the focus away from the substantive research questions. Hence a brief account of the pilot process for the questionnaire is included in this section of the report, and interested readers can find a more detailed account of the validation methodology in Appendix J.

\section{Design}

The initial intention was to use or adapt an existing questionnaire which had been piloted and validated in previous studies. Engagement scales reported on in two reviews of literature concerning definitions and measurement of engagement were evaluated (Fredricks, et al., 2004; Jimerson, Campos, \& Greif, 2003). Databases such as PsycInfo, ERIC, A+ Education, and Google Scholar were searched with queries such as Keyword $=$ (engagement $O R$ interest) $A N D$ (scale OR measure* ${ }^{*}$ OR

\footnotetext{
${ }^{8}$ During study periods at Parkville College students were supervised in a classroom but were allowed to complete any work they wished.
} 
questionnaire) to indentify scales used in studies too recent to be covered in the previously mentioned reviews. A number of engagement scales were identified, such as Martin and Marsh's (2006) academic resilience scale, piloted with 402 Australian secondary students, which contained an engagement dimension. This scale was adapted to investigate the engagement of intermediate students in a subsequent study with Year 8 students (Sullivan, et al., 2009). It took approximately 20 minutes to complete and focused primarily on substantive engagement. The Student Engagement Instrument (Appleton, Christenson, Kim, \& Reschly, 2006), piloted in the United States with 1,941 Year 10 students, contained 56 items and focused on the cognitive dimension of substantive engagement. All identified scales were unsuitable for this study because the scales:

- measured substantive engagement, not procedural engagement;

- contained too many items; and

- had not been validated in New Zealand, or with senior secondary students.

For example, Kong et al's (2003) Engagement in the Mathematics Classroom Scale was not suitable because most of the items focus on substantive engagement, not procedural engagement. A typical item such as "I think memorising mathematics is more effective than understanding it" (Kong, et al., 2003, p. 11) is unlikely to elicit differing responses from one lesson to the next. This scale has 57 items and it therefore far too long to administer during class for eight consecutive lessons. Finally, the scale was developed and validated in Shanghai with Year 6 students (Kong, et al., 2003), so it would require further trialling and refinement before it could be used with confidence with New Zealand Year 12 students.

Given the apparent lack of a suitable existing scale, a seven-item quantitative selfreport questionnaire (Appendix C) was designed to measure the level of individual students' procedural engagement in the current lesson. It contained items which focus on cognitive, emotional and behavioural aspects of engagement. The items for the first draft were based on definitions of procedural engagement given by Fredricks 
et al (2004) and items relating to procedural engagement from the Student Engagement in the Mathematics Classroom Scale (Kong, et al., 2003).

\section{$\underline{\text { Pilot }}$}

There were three criteria for the questionnaire: it needed to be short, clear, and a valid measure of engagement. It needed to be quick to administer because all students were to complete it during class for eight consecutive lessons, and might have lost interest in a lengthy questionnaire and given unconsidered responses. Therefore, the aim was for the majority of students to complete the questionnaire in under two minutes. Four iterations of the questionnaire were tested with a combined total of around 200 students over three school days, leading to the final version.

Conducting the pilot phase at Parkville College alerted me to some complexities and benefits of conducting research in a setting where I was known to a number of the students. Students sometimes initiated conversation with me and asked me for help with work, which may have been less likely to occur had I been unknown to the students. As a result of this experience I was able to plan in advance how to deal with this contingency when it arose during the experimental phase. I also felt that as a young person already known by the school community, I was a non-threatening figure and teachers always appeared willing for me to come into their classes for piloting purposes.

\section{Data collection}

I personally handed out questionnaires to each student five to seven minutes before the end of the lesson and collected them a few minutes later. This enabled me to check that students had responded to every item and initialled the questionnaire. I was also able to monitor their behaviour as they completed the questionnaire; in several cases I intervened when one student started to fill in a questionnaire for their classmate, or when students appeared not to be taking the task seriously. These incidents were non-confrontational, and students appeared happy to fill in another questionnaire when requested to. Questionnaires were coded so that the class and lesson in which they were completed could be identified. 


\subsubsection{Observations}

\section{Design}

Helme and Clark (2001) define specific, observable behaviours that can be used to measure cognitive engagement in mathematics and these were used to form the basis of the draft observation schedule. The list of behaviours is included in Version 1 of the observation schedule (Appendix K). The behaviours are grouped in four categories: individuals working in parallel, collaborative small group activity, small group interactions with teacher and whole class interaction with teacher. Previous experience with Year 12 non-academic mathematics classes led me to expect that a category "individuals working by themselves" might need to be added. Johnson and Christensen's (2008) guidelines for conducting classroom observations informed the timeframes and structure of the draft observation schedule, which included phases of carefully timed observations which ensure that all students received equal attention. During breaks between structured observation windows, field notes would be taken concerning "anything the observer believes to be worth noting" (Patton, 2002, p. 302), including teacher behaviour and aspects of student behaviour not included in the structured observations.

\section{$\underline{\text { Pilot }}$}

One lesson was observed with a Year 12 mathematics class to practice using the observation schedule, immediately exposing some weaknesses in Version 1 (Appendix K). Some categories were too vague for instantly classifying observed behaviour in real time. For instance, when students engaged in a mathematical discussion, it was not possible to reliably distinguish between verbalizing thinking, asking questions, and explaining reasoning (categories 1,3, and 6 respectively from the observation schedule). The aim was to observe behaviours which indicated the level of student engagement in learning. Given this objective, it was informative to record, for instance, whether students were helping each other with their work or talking about the football world cup, so codes for off-task and on-task peer talking were included in Version 2 of the schedule (Appendix D). 
There were a number of mainly non-verbal behaviours which seemed to indicate engagement or lack of engagement, but which did not correspond clearly with any category in Version 1. These included looking at notes on the whiteboard, copying down notes, and working silently on problems from a textbook, all of which occurred frequently. Version 2 gave each of these behaviours its own code using categories that corresponded more intuitively to actual observed behaviour, so Version 2 had a greater number of categories than Version 1. This made observation more accurate in the classroom and allowed the possibility for combining categories at a later stage. In terms of negative indicators, category 11 from Version 1, off-task actions, was divided into non-disruptive actions such as staring out the window, and disruptive actions such as throwing a dart to another student.

After experimenting with different observation intervals I found that observing one student at a time for thirty seconds provided enough time to gain a basic snapshot of one student's behaviour, and enabled all students to be observed several times per lesson. Sitting at the back of the classroom in an isolated desk was the best location because all students could be observed inconspicuously and the physical space between students and researcher reduced the likelihood of them asking for help with their work or initiating conversations. I was warm and polite towards students but had minimal interaction with them, so my involvement in the lesson is best described as that of a "participant observer", with observation emphasised over participation (Labaree, 2002, p. 97).

\section{Data Collection}

Every lesson three observation phases were conducted; one beginning five to ten minutes after the start of the lesson, one midway through the lesson, and one beginning about fifteen minutes before the end of the lesson. Each student was observed for 30 seconds during each of the three phases and the codes corresponding to the observed behaviours were recorded on paper. Observations were carried out by starting with a randomly selected student and moving systematically up and down the rows of desks. Between these observation phases other aspects of the lesson relevant to the study, such as the extent to which the teacher was incorporating the theme into his teaching, were recorded in field notes. 


\subsubsection{Interviews}

Short, semi-structured interviews (Scott \& Usher, 1999) were conducted to record students' views on thematic teaching, and factors contributing to their level of engagement in thematic teaching. Both teachers took part in debrief interviews following the experimental phase.

\section{$\underline{\text { Design }}$}

The primary purpose of conducting student interviews was to gain an understanding of students' experiences of thematic teaching and their views on the nature and extent of its effects on their engagement. A secondary purpose was to assess how effective the questionnaire had been at measuring engagement. Semi-structured interviews were used in order to ensure that all relevant points were covered in the interviews, whilst providing enough flexibility for students to express themselves in natural conversation (Scott \& Usher, 1999). The interviews were planned around a series of key questions (Appendix E) which were asked in a conversational manner. As the interviewer I was free to ask students to expand on an idea that seemed like it could be relevant or to clarify questions by referring to specific details of recent lessons.

Teacher interviews were unstructured (Scott \& Usher, 1999) and provided an opportunity for the teachers to express their views on the research process. The essential component of this interview was to elucidate the teachers' opinions on the effects of thematic teaching on student engagement. Extensive research has been conducted on barriers to implementation of thematic teaching (Handal \& Bobis, 2004), so whilst teachers were welcome to discuss this it was not analysed.

\section{$\underline{\text { Pilot }}$}

Several practice interviews were conducted during the pilot phase with nonparticipant Year 12 students. However, it was not possible to evaluate the effectiveness of the questions in eliciting students' views on thematic teaching because the students had not been in thematically taught classes. The draft interview questions (Appendix E) were retained without alteration for use in the experimental 
phase, with an awareness that modifications might need to be made during this phase. The plan was to interview a subsample of the participant students, so unsuccessful interviews could be used as "pilot" interviews and additional students interviewed.

\section{Data collection}

Twenty students were interviewed, some during the experimental phase and the majority within a few days of the completion of the experimental phase. The selection of these students was determined entirely by practical considerations; most students did not consent to participate in interviews outside of class time but were happy to do so during study periods. All students who consented to be interviewed during a study period, and had a study period at a time when I was available to conduct interviews, were interviewed. The duration of these interviews varied between three and fifteen minutes, and all interviews were recorded digitally.

It became apparent during the early interviews that not all students were aware that there had been a transition between thematic and non-thematic teaching, and needed reminders about the theme before they could comment on their preferences. The worksheets they had used were a helpful visual prompt as most students remembered the images on the thematic worksheets and this prompted their memory of the thematic lessons. Students who struggled to recall the thematic topic were shown the thematic and non-thematic worksheets for Lesson 4 (Appendices $\mathrm{L}$ and $\mathrm{M}$ respectively) during the interview. Teacher debrief interviews were conducted about a week after completion of the experimental phase, and took 20 - 30 minutes each.

\subsection{Data analysis}

The data analysis drew on a range of methodological approaches with a view to triangulating questionnaire, observation, and interview data in a mixed-methods approach (Creswell \& Plano Clark, 2007). The processing of the quantitative survey data in particular differed from that of many prior evaluation studies (Section 2.1.3). A primary aim of the quantitative analysis was to characterise individual students in terms of the extent to which thematic teaching positively or negatively affected their engagement. As a result there was extensive use of raw data from individual students and limited use of summary statistics comparing groups of students. The approach 
taken with analysis of individual data was guided by the concepts of judgementbased analysis (Gorard, 2006) and practical significance (Kirk, 1996). Judgementbased analysis involves direct and sensitive engagement with data to generate results that take into account the complexities and uncertainties that are specific to the circumstances of the data collection (Gorard, 2006). Practical significance as opposed to statistical significance is especially pertinent to the current study because of the small sample size $(n=47)$ and the decision to characterise individual students (Kirk, 1996). Null hypothesis significance testing with its tradition of quoting $p$ values as a basis for identifying statistically significant differences is problematic with small samples, especially given that engagement may not be normally distributed (Cohen, 1994; Gorard, 2010). Therefore, alternative methods of data analysis were used to supplement null hypothesis significance testing. The key processes by which survey, observation and interview data were summarised are now outlined.

\subsubsection{Questionnaire data}

Each of the seven items in the engagement questionnaire had possible responses from 1 (strongly disagree) to 5 (strongly agree) (e.g., Figure 4).

\section{1) I made an effort to concentrate on learning today}

1

2

Strongly

Disagree

disagree
3

Neutral

Agree

4

Strongly

agree

Figure 4. Item 1 in the engagement questionnaire

Each questionnaire yielded an overall engagement index (EI), calculated by adding the numerical responses to the seven items. One EI was calculated for each student each lesson that they were present with a theoretical range of 7 (strongly disagree with all items) to 35 (strongly agree with all items). For each student, a thematic preference index (TPI) was calculated by subtracting the mean EI for non-thematic lessons from the mean EI for thematic lessons: 


\section{$\mathrm{TPI}=$ mean $\mathrm{EI}_{\text {thematic }}-$ mean $\mathrm{EI}_{\text {non-thematic }}$}

A positive TPI indicated higher engagement in thematic than non-thematic lessons, and vice versa, with a TPI close to zero indicating similar engagement in thematic and non-thematic lessons. The magnitude of the TPI was an approximate indicator of the strength of the preference.

In order to interpret the TPI meaningfully it is necessary to make a judgement-based decision on what constitutes a practically significant TPI, carefully considering the measurement scale of the questionnaire. A TPI with an absolute value of seven or more represents a mean change of one scale unit for all seven items, for example from neutral to agree, representing a large, practically significant preference (Table 2). An absolute TPI value of four or more represents a change of one unit in over half of the seven items, so this served as a benchmark for identifying practically significant preferences.

Table 2. Interpretation of TPI Values

\begin{tabular}{|l|l|}
\hline TPI range & Judgement-based interpretation \\
\hline TPI $\geq 7$ & Strong, practically significant preference for thematic teaching \\
\hline $4 \leq$ TPI $<7$ & Practically significant preference for thematic teaching \\
\hline$-4<$ TPI $<4$ & Weak or no evidence of preference \\
\hline$-7<$ TPI $\leq-4$ & Practically significant preference for non-thematic teaching \\
\hline TPI $\leq-7$ & Strong, practically significant preference from non-thematic teaching \\
\hline
\end{tabular}

The TPI was a useful summary measure but it obscures trends and did not take account of how erratic or constant each student's engagement was within the four lessons of each teaching condition. Thus an engagement plot (Figure 5) was produced for each student to give a more detailed representation of the data gleaned from the engagement questionnaires. A similar style of single-subjects plots was used in Mulcahy and Krezmein's (2009) United States study of contextualised mathematics teaching with intellectually disabled middle school students. The horizontal axis represented the order of the experimental phase lessons from one to eight and the vertical axis indicated engagement on a scale covering the range of 
possible EI values. The horizontal lines at the EI values of 7, 14, 21, 28 and 35 represented mean responses of strongly disagree, disagree, neutral, agree, and strongly agree, respectively. The points were colour-coded for thematic and nonthematic lessons.

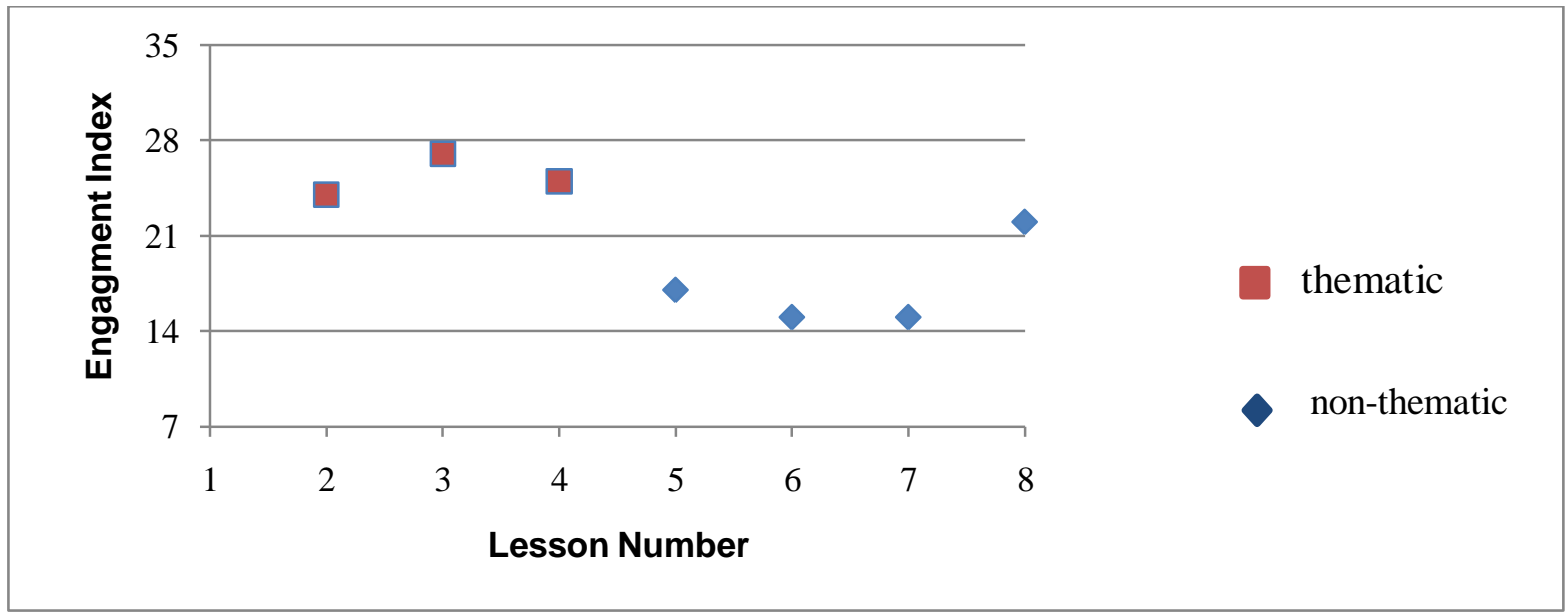

Figure 5. Example engagement plot

Note: this student was absent for lesson 1.

Engagement plots facilitate a more sophisticated analysis of individual preferences than TPI values do because the plots show the variability of engagement indices, patterns of absences and outlying values. However, in terms of interpretation one must remember that engagement plots and TPI values are alternative ways of summarising the same data. Consistency between them should be expected and does not constitute additional evidence that either one is a valid measure of student preferences.

\subsubsection{Observation data}

The raw observation data consisted of brief qualitative descriptions of what each student was doing during three 30-second windows each lesson. Each observation snapshot was characterised either as indicating engagement with learning, neutral/ambiguous, or indicating lack of engagement with learning, and assigned the value 1,0 , or -1 respectively. The sum of the three values for each lesson gave an indication of each student's engagement in that lesson on a scale of -3 to 3 , 
analogous to the EI derived from questionnaire data. Thus the observation data provided information parallel to that provided by the questionnaire-based TPIs and engagement plots, facilitating "concurrent triangulation" (Creswell \& Plano Clark, 2007, p. 64). Field notes were consulted at various stages of reporting and analysis, such as describing how thematic teaching was implemented (Section 3.2.4) and discussing the presence of potential confounding variables (Section 5.2.2).

\subsubsection{Interview data}

Audio recordings of student interviews were analysed in terms of students' stated preferences and the reasons students gave for their preferences, using a "deductive 9 content analysis" (Patton, 2002, p. 453). All comments concerning thematic and nonthematic teaching were transcribed and classified first by which teaching condition they pertained to and then whether they were discussing benefits or disadvantages of that teaching condition. Comments within each of these four quadrants were then analysed to extract common themes in students' assessments of the advantages and disadvantages of thematic and non-thematic.

\subsubsection{Data reliability and coverage}

Data coverage (Howell, 2010) was extremely high for students present in class and the main reason for missing data was absences (Figure 6). Only students who attended at least three out of four thematic lessons and at least three out of four nonthematic lessons $(n=32)$ had their questionnaire data analysed, although some interview data was used from students who did not meet this criterion. I judged that two or fewer lessons were insufficient to give a reliable indication of a student's level of engagement with a teaching style, given the high level of variability in engagement between lessons (Section 4.2.1).

\footnotetext{
${ }^{9}$ A deductive content analysis uses pre-determined criteria to categorise comments, whereas in an inductive content analysis categories emerge as the comments are analysed (Patton, 2002).
} 


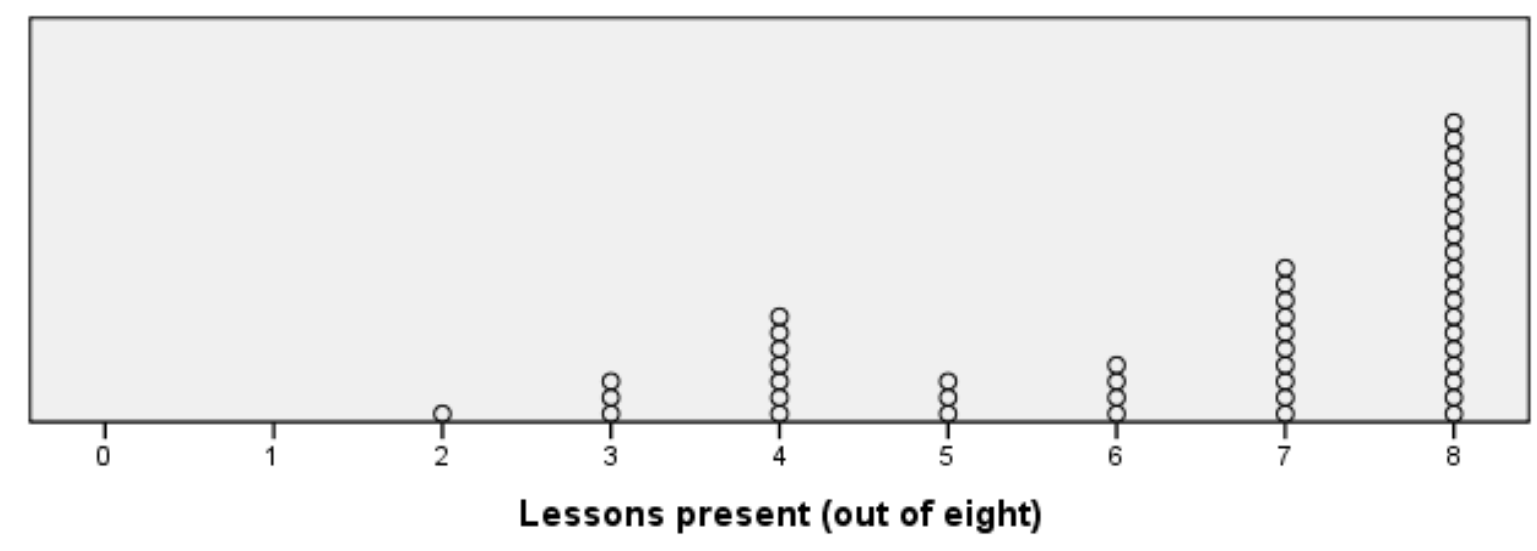

Figure 6. Number of lessons students were present in class

All students present at the end of each lesson initialled and completed every item on the engagement questionnaire. One questionnaire was misplaced. Students who were interviewed claimed that they had found the questionnaire easy to understand and had made an effort to give answers that reflected the current lesson. This evidence suggests that most students understood the questionnaire and completed it honestly. For example, after completing the questionnaire eight times one student said "I already know the questions but I do read them and I still think about what to write ... I always have a different response."

A post hoc reliability analysis of the engagement scale was conducted using all data from the 300 questionnaires completed during the experimental phase. The internal consistency, estimated using Cronbach's alpha ${ }^{10}$, was 0.91 , much higher than the minimum acceptable value of 0.7 (Johnson \& Christensen, 2008). Feedback from students during pilot and experimental phase interviews indicated that students' responses reflected thoughts, emotions and behaviours associated with procedural engagement. Thus there is good evidence to suggest that the scale was a valid indicator of students' procedural engagement ${ }^{11}$.

\footnotetext{
${ }^{10}$ A high alpha reflects a high degree of intercorellation between the items in the scale.

${ }^{11}$ Analysis of the inter-item correlations and item statistics (Appendices $\mathrm{N}$ and $\mathrm{O}$ respectively) showed that all pairs of items had positive pairwise correlations, although Item 2 'I thought about how the maths I learnt today relates to real life' has pairwise correlations of lower magnitude than the other items as well as the lowest standard deviation, indicating that it varies less between lessons and students than the other items. One explanation for this could be that the extent to which students think about how the maths they learn related to real life is quite durable, and thus that the item is an
} 


\section{Chapter 4: Results and analysis}

The data analysis was conducted sequentially, with the interpretation of one analytical stage sometimes influencing the procedure of subsequent stages. Therefore in this chapter results and analysis for each stage are presented before proceeding to the results and analysis of the following stage. The first step was to ascertain whether there was evidence that the teaching condition (thematic or non-thematic) was related to student engagement for at least some of the students. This stage involved comparing summary statistics for groups of students (Section 4.1.1) and characterising individual students in terms of their preferences (Section 4.1.2). Secondly, the characteristics of students who preferred thematic or non-thematic teaching were analysed in order to propose a set of student variables which might mediate the association between thematic teaching and engagement (Section 4.2). Thirdly, the reasons students gave for their preferences were collated and summarised (Section 4.3).

\subsection{Student preferences}

This section addresses the first research question ${ }^{12}$ by comparing engagement in the thematic and non-thematic teaching conditions. Comparisons are made firstly for the students as a group using summary statistics (Johnson \& Christensen, 2008), then for individual students using a judgement-based approach (Gorard, 2006).

\subsubsection{Grouped results}

A two-tailed, paired samples $t$-test (Johnson \& Christensen, 2008) was conducted to compare students' Engagement Indices (EIs, Section 3.4.1) in thematic and nonthematic lessons for the 32 students included in the analysis. There was no significant difference between EIs for thematic teaching $(\mathrm{M}=23.7, \mathrm{SD}=4.4)$ and non-thematic teaching $(\mathrm{M}=22.7, \mathrm{SD}=3.3) ; \mathrm{t}(31)=1.4, \mathrm{p}=0.17$.

indicator of substantive rather than procedural engagement. Any researchers using this scale in the future should consider removing or modifying Item 2 .

\footnotetext{
${ }^{12}$ What relationship, if any, does thematic teaching have to the procedural engagement of students in a non-academic Year 12 mathematics course?
} 
On average, students' responses to the engagement scale were one unit higher for thematic teaching than non-thematic teaching. Using the criteria summarised in Table 2, this difference is not practically significant, and the result in the previous paragraph shows that it is not statistically significant. In other words results from the participating students, when taken as a group, indicate no overall preference for thematic or non-thematic teaching, suggesting that there was no consistent association between thematic teaching and engagement. This result is consistent with the findings of previous studies which reported no significant overall effect of thematic teaching (e.g., Olicker, 2005; Yeap \& Melati, 2001), but differs from the findings of studies that reported positive effects of thematic teaching on engagement (e.g., Leonard, 2004; Perry \& Howard, 2008).

\subsubsection{Individual student results}

The previous section indicated that there was no consistent association between thematic teaching and procedural engagement across the group of participant students. However, this only partially answers the question of what relationship might exist between thematic teaching and student engagement. The non-significant $t$-test for the grouped data does not preclude the possibility that thematic teaching had a positive association with the engagement of some students and a negative association with the engagement of others, with the effects cancelling out when group means are calculated. Hence, individual TPI values were calculated to give an initial indication of the range of student preferences (Figure 7). According to the criteria in Table 2, 15 students had a practically significant TPI, 6 negative and 9 positive. Therefore there was an apparent association between teaching condition and procedural engagement for some students ${ }^{13}$, so a more rigorous mixed methods process of evaluating individual students' preferences was begun.

\footnotetext{
${ }^{13}$ As stipulated in Section 2.3 as a condition for proceeding to address Research Questions Two and Three.
} 


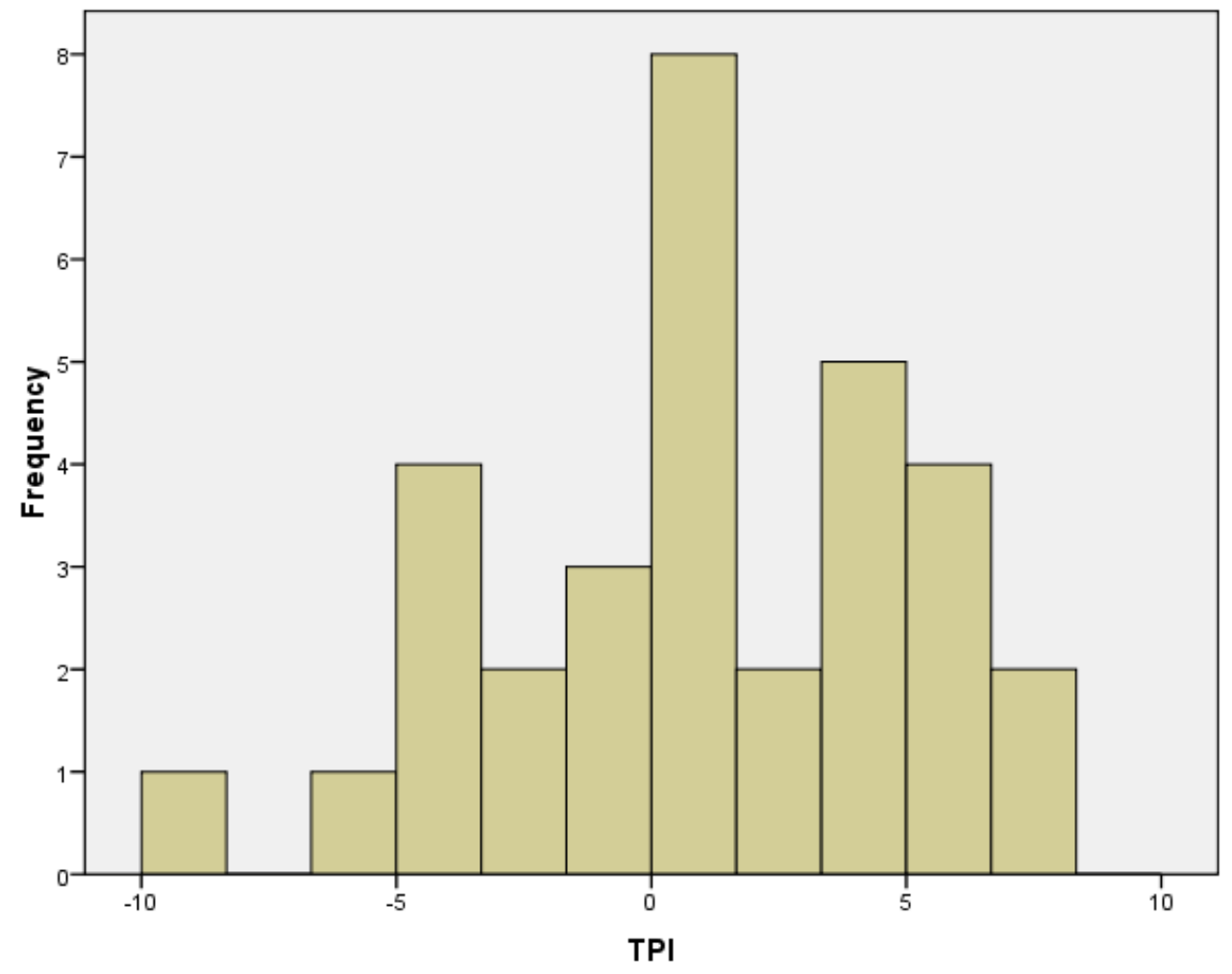

Figure 7. Distribution of TPI values

Engagement plots (Section 3.4.1) were generated for all students and used to identify students whose TPIs may have given a misleading impression of their preferences. In particular, some engagement plots showed a high degree of overlap between engagement indices for thematic and non-thematic lessons, or an extreme value for a single lesson that influenced the TPI without representing the student's typical level of engagement during a teaching condition.

Finally, observation notes were summarised for a sample of ten students representing a wide range of preferences ${ }^{14}$. An engagement score between -3 and 3 was generated for each lesson (Section 3.4.2) and the pattern of lesson scores assessed in a similar manner to the engagement plots. For all of these students, the overall preference derived from observation data was consistent with the preference derived from questionnaire data, although there were conflicting results for some individual lessons.

\footnotetext{
14 Analysis of observation data was very time consuming so observation data was checked for consistency with questionnaire data for a sample of students.
} 
Using TPI values, engagement plots, and in some cases observation data, students were classified as having no preference or as having a clear or possible preference for thematic or non-thematic teaching. Students were classified as having a clear preference if the absolute value of their TPI was greater than four, and their engagement plot indicated that the TPI value was a fair representation of their preference. The extent and direction of the difference in engagement between the two teaching conditions varies markedly between students (Table 3). Hence the nonsignificant difference between thematic and non-thematic EI values (Section 3.4.1) in the grouped data reflects a combination of positive, negative, and neutral associations for different students. The salient point here is that preferences varied across students; some preferred thematic or non-thematic teaching, and some had no preference. Thus it seems sensible to ask what factors influence student preference, or lack of preference, for thematic and non-thematic teaching.

Table 3. Distribution of Student Preferences

\begin{tabular}{|c|c|c|c|c|c|}
\hline & $\begin{array}{l}\text { Thematic } \\
\text { preference }\end{array}$ & $\begin{array}{l}\text { Possible } \\
\text { thematic } \\
\text { preference }\end{array}$ & $\begin{array}{l}\text { No } \\
\text { preference }\end{array}$ & $\begin{array}{l}\text { Possible non- } \\
\text { thematic } \\
\text { preference }\end{array}$ & $\begin{array}{l}\text { Non-thematic } \\
\text { preference }\end{array}$ \\
\hline $\begin{array}{c}\text { Number of } \\
\text { students }\end{array}$ & 5 & 7 & 12 & 1 & 8 \\
\hline
\end{tabular}

The process of determining how to classify students' will now be illustrated by explaining the process in detail for one student. Nick was a male, Pakeha, Year 12 student in Tony's class. Nick's TPI was 8 , indicating a strong, practically significant preference for thematic teaching, and his engagement plot is shown below (Figure 8). He was absent for the first thematic lesson then had engagement indices in the 24 to 27 range for the three remaining thematic lessons. During the four non-thematic lessons that followed his engagement indices were in the range of 15 to 22 . 


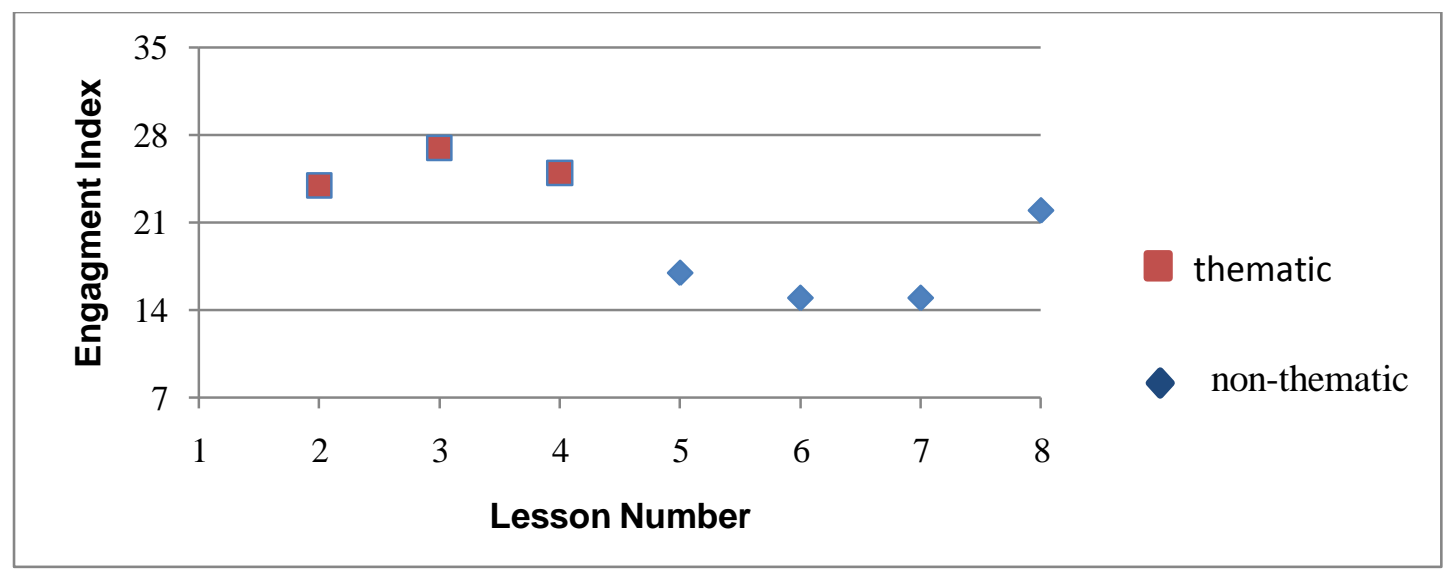

Figure 8. Nick's engagement plot

The data from observations of Nick's engagement (Table 4) were analysed as outlined in Section 3.4.2 to derive an engagement score for each lesson. The data show that during the three thematic lessons Nick was mostly on task; of the nine snapshot observations seven indicated engagement, one was neutral, and one indicated lack of engagement. In contrast, Nick's engagement was very poor during the non-thematic lessons; only three of the twelve observation snapshots during the non-thematic lessons showed evidence of engagement. The preference derived from observations was consistent with that derived from questionnaire data because both sources suggest that Nick was more engaged during thematic than non-thematic lessons. The level of consistency between questionnaire and observation data varied between lessons, as could be expected given that the observations consisted of three 30-second snapshots (Section 3.4.2). 
Table 4. Nick's Observation Data

Note: for judgement criteria see Section 3.4.2

\begin{tabular}{|c|c|c|c|c|}
\hline $\begin{array}{l}\text { Lesson } \\
\text { number }\end{array}$ & $\begin{array}{l}\text { Snapshot } 1 \\
\text { [judgment] }\end{array}$ & $\begin{array}{l}\text { Snapshot } 2 \\
\text { [judgment] }\end{array}$ & Snapshot 3 [judgment] & Total \\
\hline 1 & Absent & Absent & Absent & N.A. \\
\hline 2 & Off-task talk [-1] & $\begin{array}{l}\text { Verbalising } \\
\text { thinking; working } \\
\text { in book [1] }\end{array}$ & $\begin{array}{l}\text { Verbalising thinking; } \\
\text { working in book [1] }\end{array}$ & 1 \\
\hline 3 & $\begin{array}{l}\text { Staring into space; } \\
\text { watching Tony [0] }\end{array}$ & $\begin{array}{l}\text { Looking at board; } \\
\text { working in book [1] }\end{array}$ & Watching Tony [1] & 2 \\
\hline 4 & Working in book [1] & $\begin{array}{l}\text { Looking at board } \\
\text { and teacher [1] }\end{array}$ & $\begin{array}{c}\text { Reading notes from book } \\
{[1]}\end{array}$ & 3 \\
\hline 5 & $\begin{array}{l}\text { Looking at board; } \\
\text { taking notes; self- } \\
\text { monitoring [1] }\end{array}$ & $\begin{array}{l}\text { Verbalising } \\
\text { thinking; working } \\
\text { in book [1] }\end{array}$ & $\begin{array}{l}\text { Feet on desk; off-task talk } \\
\qquad[-1]\end{array}$ & 1 \\
\hline 6 & $\begin{array}{l}\text { Head on desk; not } \\
\text { listening at all [-1] }\end{array}$ & $\begin{array}{c}\text { Appears asleep } \\
{[-1]}\end{array}$ & Appears asleep [-1] & -3 \\
\hline 7 & $\begin{array}{l}\text { Looking at board; } \\
\text { working in book [1] }\end{array}$ & $\begin{array}{l}\text { Off-task talk; } \\
\text { sleepy body } \\
\text { language [-1] }\end{array}$ & Staring into space $[-1]$ & -1 \\
\hline 8 & $\begin{array}{c}\text { Staring into space } \\
{[-1]}\end{array}$ & $\begin{array}{c}\text { Staring into space } \\
{[-1]}\end{array}$ & $\begin{array}{l}\text { Off-task talk; sleepy body } \\
\text { language; taking notes } \\
\text { from board [0] }\end{array}$ & -2 \\
\hline
\end{tabular}

Student questionnaire data was analysed in order to determine whether each student had higher procedural engagement in one or other teaching condition. For the sample of students whose observation data was also analysed, there was a high degree of consistency between the preferences derived from questionnaires and preferences derived from observations. This consistency provides stronger evidence of the validity of the methodological assessment of preference than would have been the case had only one measure of preference been used (Creswell \& Plano Clark, 2007). 
Based on the above analysis of preferences, it appears that there is a high degree of variability between students in terms of the extent to which they were procedurally engaged in each teaching condition. Simply stated, there is evidence that some students were more engaged during thematic teaching, some were more engaged during non-thematic teaching, and some had similar levels of engagement in both conditions. This suggests that the non-significant mean TPI reported in Section 5.1 masks a complex reality in which thematic teaching may have different effects on engagement for different students.

\subsection{Mediating variables}

The previous section provided evidence that thematic teaching had no consistent relationship with the engagement of all students but that it appeared to be related to the engagement of some students who had preferences either for thematic or nonthematic teaching. The second research question ${ }^{15}$ seeks to identify student variables which may mediate the relationship between thematic teaching and procedural engagement. If such variables can be identified they may serve to explain some of the variation in students' preferences and facilitate more strategic and targeted use of thematic teaching. The following discussion evaluates whether gender, ethnicity, English language proficiency, and students' stated levels of interest in the theme appear to mediate the relationship between thematic teaching and procedural engagement. In order to carry out a valid assessment of the potential mediating influence of the above factors, it will first be necessary to address the confounding factor of class membership.

\footnotetext{
${ }^{15}$ Which student characteristics (e.g. ethnicity, English language proficiency, interest in the theme) are related to students' preferences for thematic or non-thematic teaching?
} 


\subsubsection{Results}

\section{Class membership: a confounding factor}

The distribution of teaching preferences was very different for the two classes (Table 5). All the students with a thematic preference were in Tony's class, and all the students with a non-thematic preference were in Chris' class.

Table 5. Preference Distributions by Class Membership

\begin{tabular}{c|ccccc}
\hline & $\begin{array}{c}\text { Thematic } \\
\text { preference }\end{array}$ & $\begin{array}{c}\text { Possible } \\
\text { thematic } \\
\text { preference }\end{array}$ & $\begin{array}{c}\text { No } \\
\text { preference }\end{array}$ & $\begin{array}{c}\text { Possible non- } \\
\text { thematic } \\
\text { preference }\end{array}$ & $\begin{array}{c}\text { Non-thematic } \\
\text { preference }\end{array}$ \\
\hline $\begin{array}{c}\text { Tony's } \\
\text { class }\end{array}$ & 5 & 5 & 9 & 0 & 0 \\
Chris' & 0 & 0 & 4 & 1 & 8 \\
class & & & & & \\
\hline
\end{tabular}

The mean TPI values were 3.6 and -2.7 for Tony's and Chris' classes respectively. Separate paired samples $t$-tests (Johnson \& Christensen, 2008) were conducted to compare students' Engagement Indices (Section 3.4.1) in thematic and non-thematic lessons for Tony's class and Chris' class. For Tony's class $(n=19)$, there was a significant difference between EIs for thematic teaching $(\mathrm{M}=25.6, \mathrm{SD}=3.7)$ and non-thematic teaching $(\mathrm{M}=22.0, \mathrm{SD}=3.7) ; t(18)=6.6, p<0.001$. For Chris' class $(n=13)$, there was also a significant difference between EIs for thematic teaching (M $=21.0, \mathrm{SD}=4.4)$ and non-thematic teaching $(\mathrm{M}=23.7, \mathrm{SD}=2.4) ; t(12)=3.0, p=$ 0.01. Thus students in Tony's class, on average, were more engaged during thematic lessons than non-thematic lessons, and students in Chris' class, on average, were more engaged during non-thematic lessons than thematic lessons. 


\section{English language proficiency}

Paired samples $t$-tests (Johnson \& Christensen, 2008) were conducted to compare students' Engagement Indices in thematic and non-thematic lessons for ELLs and non-ELLs. For ELLs $(\mathrm{n}=10)$, there was no significant difference between EIs for thematic teaching $(\mathrm{M}=24.0, \mathrm{SD}=4.3)$ and non-thematic teaching $(\mathrm{M}=25.0, \mathrm{SD}=$ $1.4) ; t(9)=-0.84, p=0.43$. For non-ELLs $(\mathrm{n}=22)$, there was a significant difference between EIs for thematic teaching $(\mathrm{M}=23.6, \mathrm{SD}=4.5)$ and non-thematic teaching $(\mathrm{M}=21.6, \mathrm{SD}=3.4) ; t(21)=2.3, p=0.03$. This result suggests that, as a group, ELLs tended to have a lower TPI than non-ELLs. The distribution of preferences for ELLs contains a higher proportion of students who preferred non-thematic teaching and a lower proportion of students who preferred thematic teaching than the distribution for non-ELLs (Table 6).

Table 6. Preference Distributions by ELL status

\begin{tabular}{c|ccccc}
\hline & $\begin{array}{c}\text { Thematic } \\
\text { preference }\end{array}$ & $\begin{array}{c}\text { Possible } \\
\text { thematic } \\
\text { preference }\end{array}$ & $\begin{array}{c}\text { No } \\
\text { preference }\end{array}$ & $\begin{array}{c}\text { Possible non- } \\
\text { thematic } \\
\text { preference }\end{array}$ & $\begin{array}{c}\text { Non-thematic } \\
\text { preference }\end{array}$ \\
\hline $\begin{array}{c}\text { ELLs } \\
(n=10)\end{array}$ & 0 & 1 & 5 & 1 & 3 \\
Non- & 5 & 4 & 8 & 0 & 5 \\
ELLs & & & & & \\
$(n=22)$ & & & & & \\
\hline
\end{tabular}

The above results are potentially misleading because the proportion of ELLs in Tony's class (21\%) was much lower than that in Chris' class (46\%). Based on this data alone there are three possible interpretations: both class membership and ELL status are related to engagement, class membership but not ELL status is related to engagement, or ELL status but not class membership is related to engagement. The sample size was too small to make valid use of multiple linear regression analysis (Howell, 2008) so the main and interaction effects of class membership and ELL status were examined graphically (Figure 9). 


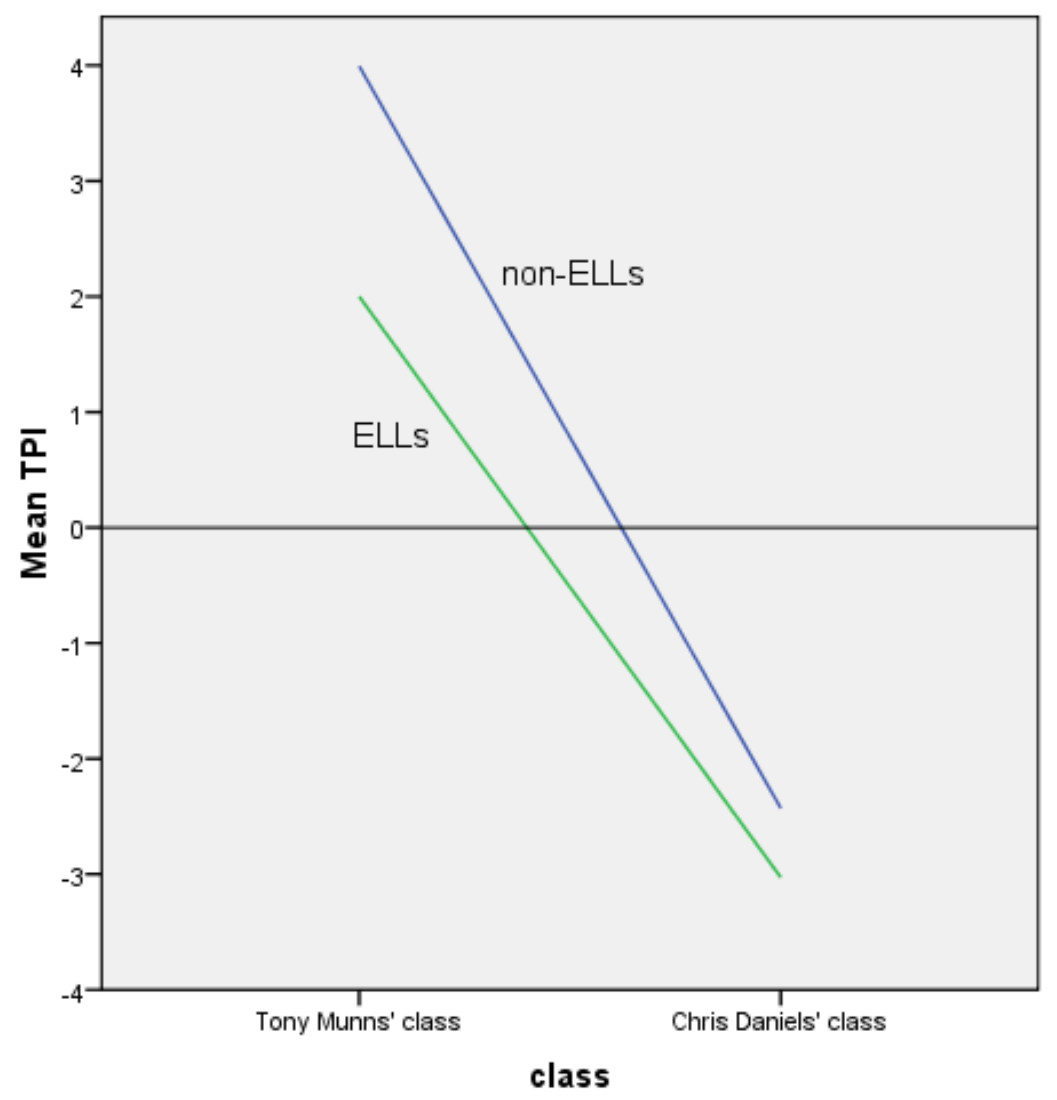

Figure 9. Effects of class membership and ELL status on TPI

The main effect of class membership is shown by the vertical difference between the top and bottom of each line. There is a large difference between the mean TPI of students in Tony's class and students in Chris' class for both ELLs and non-ELLs. The effect of class membership is of particular practical significance because, for both ELLs and non-ELLs, the mean TPI is positive for Tony's class and negative for Chris' class.

The main effect of ELL status is shown by the vertical distance between the two lines. For both classes, mean TPI is lower for ELLs than for non-ELLs, thus the difference in mean TPI between ELLs and non-ELLs appears to be partially explained by a genuine relationship between TPI and ELL status. However, the main effect of ELL status is smaller in magnitude than the main effect of class membership, and is of less practical significance because, for both classes mean TPI has the same sign for both ELLs and non-ELLs. The two lines have similar gradients, indicating that any interaction between the two main effects just discussed is small. 


\section{Ethnicity}

A graphical analysis of TPI data by school-reported ethnicity indicates that Pakeha and Asian students tended to have higher TPI than Pasifika students, although the distributions do overlap (Figure 10). Māori students appear to have a very high preference for thematic teaching, but this result is based on two students and thus does not warrant further analysis in this study. However, future studies with larger numbers of Māori participants could investigate this finding further. The lower quartile for Pakeha students is above the upper quartile for Pasifika students, so for the participant students there was a practically significant difference between these two groups, with the engagement of Pakeha students responding more positively to thematic teaching than that of Pasifika students.

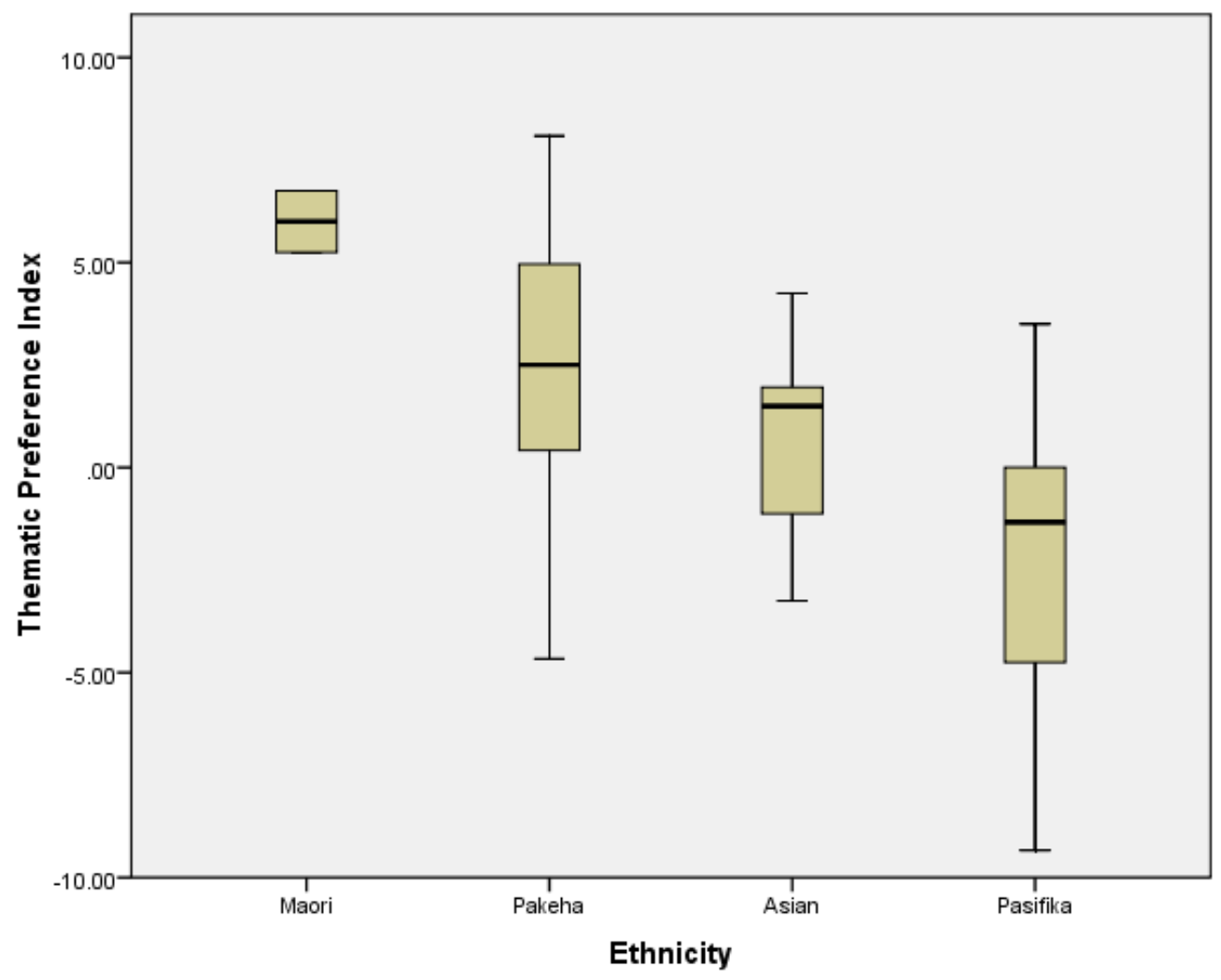

Figure 10. TPI distribution by ethnicity for Māori $(\mathrm{n}=2)$, Pakeha $(\mathrm{n}=15)$, Asian $(\mathrm{n}=8)$ and Pasifika ( $\mathrm{n}=7)$ students 


\section{$\underline{\text { Gender }}$}

The female $(\mathrm{n}=18)$ and male $(\mathrm{n}=14)$ sub-samples both had mean TPI values of 1 , and the $95 \%$ confidence intervals of both means included zero, so there is no evidence that gender mediated the relationship between thematic teaching and procedural engagement.

\section{$\underline{\text { Work Habits }}$}

Students' work habits emerged from field notes and teacher interviews as a possible mediating variable between thematic teaching and procedural engagement. My observations of students over a period of eight lessons gave me an impression of which students habitually completed set work and which students were likely to avoid working unless the teacher put pressure on them. Students in the latter category were strongly represented amongst the students with a strong preference for thematic teaching. After completing the preliminary data analysis I told Tony the names of the five students identified as having the strongest preferences for thematic teaching without any explanation and asked him whether they had anything in common. His immediate response was: "they never do any work!"

\subsubsection{Discussion}

The comparisons between the two classes appears to indicate that, overall, students in Tony's class preferred thematic teaching and students in Chris' class preferred non-thematic teaching. This difference is consistent with an explanation by teacher variables, which have been shown to influence engagement (Fredricks, et al., 2004; Yair, 2000). Yet the explanation by teacher variables is problematic due to the potential confounding effects of the mathematical content of the lessons on engagement. Both classes showed higher levels of engagement during the first teaching phase, which was thematic for Tony's class and non-thematic for Chris' class, due to the counterbalanced design (Section 3.1.3 and Figure 3). Hence the results comparing the preferences of the two classes are subject to a rival explanation: the content of the first four lessons of the experimental phase was more engaging than the content of the last four lessons. This possible rival explanation was explored graphically by superimposing engagement plots of the two classes (Figure 
11). Both classes exhibited a marked drop in engagement between the fourth and fifth lessons, coinciding with transition from thematic to non-thematic teaching for Tony's class and from non-thematic to thematic teaching for Chris' class. However, the drop in engagement also coincided with the start of the more algebraically challenging portion of the topic, so the results regarding the respective preferences of each class should be interpreted with caution.

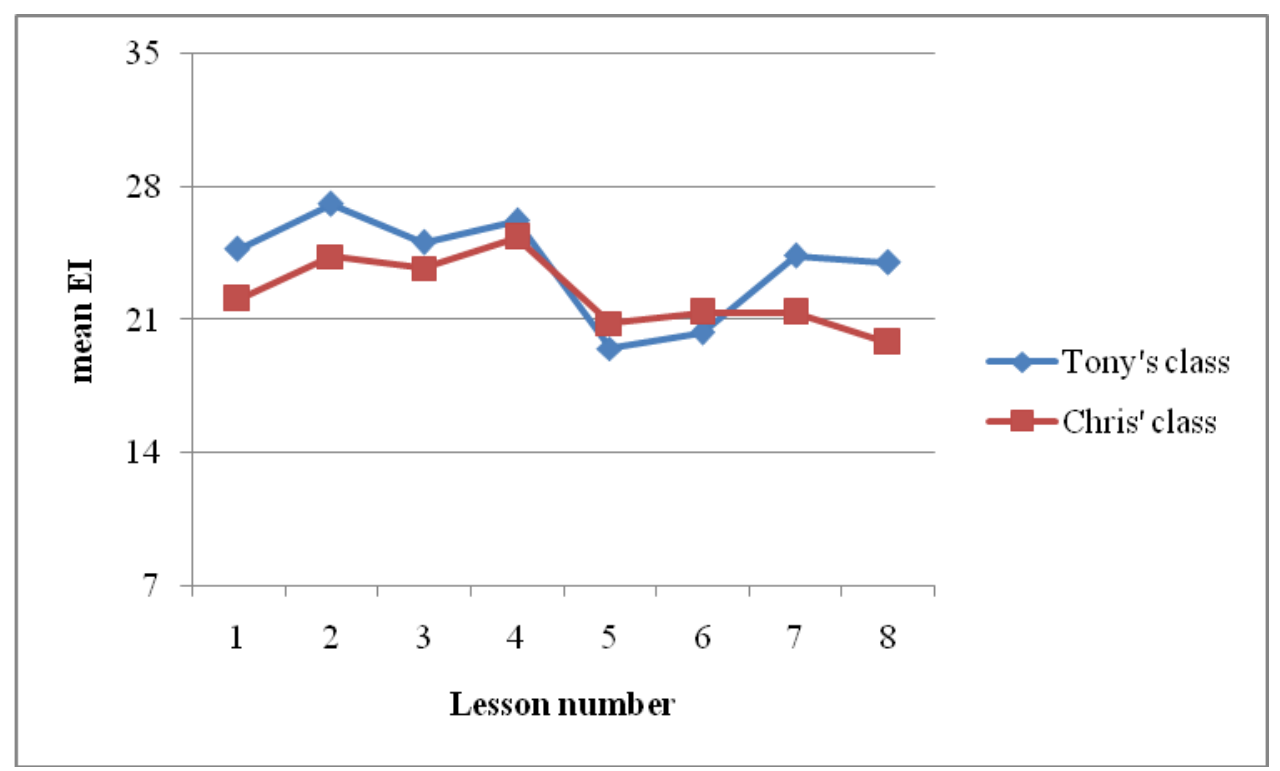

Figure 11. Class engagement plots

My observations of both teachers' implementation of thematic and non-thematic teaching gave me no reason to anticipate any differences in how students would respond to their teaching. Neither teacher seemed more comfortable with thematic teaching than the other, nor more engaging in the way they incorporated the theme into their teaching. Thus there is no immediately apparent explanation as to why Tony's students should prefer thematic teaching and Chris' students non-thematic teaching. There are, however, substantive reasons to expect a drop in engagement around the fifth lesson. This lesson marked the transition from the procedurally simple skills of finding lengths, midpoints, and gradients of straight lines to finding equations and intersection points of straight lines, which required a higher level of algebraic manipulation. During the planning phase it had been more difficult to develop thematic resources for this second part of the coordinate geometry topic, and both teachers commented in the debrief interviews that the mathematics in the latter 
part of the topic was more challenging to teach thematically. Tony commented on a number of occasions that Chris had the tougher job in teaching the more complicated mathematics thematically. Moses, a student in Chris' class described how student engagement can decline very rapidly when students become confused by the content, even if the context itself is interesting. This rival explanation is sufficiently plausible that there is insufficient evidence to conclude that teacher variables explain the differences in preferences between the two classes.

The difference in TPI between ELLs and non-ELLs suggest that students who are learning English as an additional language find thematic teaching less engaging than students who speak English fluently. Although the magnitude of the difference is not large, the result is worth noting as it is consistent across both classes and is reaffirmed by interview data (Section 4.3.1). ELLs were amongst those who most clearly articulated disadvantages of thematic teaching in their interviews, and these reasons often related to language difficulties.

The analysis by ethnicity suggests that Pakeha students tend to have higher preference for thematic teaching than Pasifika students. This result was not expected given the strong Pacific focus of the theme, and is further discussed in Section 5.3. Gender did not appear to be related to students' preferences, consistent with prior studies in which results were analysed by gender (Ching, 2009; Henderson \& Landesman, 1992; Lam, 2007).

The impression that students with poor work habits were more engaged in thematic than non-thematic teaching is based on a less rigorous analysis than the other findings, and merits further analysis in future studies. A possible explanation could be that some students complete set work regardless of whether they find it interesting, whereas students who apply themselves less consistently are more strongly influenced by an engaging theme. However, this finding should be treated as an emerging hypothesis rather than a reliable result.

\subsection{Reasons for preferences}

This section addresses the third research question: What reasons do students give for their preferences for thematic or non-thematic teaching? 


\subsubsection{Results}

Some students said they preferred thematic teaching, some that they preferred nonthematic teaching, and others did not express a preference. Although a few students expressed reasons for and against thematic teaching, most maintained a single stance throughout the interview. Students' reflections and opinions were coded according to whether they pertained to thematic or non-thematic teaching, and whether they were reasons for or against the teaching style under discussion. There were student responses in all categories, although students tended to frame their responses in terms of thematic teaching. Even if asked to explain why they preferred non-thematic teaching, their response was often expressed in terms of the disadvantages of thematic teaching. The reasons given by students are summarised in Table 7 .

Table 7. Reasons for Preferences

\begin{tabular}{|l|l|l|}
\hline & Thematic teaching & Non-thematic teaching \\
\hline Advantages & More interesting & Easy to understand \\
& $\begin{array}{l}\text { More fun } \\
\text { Connected to real life } \\
\text { More depth and meaning } \\
\text { Additional non-mathematical learning } \\
\text { Easier to access }\end{array}$ & Procedurally simple \\
& "Not so math" & \\
\hline Disadvantages & $\begin{array}{l}\text { Hard to understand/Confusing } \\
\text { Complicated } \\
\text { Additional non-mathematical learning boring } \\
\text { Hard to interpret }\end{array}$ & Prescribed "so math" \\
\hline
\end{tabular}

\subsubsection{Discussion}

Most of the students who preferred thematic teaching commented that it made learning more interesting. Closely related to this were comments that the 
mathematics was more "related to real life" and had more meaning in context, with many students referring to specific elements of the theme, such as the locations of islands. When these students spoke of non-thematic teaching, they described it as boring, almost like something is missing from it because it was "just numbers". When students specifically commented on the impact of thematic teaching on the process of their mathematics learning, most described a benefit to learning as a result of increased interest and participation, whilst a few said that the theme actually made the mathematics easier to learn: "it makes it more interesting so it's easier to learn, easier to get into". One student liked the additional non-mathematical learning that took place.

Students who preferred non-thematic teaching consistently said that they preferred it because it was easier and simpler. They described thematic teaching as confusing, complicated, and difficult to access: "I don't like it with all the stories, I just prefer numbers". A few students said that they found the theme itself boring, and that they did not want to learn non-mathematical content during mathematics: "the history part was pretty boring but the rest of it was alright." The above responses suggest that these students want to learn mathematics in as straightforward and efficient a manner as possible and see the context as a superfluous and troublesome imposition.

Students of both preferences showed in the language that they used that thematic teaching has an additional element not present in non-thematic teaching, variously described as a "story", "context", "history", or "that Pacific Ocean stuff". The students differed in terms of how this additional contextual element affected their experience of learning mathematics. Some students viewed the context positively because it added meaning and flavour to otherwise dry and abstract learning, whilst others viewed abstract mathematical learning as the heart of their purpose for being in a mathematics lesson and the context simply a nuisance and a distraction from this purpose.

Students of both preferences classified the theme as learning associated with other school subjects, namely History and Geography. Blake, who preferred thematic teaching, said that he felt good about the extra learning that he was able to do, whilst 
Moses and Shelley both saw this learning as out of place in a mathematics lesson. Moses explained,

We're not in History, we're in Maths! It's too hard to think 'cos if you see numbers you can think are you adding it or multiplying, but if you do countries, you can’t add countries, so that makes it hard.

Students were in agreement about the nature of thematic and non-thematic teaching, in that they both saw the theme as distinct from and additional to the mathematics they were there to learn, but they differed in their responses to this additional learning. 


\section{Chapter 5: Conclusions}

This concluding chapter revisits the three research questions that were introduced in Chapter Two, and summarises the key findings with respect to each question (Section 5.1). The findings are discussed in terms of their consistency with previous studies and the new knowledge that they contribute to the field of thematic teaching in mathematics. The discussion of findings is followed by a critical evaluation of this study (Section 5.2). In particular, the theoretical framing and methodology are evaluated, with strengths acknowledged and recommendations made for changes that could be made to similar studies in the future. Finally the implications of the current study for teaching, course design, educational policy, and future research are discussed (Section 5.3).

\subsection{Research questions revisited}

This study aimed to address three questions, all concerned with the relationship between thematic teaching and procedural engagement. The purpose of addressing these questions was to gain a greater understanding of the reasons for the mixed success of thematic teaching reported in prior research. Whilst student variables, teacher variables, and other out-of-school factors all affect engagement (Yair, 2000), the current study focused on student variables. The research was designed to focus on the variation between students in terms of any effect that thematic teaching had on their engagement. The key findings associated with each research question are summarised below.

(1) What effect, if any, does thematic teaching have on the procedural engagement of students in a non-academic Year 12 mathematics course?

Thematic teaching had no consistent effect on student engagement. Some students were more engaged during thematic lessons, some were more engaged during nonthematic lessons and others had similar engagement in thematic and non-thematic lessons.

(2) Which student characteristics (e.g., ethnicity, English language proficiency, interest in the theme) are related to students' preferences for thematic or nonthematic teaching? 
Students in the process of learning English as an additional language were more likely to prefer non-thematic teaching than other students. Pasifika students were more likely to prefer non-thematic teaching than Pakeha students. There is some evidence that the students with the greatest preference for thematic teaching were those with poor or inconsistent work habits.

(3) What reasons do students give for their preferences for thematic or nonthematic teaching?

Students who preferred thematic teaching found that the theme made learning mathematics more interesting, meaningful, and fun. The theme stimulated their interest and thereby their inclination to put effort into learning. Some valued the nonmathematical learning associated with the Pacific theme for its own sake, aside from any benefit it might have had for their mathematical learning. Compared with thematic teaching, these students found non-thematic teaching dry and uninspiring.

Students who preferred non-thematic teaching valued the simplicity and accessibility of non-thematic tasks. They reported finding the theme a barrier to learning and a distraction from their primary purpose: learning mathematics. These students voiced an important word of caution to anyone attempting to teach thematically: students cannot engage with learning if they do not understand the mathematics, no matter how interesting the theme might be.

\section{Consistency with previous literature}

Despite the large body of previous studies which evaluated thematic teaching interventions, none were found with results directly comparable to the results of the current study. Most large-scale evaluations of thematic interventions (e.g., Ching, 2009; Henderson \& Landesman, 1992) used achievement and relatively durable attitudinal traits as outcome variables. In a sense most prior studies examined the impact of thematic teaching with a wide-angle lens; an intervention was designed and implemented, and researchers attempted to gauge the extent to which students' achievement or attitude towards mathematics had changed over the duration of the intervention. Whilst some of these large-scale evaluation studies reported significant positive effects of thematic teaching, taken as a body of research, they are 
inconclusive. The current study's non-significant overall difference between engagement in thematic and non-thematic lessons is consistent with the pattern of previous results in the sense that thematic teaching does not appear consistently or reliably to predict changes in the outcome variable of interest. However, this study examined the effects of thematic teaching on a shorter timescale than previous studies and used a more fluid outcome variable, procedural engagement, so the results are not directly comparable. Gender did not appear to mediate the effect of thematic teaching on engagement; this is consistent with prior studies which did not report any gender differences in the impacts of thematic interventions.

\section{New knowledge}

The tendency for ELLs to prefer non-thematic teaching was not reported in any study contained in the review of literature. However, there is a large body of literature concerning the learning of ELLs in mathematics classrooms which was not examined in the literature review because it pertains to the language of learning in general rather than to thematic teaching in particular (e.g., Gibbons, 2002; Sfard \& Keiran, 2001; White, 2003). ELLs usually take 5 - 7 years to reach a level of comprehension of academic English comparable to that of their English first-language peers, even though their conversational English can seem quite fluent within two years (Gibbons, 2002). Despite the widespread perception of mathematics as a language neutral subject, ELLs frequently struggle to decode the syntax of written and spoken English and to 'translate' the meaning into the precise language of formal mathematics (White, 2003). Teachers often assume that vocabulary is the main barrier to mathematic learning for ELLs, whereas in fact the greatest difficulty is often found in interpreting the grammar. Common words and phrases such as 'of' and 'out of' have very precise mathematical meanings when they occur in word problems, so ELLs may be disadvantaged even when problems appear to utilise fairly basic language (Anthony \& Walshaw, 2007). A comprehensive analysis of the role of language-rich mathematics problems for ELLs is beyond the scope of the current analysis. The salient point is that a post hoc review of language learning literature provides a possible explanation for the difficulty that ELLs experienced with thematic teaching. Thematic teaching was more language-rich than non-thematic 
teaching, and this was more of a barrier to mathematical understanding for ELLs than for non-ELLs.

The reasons students gave for preferring thematic or non-thematic teaching are results for which I am unaware of any direct parallels in prior studies. The one reviewed study which included student interviews reported adult mathematics learners' attitudes to word problems, and reports that one ELL lamented "extraneous words cluttering up what he seemed to think of as real mathematics" (Marr, 1998, p. 14). However, the current study contributes original knowledge to the thematic teaching literature by summarising themes across a number of student interviews.

In terms of participants, the current study examines thematic mathematics teaching with senior secondary students, an age group seldom represented in studies of thematic teaching. As a teacher, I had noticed a reduction in teachers' efforts to stimulate student engagement as students moved into the senior school. This was perhaps based on the assumption that students sitting high-stakes assessments would want to focus on learning the mathematical content by the path of least resistance, and should not need to be 'entertained' any more. The current study demonstrates that senior students can benefit from creative and engaging teaching practices. In terms of ethnicity, I am unaware of any empirical studies comparing the effectiveness of thematic teaching between Pasifika and Pakeha students. The sample size for the ethnic comparisons was very small in this study so it cannot be generalised without further investigation, but the apparent dislike of Pasifika students for thematic teaching is inconsistent with the predictions of some Pacific scholars (Manu'atu, 2009; Nabobo-Baba, 2006). The result of this ethnic comparison highlights the need for further evaluation of Pasifika students' engagement with thematic mathematics teaching, including how thematic practices can be refined so that the benefits envisioned by Pacific scholars can be harnessed more fully than they were in this study. Given that the context was strongly focused on Pacific culture and heritage but still failed to engage Pasifika students, perhaps thematic teaching needs to incorporate more explicitly principles of culturally responsive pedagogy, which extend far beyond the mathematical and contextual content (Averill, et al., 2009). Finally, this study supplements the international body of literature by adding a New 
Zealand study to the thematic teaching literature at a time when many senior mathematics courses in New Zealand are being significantly re-designed.

\subsection{Evaluation and limitations}

\subsubsection{Theoretical framework}

This study has sought to make sense of inconsistencies and variability in engagement with thematic teaching rather than to make summary statements about the effects of thematic teaching for all students. Roth's (1996) framing of contexts in mathematics as co-constructed by the author of the problem and the student reading the problem provided a basis for supposing that different students may interpret a context in different ways depending on their prior knowledge and experiences. Roth's theoretical framework laid the foundation for asking questions about students' cultural and linguistic backgrounds and how these related to their learning experiences. If each students' understanding of the human settlement of the Pacific was constructed using their prior knowledge and language then it should be expected that students will construe the context in different ways depending on their English language skills and prior knowledge of Pacific geography, seafaring, and so on.

Roth (1996) also describes contexts as phenomena which students experience. It is common knowledge that people engage with the same phenomena to vastly different extents; take for example the spectrum of experiences ranging from boredom to gripping tension as seen in a group of people watching a rugby match. Roth's phenomenological theorising of contexts in mathematics word problems problematises the notion that a context can be objectively interesting or relevant, and creates space for diverse experiences of the same learning task. The phenomenological framework shaped the interpretation of divergent experiences of the Pacific context. Some students enjoyed learning about the human settlement of the Pacific whilst others found it boring. Interpreting this result phenomenologically meant that it was not treated as an anomaly or as indicating 'conflicting' results, but as a demonstration of the extent to which students' experiences of the Pacific context and their interest in this theme varied. In summary, Roth's (1996) student-centred, phenomenological framing of student engagement with contexts in mathematics was 
very well suited to making sense of variability with respect to student engagement in thematic teaching.

\subsubsection{Methodology and methods}

The mixed-methods approach proved effective in that the quantitative data provided a good indicator of engagement, enabling statistical and graphical analysis to be conducted to make global comparisons between thematic and non-thematic teaching and to compare the preferences of different groups of students. The individual tagging of data was crucial to the effectiveness of the study; between-group comparisons of preferences based on gender, ethnicity, and ELL status and work habits would have been impossible had data been collected anonymously. The engagement questionnaire was brief and clear enough that it yielded $100 \%$ data coverage and was relatively unintrusive. The sample size was small enough to provide a manageable set of data and large enough to give an indication of factors that could contribute to students' preferences for teaching styles, although a larger sample would be required to yield results that could be generalised beyond the study sample.

A bewildering range of uncontrolled factors influence student engagement: being Friday last period, a fight at lunchtime, the mood of the teacher, and the presence or absence of disruptive classmates. These confounding effects cannot be removed from a naturalistic classroom setting, but the extent to which they cause bias in measured engagement decreases as the number of lessons during which engagement is measured increases. The measure of each student's engagement with thematic and non-thematic teaching is based on three or four lessons and is therefore highly sensitive to extreme values which may be the result of the unusual circumstances of a particular lesson. The TPI values which were the dependent variable in most of the quantitative analysis would have been a more robust indicator of students' true preferences had the number of lessons been increased.

The study could have yielded richer results had more demographic and achievement data been collected from the students. Firstly, had prior achievement data been collected it would have been possible to analyse the relationship between prior achievement and thematic preference. This could have proved informative to 
teachers of remedial classes and those wishing to implement differentiated programmes within a single classroom. Secondly, given the influence of English language proficiency on students' preferences, it would have been instructive to obtain measures of English reading comprehension, as the school's classification of students as either ELLs or non-ELLs was a very crude indicator of language ability. Thirdly, although student ethnicity data was obtained from the school database, students often identify with more than one ethnicity, and use of school-generated ethnicity data can be misleading (Averill, et al., 2009). In summary, differences between students were a primary focus of the study, so more accurate and comprehensive student data should have been collected.

An unanticipated limitation of the study design was that the transition between thematic and non-thematic teaching coincided with a sharp increase in the difficulty of the mathematical content. Students reported finding the mathematics in the second half of the topic more complex and difficult to engage with. This is a potential source of bias in the TPI of all students, increasing the TPI of students in Tony's class and decreasing the TPI of students in Chris' class. This effect contributes to the uncertainly with which results based on TPI values must be interpreted.

Researchers conducting similar studies in the future could learn from the above limitations by increasing the length of the study so as to gain more reliable thematic preference indices. Collection of mathematics achievement data, language development data and more detailed demographic data from students would facilitate a more comprehensive analysis of which student variables mediate students' teaching preferences. Attention should be given to the timing of the transition between thematic and non-thematic teaching, so that the mathematical content in each teaching condition is of comparable difficulty.

\subsection{Implications}

The implications of the study are now discussed as they pertain to:

- $\quad$ teaching practice (Section 5.3.1),

- course design (Section 5.3.2),

- educational policy (Section 5.3.3), and 
- future research (Section 5.3.4).

Any recommendation for teachers, course designers, or policy makers based on this research assumes that the findings are able to be generalised beyond the study participants, which is problematic given the small scale of the study. The findings demonstrate what took place with two classes of students in Parkville College, studying coordinate geometry, with a theme based on the human settlement of the Pacific. The findings may not hold true for other students, teachers, schools, topics, or themes. Yet they demonstrate some of the factors that it is important to consider when planning and evaluating thematic teaching, in particular by eliciting and giving voice to the experiences and preferences of students. This study examined thematic teaching with a much closer focus than most prior studies and has generated a number of findings which could have significant implications for teaching practice, course design, and educational policy if replicated in larger-scale studies. Thus perhaps the most important implications of this study are those that pertain to future research.

\subsubsection{Implications for teaching practice}

New Zealand mathematics teachers are under pressure to teach mathematics more contextually, with the New Zealand Curriculum (Ministry of Education, 2007) strongly encouraging a contextual approach and NCEA mathematics assessments including a high proportion of contextual word problems. This study highlights some factors that classroom teachers could consider when teaching mathematics thematically. The most basic of these is that not all students will find thematic teaching more engaging than non-thematic teaching. Even if the theme is chosen because of its apparent relevance to a given group of students, they may not find it as interesting as the teacher expects, as demonstrated in the current study by the low level of engagement with thematic teaching from Pasifika students. In particular, ELLs may find the greater linguistic demands of thematic teaching frustrating, and require support and scaffolding to decode the required mathematics. Some students seem to prefer the path of least resistance to acquiring the procedural skills they require to pass assessments, and may perceive the theme as a distraction from what they consider to be real mathematics learning. 
Teachers often plan their lessons under considerable time pressure and must prioritise which aspects of the lesson it is essential to plan effectively. The current study suggests that the clarity of the mathematical content is of paramount importance. Most students could be persuaded to work on learning tasks even if they found them boring, so long as they were able to cope with the mathematical demands of the task. On the other hand, students were very quick to give up on tasks that they did not understand mathematically, even if they found the context itself highly engaging. In short, an engaging context is not a substitute for clear explanations and mathematics which is at an appropriate level for the students.

\subsubsection{Implications for course design}

The current study provides no clear basis for a recommendation either for or against including thematic teaching explicitly in the design of Year 12 non-academic mathematics courses. However, thematic teaching appeared to have a positive effect on the engagement of some students, so it should be an option available to teachers. The preparation of the thematic resources used for the current study was very timeconsuming, so every effort should be made by course coordinators to share resources. As the revised Standards come into effect and resources are generated for use with a particular Unit Standard or Achievement Standard, these resources should be shared via school-wide and nationwide resource banks. The New Zealand Association of Maths Teachers (NZAMT) already has such a resource database on its website (NZAMT, 2011), and it would be mutually beneficial for course coordinators to use this forum to share and improve each other's thematic resources.

\subsubsection{Implications for policy and curriculum}

It is not possible on the basis of this study to make a recommendation in terms of whether thematic teaching of mathematics should be incorporated more explicitly into the mathematics learning area of the curriculum, or whether more resourcing should be devoted to the training of mathematics teachers in thematic teaching methods. Such a recommendation would need to emerge from a much larger sample size, a three-way comparison of abstract mathematical teaching, teaching with word problems but no long-term theme, and thematic teaching, and measurement of achievement data. From the policy perspective this study serves as a cautionary tale; 
the nationwide mandate that mathematics is to be taught "in a range of meaningful contexts" (Ministry of Education, 2007, no page number) should be accompanied by warnings of the pitfalls associated with contexts. Firstly, teachers need to be aware of the linguistic demands of contextual and thematic teaching, and provide students, especially ELLs, with appropriate support (Gibbons, 2002; Sfard \& Keiran, 2001). Secondly, it is not trivial to determine what kind of context will be meaningful to a particular group of students (Boaler, 1993; Gainsburg, 2008).

There is a large body of professional development material available for teachers of ELLs, for example the English language learning progressions (Ministry of Education, 2008) and the ESOL Online website (Ministry of Education, 2011). Heads of department should encourage mathematics teachers to participate in this professional development, as not all mathematics teachers are likely to perceive it as highly relevant to their mathematics teaching practice. The current study highlights the need for mathematics teachers to develop their awareness of the crucial role of language in learning mathematics (White, 2003).

\subsubsection{Implications for future research}

This study raised more questions than it answered, providing a point of departure for future research. Methodological improvements which would enable the same research questions to be addressed more rigorously have already been discussed (Section 5.2.2), so this section focuses on potential future studies which could address questions about thematic mathematics teaching on which this study did not focus.

Future studies could make finer distinctions between contextual interventions by facilitating a three-way comparison between abstract mathematics teaching, teaching mathematics with contextual word problems, and teaching mathematics with a sustained theme. Many existing teaching resources, including New Zealand's most commonly used textbooks, employ a combination of abstract teaching and word problems, but not extended themes. Although the current study evaluated a thematic intervention, it provides no basis for distinguishing between effects of sustained thematic teaching and the effects of contextual word problems in general, since the thematic intervention consisted of thematically linked word problems. There are 
theoretical grounds for suggesting that students will experience fully thematic teaching as more coherent and engaging than a series of contextually unrelated word problems (Manu'atu, 2009) but further research is required to test this suggestion empirically. Assuming that data collection methods used were similar to those of the current study, the primary methodological changes would be the implementation of separate thematic and word-problem teaching interventions, and further interview questions relating to students' experiences of each of these teaching styles. The findings of such a study would help teachers use their planning time efficiently; if there is little difference between thematic teaching and simply using contextual word problems then existing resources can be used rather than developing new thematic resources.

The current study somewhat artificially tests the effects of thematic teaching in isolation, with other aspects of teaching practice constant across the thematic and non-thematic teaching conditions. It appeared that thematic teaching has its pitfalls, particularly in relation to increased demands on students' language decoding skills and choosing themes that students experience as genuinely engaging. It is plausible that these barriers to learning could be ameliorated by adjusting other aspects of the teaching intervention. In particular, the language demands of thematic teaching might be less of a barrier to mathematics learning if appropriate steps were taken to make the language accessible, for example seating ELLs with confident English speakers and explicitly teaching problem solving strategies alongside mathematical processes (White, 2003). Culturally responsive teaching literature (e.g., Averill, et al., 2009; Gay, 2010) could inform the way teachers help students engage with certain contexts, for example by creating a forum for students to contribute their own contextual knowledge to their peers. This proposed research would go beyond analysing thematic teaching in isolation and evaluate a potentially complementary combination of teaching practices. Such a study would take significant time to prepare, as the intervention could be challenging for teachers to implement. Therefore it could be suited to an action research methodology (Patton, 2002) in which a practitioner-researcher documents the process of moving towards implementation of a thematic, culturally responsive and linguistically supportive teaching programme. 


\subsection{Summary}

During the current era of rapid change in New Zealand secondary mathematics education it is important to ensure that, as the education community, we are moving in a direction that will benefit our students. The New Zealand Curriculum (Ministry of Education, 2007) emphasises the importance of teaching mathematics in meaningful contexts, and thematic teaching attempts to make contexts meaningful by moving away from the often disjointed and unrelated contexts of word problems to the more coherent and sustained use of a single context over time. However, prior studies of thematic interventions have yielded conflicting results. Despite the large number of prior studies of thematic teaching, it is still unclear precisely what effects thematic teaching has on students' learning.

The current study aimed to examine the effects of thematic teaching in detail by analysing differences in students' responses to thematic teaching. The mathematical content was coordinate geometry and the theme chosen was the human settlement of the Pacific Islands. The engagement of thirty-two Year 12 students in two classes was measured using questionnaires and observations during four thematic and four non-thematic mathematics lessons. Twenty students were interviewed and given the opportunity to describe their experience of thematic teaching and give reasons for their preferred teaching style.

There was no statistically significant difference between the mean engagement of students with thematic and non-thematic teaching. However, this overall result masks a complex reality in which many individual students preferred either thematic or non-thematic teaching. ELLs and Pasifika students tended to prefer non-thematic teaching, whereas non-ELLs and Pakeha students tended to prefer thematic teaching, although there were a number of exceptions. There is some evidence that the students with the strongest preferences for thematic teaching were those with low motivation and poor productivity. Students who preferred thematic teaching said that it was more interesting, more fun, and gave more meaning to their learning, whereas nonthematic teaching was dry and meaningless. Students who preferred non-thematic teaching found that the theme obstructed rather than helped their learning, adding an element to the lesson that they perceived as irrelevant to their mathematics learning. 
Whist it appears that some students may benefit from thematic mathematics teaching, there are pitfalls that teachers, course designers and curriculum developers should be aware of. Students learning English as an additional language may struggle with the increased linguistic demands of thematic teaching and need extra support to successfully interpret thematic problems. Developing a meaningful, engaging theme is not a trivial task (Beswick, 2011), and teachers need to be willing to learn from their students about what is going to be most engaging. This study provided tentative support for the current curricular emphasis on contextual teaching, and suggests steps that can be taken to ensure that the widest possible range of students benefit from learning mathematics in context. 


\section{References}

Ajideh, P. (2003). Schema theory-based pre-reading tasks: A neglected essential in the ESL reading class. Reading Matrix, 3(1), 1-14.

Anderson, J., \& Schaffner, D. (2000). The sport of thought: a mathematics resource guide for the Olympic Games. Prime Number, 15(2), 4-12.

Anthony, G., \& Walshaw, M. (2007). Effective pedagogy in pangarau / mathematics: best evidence synthesis iteration (BES). Wellington: Ministry of Education.

Appleton, J. J., Christenson, S. L., Kim, D., \& Reschly, A. L. (2006). Measuring cognitive and psychological engagement: Validation of the Student Engagement Instrument. Journal of School Psychology, 44(5), 427-445.

Averill, R., Anderson, D., Easton, H., Maro, P. T., Smith, D., \& Hynds, A. (2009). Culturally Responsive Teaching of Mathematics: Three Models from Linked Studies. Journal for Research in Mathematics Education, 40(2), 157-186.

Beaton, M. J. (2004). Harry Potter as a context for problem-based learning. Science scope, 27(4), 15-17.

Beswick, K. (2011). Putting context in context: An examination of the evidence for the benefits of "contextualised" tasks. International Journal of Science and Mathematics Education, 9(2), 367-390.

Boaler, J. (1993). The role of contexts in the mathematics classroom: Do they make mathematics more "real"? For the Learning of Mathematics, 13(2), 12-17.

Cherryholmes, C. H. (1992). Notes on pragmatism and scientific realism. Educational Researcher, 21(6), 13-17.

Ching, G. S. (2009). Implications of an experimental information technology curriculum for elementary students. Computers and Education, 53(2), 419428.

Chronaki, A. (2000). Teaching mathematics through theme-based resources: Pedagogic style, 'theme' and 'maths' in lessons. Educational Studies in Mathematics, 42(2), 141-163.

Cohen, J. (1994). The earth is round $(p<.05)$ (Publication no. 10.1037/0003066x.49.12.997). American Psychologist, 49(12), 997-1003.

Creswell, J. W., \& Plano Clark, V. L. (2007). Designing and conducting mixed methods research. Thousand Oaks, California: Sage.

Ellis, M. V. (1999). Repeated measures designs. The Counseling Psychologist, 27(4), 552-578.

Feilzer, M. Y. (2010). Doing mixed methods research pragmatically: Implications for the rediscovery of pragmatism as a research paradigm. Journal of Mixed Methods Research, 4(1), 6-16.

Fredricks, J. A., Blumenfeld, P. C., \& Paris, A. H. (2004). School Engagement: Potential of the Concept, State of the Evidence. Review of Educational Research, 74(1), 59-109. 
Gainsburg, J. (2008). Real-world connections in secondary mathematics teaching. Journal of Mathematics Teacher Education, 11(3), 199-219.

Gay, G. (2010). Culturally Responsive Teaching (2nd ed.). New York: Teachers College Press.

Gibbons, P. (2002). Scaffolding language, scaffolding learning: Teaching second language learners in the mainstream classroom. Portsmouth, $\mathrm{NH}$ : Heinemann.

Gorard, S. (2006). Towards a judgement-based statistical analysis. British Journal of Sociology of Education, 27(1), 67 - 80.

Gorard, S. (2010). All evidence is equal: the flaw in statistical reasoning. Oxford Review of Education, 36(1), 63 - 77.

Handal, B., \& Bobis, J. (2004). Teaching mathematics thematically: teachers' perspectives. Mathematics education research journal, 16(1), 3-18.

Helme, S., \& Clarke, D. (2001). Identifying cognitive engagement in the mathematics classroom. Mathematics Education Research Journal, 13(2), 133-157.

Henderson, R. W., \& Landesman, E. M. (1992). Mathematics and Middle School students of Mexican descent: The effects of thematically intergrated instruction. Santa Cruz: UC Berkeley: Center for Research on Education, Diversity and Excellence.

Howe, K. R. (Ed.). (2006). Vaka Moana: Voyages of the ancestors: The discovery and settlement of the Pacific. Auckland: David Bateman.

Howell, D. C. (2008). Fundamental statistics for the behavioral sciences (6th ed.). Belmont, CA: Thomson Wadsworth.

Howell, D. C. (2010). Statistical methods for psychology (7th ed.). Belmont, CA: Thomson Wadsworth.

Jimerson, S. R., Campos, E., \& Greif, J. L. (2003). Towards an understanding of definitions and measures of school engagement and related terms. The California School Psychologist, 8, 7-27.

Johnson, B., \& Christensen, L. (2008). Educational research: quantitative, qualitiative and mixed approaches (3rd ed.). Los Angeles: Sage Publications.

Kirk, R. E. (1996). Practical significance: A concept whose time has come. Educational and Psychological Measurement, 56(5), 746-759.

Kong, Q. P., Wong, N. Y., \& Lam, C. C. (2003). Student engagement in mathematics : development of instrument and validation of construct. Mathematics education research journal, 15(1), 4-21.

Labaree, R. V. (2002). The risk of 'going observationalist': Negotiating the hidden dilemmas of being an insider participant observer. Qualitative Research, 2(1), 97-122. 
Lam, T. T. (2007). Contextual Approach in Teaching Mathematics: An Example Using the Sum of Series of Positive Integers. International Journal of Mathematical Education in Science and Technology, 38(2), 273-282.

Leonard, J. (2004). Integrating mathematics, social studies, and language arts with "A tale of two cities". Middle School Journal, 35(3), 35-40.

Lipson, M. Y., Valencia, S. W., Wixson, K. K., \& Peters, C. W. (1993). Integration and thematic teaching: Integration to improve teaching and learning. Language arts, 70(4), 252-263.

Loughran, S. B. (2005). Thematic Teaching in Action. Kappa Delta Pi Record, 4l(3), 112-117.

Manu'atu, L. (2009). Pacific processes and pedagogies. In K. Sanga \& K. H. Thaman (Eds.), Re-thinking educational curricula in the Pacific: Challenges and prospects (pp. 172-182). Wellington: He Parekereke, Institute for Research and Development in Maori and Pacific Education, Victoria University of Wellington.

Marr, B. (1998). Making connections : listening to the voices of adult numeracy students. Fine Print, 21(3), 12-15.

Martin, A. J., \& Marsh, H. W. (2006). Academic resilience and its psychological and educational correlates: A construct validity approach. Psychology in the Schools, 43(3), 267-281.

McCarthy, C. B. (2005). Effects of thematic-based, hands-on science teaching versus a textbook approach for students with disabilities. Journal of Research in Science Teaching, 42(3), 245-263.

Ministry of Education (2007). The New Zealand curriculum. Wellington: Learning Media Limited.

Ministry of Education (2008). The English language learning progressions: A resource for mainstream and ESOL teachers. Wellington: Learning Media Limited.

Ministry of Education (2011). ESOL Online Website. Retrieved 11 April, 2011, from http://esolonline.tki.org.nz/.

Mulcahy, C. A., \& Krezmien, M. P. (2009). Effects of a Contextualized Instructional Package on the Mathematics Performance of Secondary Students with EBD. Behavioral Disorders, 34(3), 136-150.

Nabobo-Baba, U. (2006). Knowing and learning : An indigenous Fijian approach. Suva: Institute of Pacific Studies.

Nicol, C., \& Crespo, S. (2005). Exploring mathematics in imaginative places: Rethinking what counts as meaningful contexts for learning mathematics. School Science and Mathematics, 105(5), 240-251.

Noddings, N. (2003). Happiness and education. New York: Cambridge University Press.

NZAMT. (2011). New Zealand Association of Maths Teachers. Retrieved 4th January, 2011, from http://nzamt.org.nz. 
NZQA. (2009). Standards review guidelines for subject associations. Retrieved 22 February, 2010, from http://www.nzqa.govt.nz/ncea/for-schools/curric-stdsreview/docs/stds-review-guidelines.pdf

NZQA. (2010a). Qualifications: NCEA Standards. Retrieved 23 September, 2010, from http://www.nzqa.govt.nz/qualifications-standards/qualifications/ncea/ understanding-ncea/how-ncea-works/standards/

NZQA. (2010b). Unit standard 5245: Solve coordinate geometry problems. Retrieved 10 April, 2011, from http://www.nzqa.govt.nz/ nqfdocs/units/pdf/5245.pdf.

Olicker, C. L. (2005). A comparison of content-based and context-based teaching on ninth-grade mathematics achievement Florida International University, Miami, Florida.

Patton, M. Q. (2002). Qualitative research and evaluation methods (3rd. ed.). Thousand Oaks, CA: Sage Pulications.

Perry, B., \& Howard, P. (2008). Mathematics in indigenous contexts. Australian Primary Mathematics Classroom, 13(4), 4-9.

Ross, S. M., McCormick, D., \& Krisak, N. (1986). Adapting the Thematic Context of Mathematical Problems to Student Interests: Individualized versus GroupBased Strategies. Journal of Educational Research, 79(4), 245-252.

Roth, W.-M. (1996). Where is the Context in Contextual Word Problems?: Mathematical Practices and Products in Grade 8 Students' Answers to Story Problems. Cognition and Instruction, 14(4), 487-527.

Ruthven, K. (2011). Using international study series and meta-analytic research syntheses to scope pedagogic development aimed at improving student attitude and achievement in school mathematics and science. International Journal of Science and Mathematics Education, 9(2), 419-458.

Saenz, C. (2009). The Role of Contextual, Conceptual and Procedural Knowledge in Activating Mathematical Competencies (PISA). Educational Studies in Mathematics, 71(2), 123-143.

Scott, D., \& Usher, R. (1999). Researching education: Data, methods and theory in educational enquiry. London: Continuum.

Sfard, A., \& Keiran, C. (2001). Cognition as communication: Rethinking learningby-talking through multi-faceted analysis of students' mathematical interactions. Mind, Culture, and Activity, 8(1), 42-76.

Siber, L. (2004). Further units in maths (1 ed.). North Shore, Auckland: Pearson Education.

Singh, N. N., Lancioni, G. E., Winton, A. S. W., Molina, E. J., Sage, M., Brown, S., et al. (2004). Effects of Snoezelen room, Activities of Daily Living skills training, and Vocational skills training on aggression and self-injury by adults with mental retardation and mental illness. Research in Developmental Disabilities, 25(3), 285-293. 
Sullivan, P., Mornane, A., Prain, V., Campbell, C., Drane, S., Faulkner, M., et al. (2009). Junior secondary students' perceptions of influences on their engagement with schooling. Australian Journal of Education, 53(2), 176-191.

Symonds, R., Lawson, D., \& Robinson, C. (2008). Promoting student engagement with mathematics support. Teaching Mathematics and its Applications, 27(3), 140-149.

Taylor, L. (1999). An integrated learning system and its effect on examination performance in mathematics. Computers and Education, 32(2), 95-107.

White, D. Y. (2003). Promoting productive mathematical classroom discourse with diverse students. Journal of Mathematical Behaviour, 22, 37-53.

Wilson, S. (2009). The CRIMSPL : the Context Rich Integrated Maths and Science Professional Learning Project. Paper presented at the AARE 2009 International education research conference. Retrieved 3 October, 2010, from http://www.aare.edu.au/09pap/wil091573.pdf

Yair, G. (2000). Educational battlefields in America: The tug-of-war over students' engagement with instruction. Sociology of Education, 73(4), 247-269

Yeap, B. H., \& Melati, A. G. (2001). Facilitating sense-making in primary mathematics through word problems. Paper presented at the Australian Association of Reaseach in Education (AARE) Conference. Retrieved 3 October, 2010, from http://www.aare.edu.au/01pap/yea01420.htm 


\section{Appendices}

\section{Appendix A. Reports of the implementation of thematic teaching}

\begin{tabular}{|l|l|l|}
\hline Study & Location & Summary \\
\hline (Chronaki, 2000) & England & Discussion of two teachers' ways of interpreting context in mathematics. \\
\hline $\begin{array}{l}\text { (Beaton, 2004) } \\
\text { (Handal \& Bobis, }\end{array}$ & Canada & Amaginative science programme based on Harry Potter described, no formal measurement of outcomes. \\
\hline $\begin{array}{l}\text { (Lipson, et al., } \\
\text { 1993) }\end{array}$ & USA & Discusses barriers to implementation of thematic teaching, based on interviews with 10 teachers. \\
\hline $\begin{array}{l}\text { (Anderson \& } \\
\text { Schaffner, 2000) }\end{array}$ & Australia & $\begin{array}{l}\text { Discusses and gives examples of activities based on the Olympic games. Activity exemplar, not a report of } \\
\text { implementation or effects. }\end{array}$ \\
\hline
\end{tabular}




\begin{tabular}{|l|l|l|}
\hline (Lam, 2007) & Singapore & $\begin{array}{l}\text { Students in a pre-university mathematics programme in Singapore were able to recall and use various } \\
\text { mathematical techniques from secondary mathematics and to apply these techniques in a contextual approach as } \\
\text { opposed to the traditional topic sequential approach. A preliminary study. }\end{array}$ \\
\hline (Loughran, 2005) & USA & $\begin{array}{l}\text { Early primary age students turned their classroom into a French restaurant in a thematic topic that incorporated a } \\
\text { wide range of learning areas including mathematics, writing, nutrition, music and French language. }\end{array}$ \\
\hline
\end{tabular}




\section{Appendix B. Studies of the effects of thematic teaching}

\begin{tabular}{|c|c|c|c|c|}
\hline Study & Location & Participant school year & Thematic intervention & Observed effects of intervention \\
\hline (Ching, 2009) & Taiwan & Year 2-7 & $\begin{array}{l}\text { Some IT-based thematic lessons in mathematics } \\
\text { over a } 1 \text {-year period }\end{array}$ & $\begin{array}{l}\text { Small improvement in achievement for Year } 3,6 \text { and } \\
7 \text {, small decrease in achievement for Years } 2 \text { and } 4 \text {, } \\
\text { no difference for Year } 5 \text {. }\end{array}$ \\
\hline $\begin{array}{l}\text { (Henderson \& } \\
\text { Landesman, } \\
\text { 1992) }\end{array}$ & USA & $\begin{array}{l}\text { Middle schools students } \\
\text { of Mexican descent, at } \\
\text { risk of school failure }\end{array}$ & $\begin{array}{l}\text { "small collaborative learning groups and } \\
\text { hands-on activities designed to help } \\
\text { students make real-world sense of } \\
\text { mathematical concepts" (p. 1) }\end{array}$ & $\begin{array}{l}\text { Improvement in: achievement on mathematical } \\
\text { concepts and applications. No effect on students' } \\
\text { attitudes towards mathematics or self- } \\
\text { perceptions of motivation in mathematics }\end{array}$ \\
\hline (Leonard, 2004) & USA & Year $7\left(6^{\text {th }}\right.$ grade $)$ & $\begin{array}{l}\text { Integrated learning of mathematics, } \\
\text { language arts and social studies with } \\
\text { architecture theme }\end{array}$ & $\begin{array}{l}\text { Improved motivation, time on task and attitude } \\
\text { towards mathematics }\end{array}$ \\
\hline $\begin{array}{l}\text { (McCarthy, } \\
\text { 2005) }\end{array}$ & USA & $\begin{array}{l}\text { Middle school students } \\
\text { with "serious emotional }\end{array}$ & $\begin{array}{l}\text { Thematic-based hands-on approach for } \\
\text { "matter" }\end{array}$ & $\begin{array}{l}\text { Improved practical and short-answer test results } \\
\text { but no improvement in multi-choice or }\end{array}$ \\
\hline
\end{tabular}




\begin{tabular}{|c|c|c|c|c|}
\hline & & disturbances" (p. 245) & & behaviour. \\
\hline (Olicker, 2005) & USA & $\begin{array}{l}\text { Year } 10\left(9^{\text {th }} \text { grade }\right) \text { at-risk } \\
\text { students }\end{array}$ & $\begin{array}{l}\text { Thematically-structured (business } \\
\text { education) algebra. }\end{array}$ & No improvement in academic performance. \\
\hline (Taylor, 1999) & UK & Yr 7-8 & $\begin{array}{l}\text { Thematic computer-based tool "Learning } \\
\text { Expedition" over one year. }\end{array}$ & $\begin{array}{l}\text { Positive* correlation between use of tool and } \\
\text { end-of-year achievement }\end{array}$ \\
\hline Wilson (2009) & Australia & Primary and secondary & $\begin{array}{l}\text { Integrated (maths/science), student-centred } \\
\text { activities using "Meaningful and } \\
\text { worthwhile" contexts (p. 3) }\end{array}$ & $\begin{array}{l}\text { "Teachers reported higher student engagement, } \\
\text { enthusiasm and confidence when approaching } \\
\text { maths" (p. 6). }\end{array}$ \\
\hline $\begin{array}{l}\text { (Perry \& } \\
\text { Howard, 2008) }\end{array}$ & $\begin{array}{l}\text { Rural } \\
\text { Western } \\
\text { NSW }\end{array}$ & $\begin{array}{l}\text { Primary and secondary, } \\
\text { high } \\
\text { Aboriginal }\end{array}$ & $\begin{array}{l}\text { Field trip connecting maths to a site of } \\
\text { historical and cultural significance }\end{array}$ & $\begin{array}{l}\text { Participants reported increased engagement of all } \\
\text { students. }\end{array}$ \\
\hline $\begin{array}{l}\text { (Yeap \& Melati, } \\
\text { 2001) }\end{array}$ & Singapore & Year 3 & $\begin{array}{l}\text { lessons on sense-making from word } \\
\text { problems that require contextual } \\
\text { considerations once in three weeks for six }\end{array}$ & $\begin{array}{l}\text { Improved success in non-standard word } \\
\text { problems (that require sense-making), but only } \\
\text { for problems that were very similar to those used }\end{array}$ \\
\hline
\end{tabular}




\begin{tabular}{|l|l|l|l|l|}
\hline & & months & in the study. \\
\hline (Marr, 1998) & Australia & Adult & $\begin{array}{l}\text { Observations and interviews in adult } \\
\text { numeracy classes involving word problems }\end{array}$ & $\begin{array}{l}\text { Contexts can be helpful, but can also be } \\
\text { problematic because they are irrelevant, } \\
\text { confusing etc. }\end{array}$ \\
\hline
\end{tabular}


Appendix C. Engagement questionnaire ${ }^{16}$

:

Faculty of Education

Mathematics in Context: Student Questionnaire

Please circle the response that best describes how you participated in today's lesson.

1) I made an effort to concentrate on learning today.

$\begin{array}{lcccc}1 & 2 & 3 & 4 & 5 \\ \text { Strongly } & \text { Disagree } & \text { Neutral } & \text { Agree } & \text { Strongly } \\ \text { disagree } & & & & \text { agree }\end{array}$

2) I thought about how the maths I learnt today relates to real life.

$\begin{array}{lllll}1 & 3 & 4 & 5\end{array}$

Strongly Disagree Neutral Agree Strongly

disagree agree

3) The maths I learnt today made sense to me.

$\begin{array}{lcccc}1 & 2 & 3 & 4 & 5 \\ \text { Strongly } & \text { Disagree } & \text { Neutral } & \text { Agree } & \text { Strongly } \\ \text { disagree } & & & & \text { agree }\end{array}$

4) I found the lesson interesting today.

$\begin{array}{lcccc}1 & 2 & 3 & 4 & 5 \\ \text { Strongly } & \text { Disagree } & \text { Neutral } & \text { Agree } & \text { Strongly } \\ \text { disagree } & & & & \text { agree }\end{array}$

${ }^{16}$ The questionnaire used in the study fitted onto one side of A4 with narrow margins. 
5) I enjoyed learning maths today.

$\begin{array}{lcccc}1 & 2 & 3 & 4 & 5 \\ \text { Strongly } & \text { Disagree } & \text { Neutral } & \text { Agree } & \text { Strongly } \\ \text { disagree } & & & & \text { agree }\end{array}$

6) I paid attention to the teacher today.

$\begin{array}{lcccc}1 & 2 & 3 & 4 & 5 \\ \text { Strongly } & \text { Disagree } & \text { Neutral } & \text { Agree } & \text { Strongly } \\ \text { disagree } & & & & \text { agree }\end{array}$

7) I completed a good amount of work today.

$\begin{array}{lcccc}1 & 2 & 3 & 4 & 5 \\ \text { Strongly } & \text { Disagree } & \text { Neutral } & \text { Agree } & \text { Strongly } \\ \text { disagree } & & & & \text { agree }\end{array}$

Initials:

Thanks :-) 


\section{Appendix D. Observation schedule Version 2}

The categories in Version 2 (final version) of the observation schedule were:

\section{Positive Indicators:}

1. Looking at teacher

2. Looking at whiteboard

3. Taking notes

4. Self-monitoring (e.g. checking answers)

5. Working quietly in workbook

6. Asking questions

7. Answering questions

8. On-task conversation with peer(s)

9. On-task conversation with teachers

10. Gestures of concentration

11. Expression of enjoyment of learning

\section{Negative indicators}

12. Doing nothing

13. Staring into pace / out the window

14. Off-task action (non-disruptive)

15. Off-task action (disruptive)

16. Off-task talking

17. Gestures of boredom

18. Avoiding work

19. Off-task use of technology (e.g. texting, gaming)

20. Ignoring learning-related request

For observation timing and other details see Section 3.3.2. 


\section{Appendix E. Interview questions}

1. Greet student and thank them for their time.

2. How interesting do you normally find maths?

3. How hard to you work in maths?

4. How easy or difficult a subject is maths for you?

5. How much do you find maths connects to the real world?

6. You might have noticed [your teacher] doing something a little different over the last week. If you have, could you describe what you think the teacher is doing that's different from usual?

7. Ok, you've described what was different. What do you think of that way of teaching? Why?

8. What are the advantages and disadvantages of that way of teaching?

9. Could you please explain what effect this type of teaching had on how much you concentrated?

10. If a teacher had decided to teach this way, is there anything you can think of that would make it work even better?

11. Overall, which style of teaching do you think you prefer?

For guidelines on interview style and tone, see Section 3.3.3. 


\section{Appendix F. Sample thematic worksheet}

\section{Complete the following exercise on a $10 \times 10$ grid.}

1. Mark the stars of the Southern Cross at coordinates $(-4,9),(-5,7),(-2,6)$ and $(-2,9)$.

2. Mark the two Pointers at $(-7,1)$ and $(-9,-3)$.

3. Find the coordinates of the midpoint between the Pointers.

4. Find the distance between the Pointers.

5. Find the gradient of the line that joins the Pointers.

6. Find the gradient of the line that is perpendicular (at right angles) to the line that joins the pointers. Hint: to find the gradient of a perpendicular line, use the formula: perpendicular gradient $=\frac{-1}{\text { original gradient }}$

7. Find the equation of the line that goes through the midpoint between the pointers, and is perpendicular to the line that connects the Pointers.

8. Find the equation of the line that goes through the long axis of the Southern Cross (see the diagram below. This question has several steps.

9. Use the equations from questions 7 and 8 to find the coordinates of the intersection point of these two lines.

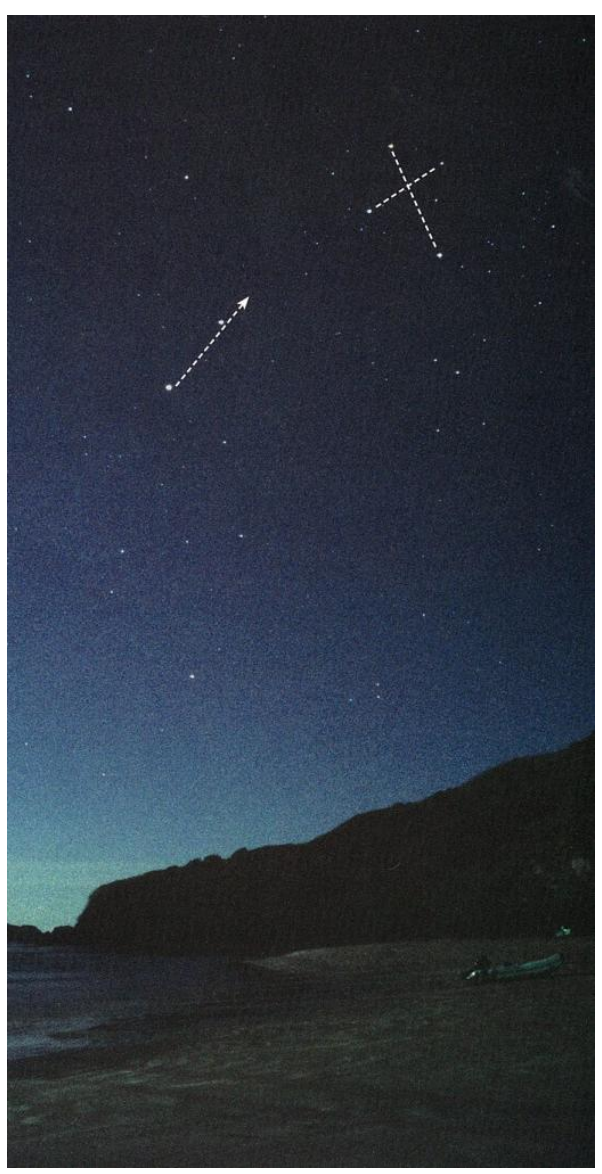

10. Rule the two lines onto the grid to check your answer to Question 9.

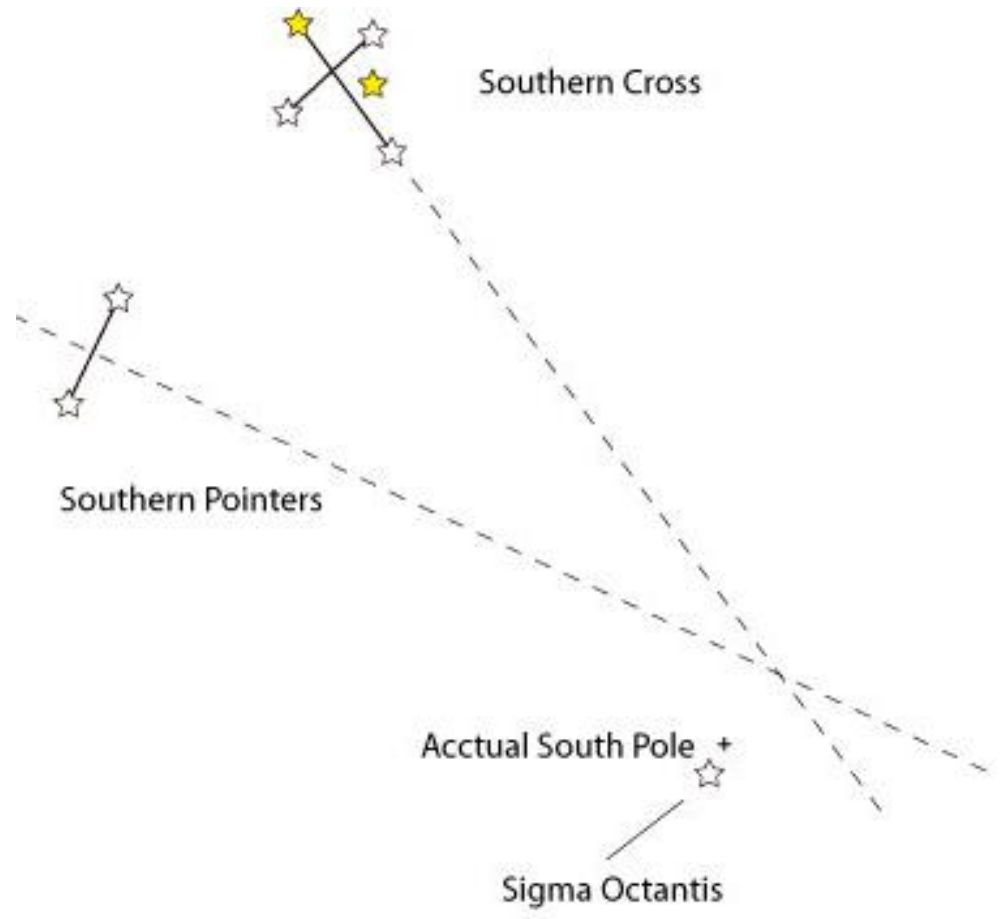


From different places in the Pacific the stars have different coordinates, and the lines have different equations. Find the intersection points of these pairs of lines.
11. $y=2 x-7$ and $y=-x+8$
12. $y=0.5 x+8$ and $y=-3 x-6$
13. $y=6$ and $y=3 x$
14. $y=0.25 x-5 y=-1.5 x-1.5$
15. Extension: Exercise 18.07 (p. 221) and Exercise 18.08 (p. 222) from Theta Mathematics.

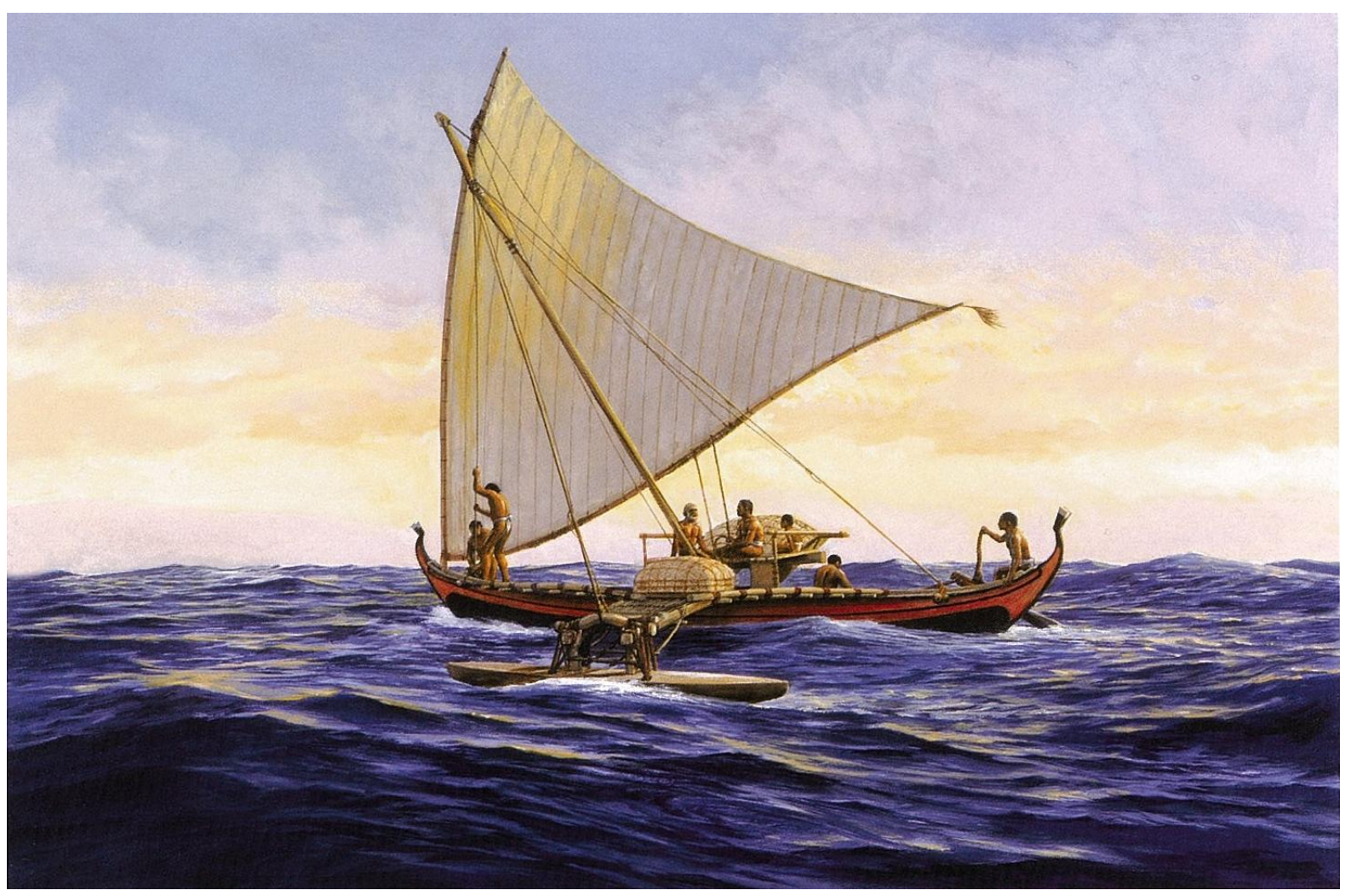

A Caroline Islands sailing vaka. Painting by Herb Kane, published in Vaka Moana (Howe, 2006). 


\section{Appendix G.Thematic worksheet for Lesson 1}

Starter

1. This grid contains a map of some of the Southern Cook Islands.

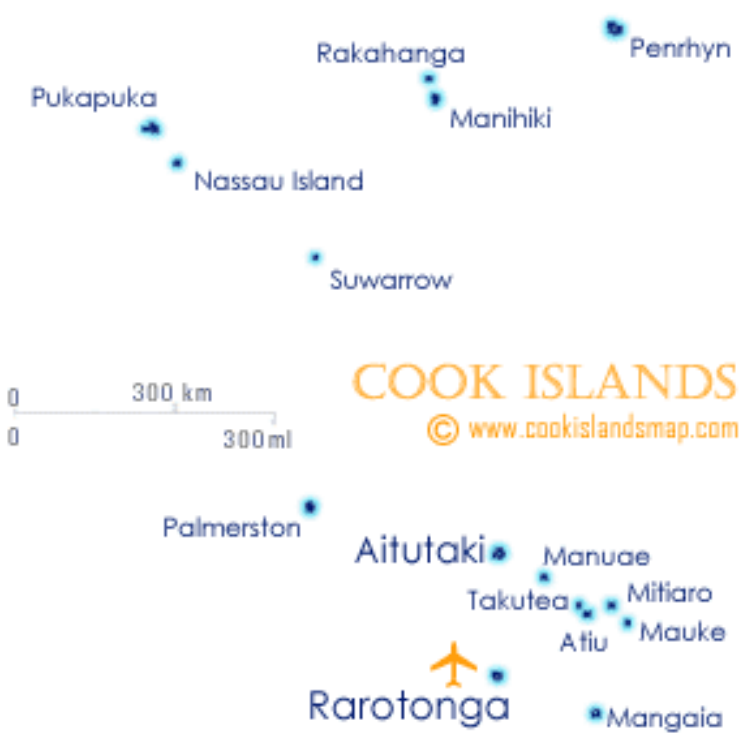

1. Which Island has the coordinates:
a) $\quad(3,-0.5)$
b) $\quad(-5,-4)$

2. Write the coordinates of:
a) Mitiaro
b) Aitataki

3. These three islands in the Northern Cooks form a right angle. Find the distance from Pukapuka to Rakahanga (nearest $10 \mathrm{~km}$ ). 


\section{Human settlement of the Pacific: How long was the journey?}

There are lots of clues people have used to work out where the people of the Pacific Ocean originally came from. Oral histories, language similarities and differences, cultivated plants and DNA analysis are some of the tools that help put together the picture. This map shows a likely pattern of human settlement of the Pacific ${ }^{17}$.

Your task is to use the formula for the distance between two points (on your formula sheet) to find the distance of the voyages shown by arrows on the map. You will need to estimate the coordinates of each island group from the grid.

Each unit in the grid over the map is about $325 \mathrm{~km}$ (it is not exact because the Earth is not flat!)

1) In your workbooks, find the following distances. Round your answers sensibly.

a) Palau $(-13.2,6.5)$ to the Mariana Islands $(-10,9)$

b) Solomon Islands to Vanuatu

c) Santa Cruz Islands to Kiribati

d) Kiribati to Marshall Islands

e) Vanuatu to New Caledonia

f) Vanuatu to Fiji

g) Fiji to Tonga

h) Tonga to Society Islands

i) Society Islands to Marquesas Islands

j) Marquesas Islands to Hawai'i

k) Society Islands to Pitcairn Island

1) Pitcairn Island to Easter Island

m) Society Islands to New Zealand

2) In good conditions, some of the vaka (canoes) travelled about $200 \mathrm{~km}$ per day. How long would the above voyages have taken?

3) What challenges do you think people would have had on these voyages?

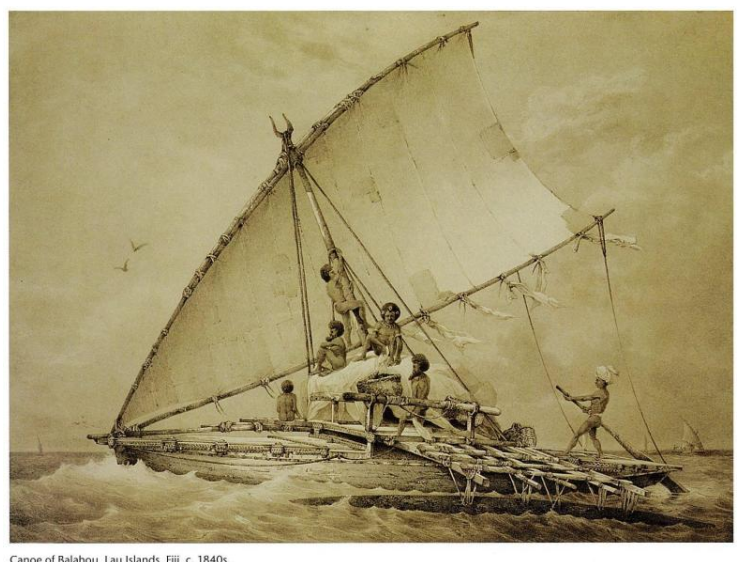

\footnotetext{
${ }^{17}$ From the book Vaka Moana: Voyages of the ancestors: The discovery and settlement of the Pacific (Published in 2006). Edited by K. R. Howe.
} 
LIKELY PATTERN OF EARLY HUMAN SETTLEMENT IN THE PACIFIC THE LAPITA DISPERSAL FROM THE BISMARCK ARCHIPELAGO TO WEST POLYNESIA IS QUITE CLOSELY DATED TO THE PERIOD 3400 BP TO 2900 BP. HOWEVER, THE CHRONOLOGY OF POLYNESIAN SETTLEMENT REMAINS UNCERTAIN AND CONTENTIOUS.

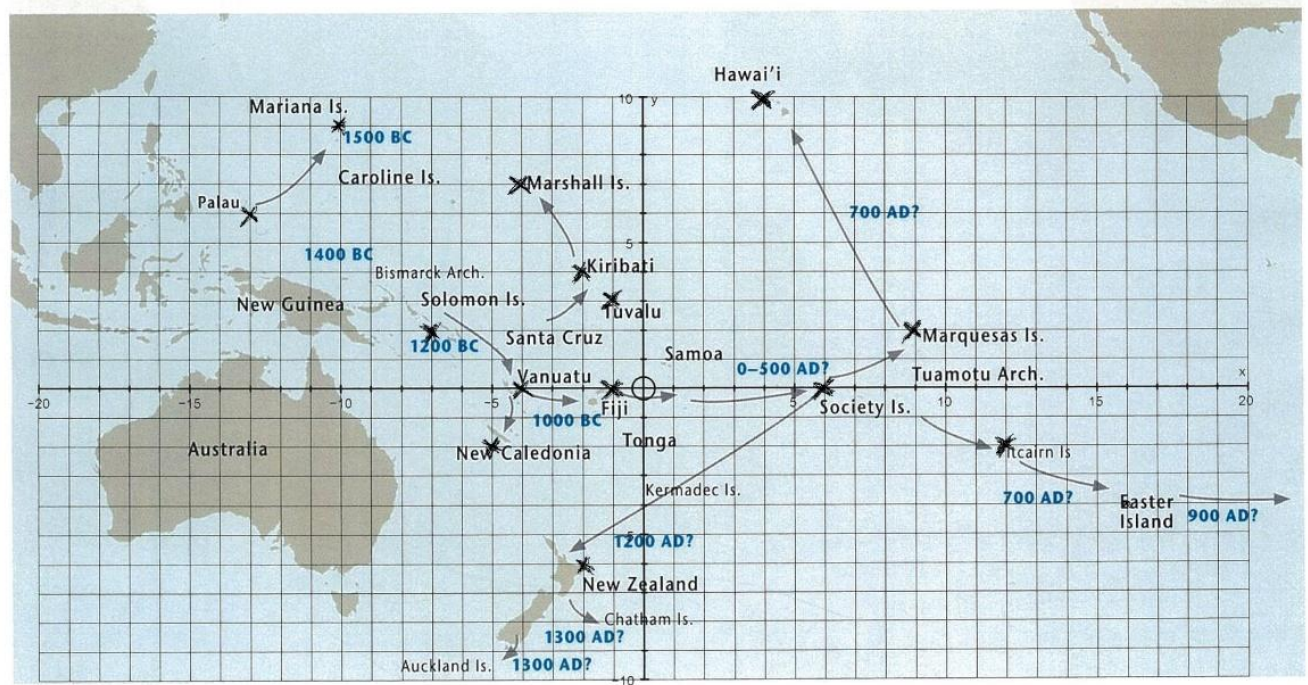




\section{Appendix H. Student information letter ${ }^{18}$}

\section{Student Information for Mathematics in Context Study}

$\mathrm{Hi}$, I'm David Pomeroy, a Masters student studying Education at Victoria University. As part of my study I'm doing some research which looks at the way real-world contexts are used in senior maths classes, and how this affects student engagement. Your teacher has agreed to help out with this research. The University requires all research to get ethical approval, and my project has been approved by Faculty of Education Ethics Committee. The findings of this research could be useful for teachers wanting to know about how to make their lessons as relevant and interesting as possible.

If you agree to participate in this research, then I will:

- Observe and make written notes on eight lessons in Term 3;

- Ask you to complete a short questionnaire near the end of each of those lessons, and put your initials on it;

- Keep any information that could be linked to you as an individual strictly confidential.

- Keep the data on a password-protected computer and delete it within 5 years.

Also, I might:

- Ask you to participate in a one-to-one interview at interval or lunchtime (about 15 minutes), which I will record (audio, not video);

- Ask to photograph some of your written work.

I will NOT:

- Publish or release your name, your teacher's name, or the name of your school;

- Take any videos of photos of you;

- Interrupt your teacher's plan for what content to cover;

- Show your teacher any information that could be linked to you personally.

\footnotetext{
${ }^{18}$ In the interests of space, only the student information letter is included here. Separate parent, teacher, and Principal information letters were also produced.
} 
Taking part is voluntary; you don't have to participate. If you don't want to participate, you can come to class as usual but you won't fill out any questionnaires or do any interviews, and I'll ignore you in my observations. If you do participate, you can pull out at any time before the end of data collection, and don't have to give a reason why.

The results of this research will be published in my Masters Thesis and might be published in journals or presented at conferences. The findings from this research could help teachers plan more interesting maths lessons. You can get a free summary if you'd like one, just tick the box on the consent form.

If you've got any questions you can call me on 463xxxx extension $x x x x$ or email xxxx@vuw.ac.nz. My supervisor is Dr Robin Averill and her email is xxxx@vuw.ac.nz.

See you again soon,

David 


\section{Appendix I. Student consent form ${ }^{19}$}

Consent to Participate in Research-Student Form

Please tick the boxes that apply to you, if you agree. Hand the completed form in to your teacher.

\section{Mathematics in Context Study (researcher: David Pomeroy)}

I have read the Information Sheet, and understand what is involved in this study

I agree to fill out and initial a short questionnaire each lesson for eight lessons

I agree for the researcher to observe my behaviour during class time

I agree to participate in an interview outside of class time, if I am selected to do so

I consent for any data collected to be published

I understand that any information that could be used to identify me, my teacher or my school will be kept confidential to the researcher, his supervisor and the person who transcribes the interview recordings

I understand that participating is optional, and I can pull out at any time before data collection is finished without having to give a reason

I would like a summary of the results of this research when it is finished (optional)

If you have ticked the last box, please provide a postal or email address. It will only be used to send you a summary of the results, and then deleted. Postal or email address:

Signed:

Date:

Name of participant:

(Please print clearly)

\footnotetext{
${ }^{19}$ In the interests of space, only the student consent form is included here. Separate parent, teacher, and Principal consent forms were also produced.
} 


\section{Appendix J. Validation of self-report questionnaire}

The self-report questionnaire (Appendix C) was developed at Parkville College, with students who were not part of the experimental phase of the study. This maximised the similarity between the pilot and experimental conditions, as suggested by Johnson and Christensen (2008), without exposing the participant students to the questionnaire prior to the study. The pilot phase took place on three days over the period of one week. The aim of this phase was to ensure that the questionnaire was:

- $\quad$ short (less than two minutes to complete),

- internally consistent,

- easy to understand, and

- elicited responses that genuinely reflected students' procedural engagement (Johnson \& Christensen, 2008).

The validation process used a mixed methods approach, employing statistical analysis of response patterns to 200 questionnaires, qualitative feedback from students, and classroom observations.

\section{Length}

It was clear from classroom observations that most students took between 15 and 60 seconds to complete the questionnaire. This timeframe comfortably satisfied the brevity criterion.

\section{Internal consistency}

The internal consistency of the scale was analysed by calculating Cronbach's alpha ${ }^{20}$ (Johnson \& Christensen, 2008). Version 1 of the questionnaire had a coefficient alpha of 0.84 for a sample of 20 Year 12 students, which suggests that the items in the questionnaire received sufficiently similar responses to be considered internally

\footnotetext{
${ }^{20}$ Cronbach's alpha provides a quantitative estimate of the extent to which a scale is internally consistent. The value of coefficient alpha has theoretical limits of zero and one, one indicating perfect congruity between responses to different questions. A value over 0.7 is considered good reliability for research purposes (Johnson \& Christensen, 2008).
} 
consistent. Although this result was encouraging, 20 is a small sample size for calculating coefficient alpha, and the figure was interpreted cautiously.

An item-by-item analysis showed that removing Item 4, I enjoyed the lesson, would have increased alpha, making the scale more reliable, but that removing any of the other items would have reduced the coefficient alpha, making the scale less reliable. In a questionnaire which would have contributed to this result, one student strongly agreed with Item 4, I enjoyed the lesson, but strongly disagreed with Item 3, I found the lesson interesting. Both of these items were designed to assess emotional engagement, but received very different responses. One student wrote on the questionnaire beside Item 4: Its [sic] work. You're not meant to enjoy it. Item 4 had a low correlation of 0.31 with other items in the questionnaire. All of the other items had correlations in the range of 0.59 to 0.79 . One response to this would simply be to remove Item 4 from the questionnaire. However, enjoyment of learning is a key component of emotional engagement (Helme \& Clarke, 2001). Instead, the wording was changed from I enjoyed the lesson to I enjoyed learning maths (Version 2). Version 3 was a parallel revision of Version 1 and included I enjoyed the lesson and $I$ enjoyed learning maths, to see whether this change in wording would have an effect on student responses.

During the following pilot session, I trialed Version 2 of the questionnaire with a Year 12 Mathematics class of thirteen students. The coefficient alpha was 0.65 , much lower than the value of 0.84 from the previous trial of Version 1 , and is not indicative of a reliable instrument (Johnson \& Christensen, 2008). I also trialed Version 3 of the questionnaire with 26 students from Mr Daniels' Year 10 class. The coefficient alpha was 0.63 , which again did not suggest that the scale was reliable. The inter-item correlation between the items I enjoyed the lesson and I enjoyed learning maths was 0.31 suggesting that students perceived these statements to be only weakly related in meaning.

During the third and final iteration of the pilot phase Version 4 of the questionnaire was completed by 85 students. Version 4 did not contain the problematic item I enjoyed the lesson and contained a new item I thought about which ideas were most important to understand in today's lesson. Cronbach's alpha for this sample of 
students was 0.88 , indicating an excellent level of internal consistency between the items. An item-by-item analysis showed that the statement I thought about how the maths I learned today relates to real life had a lower squared item-total correlation than the other items (0.30, compared to a range of 0.44 to 0.64 for the other items) indicating that this item was sometimes the "odd one out" in students' responses.

\section{Clarity}

It is a principle of good quantitative questionnaire items is that they are easy to understand and unambiguous in their meaning (Johnson \& Christensen, 2008). This was particularly crucial in the current study as many participants had weak reading comprehension skills. Of the 47 students, 9 qualified for reader/writer assistance in assessments and another 10 were classified by the school as ELLs. Thus part of the purpose of the pilot process was to check student understanding, and remove or reword confusing or ambiguous items.

During the pilot phase students were asked to complete the questionnaire, and then to note any questions that were confusing or unclear. The "think-aloud technique" of questionnaire piloting (Johnson \& Christensen, 2008, p. 189) was used to check whether students were interpreting the questionnaire as intended. Students were given the questionnaire one at a time and asked them to explain what they were thinking as they filled it out, including reasons for their responses and what they thought the questions meant. Analysis of audio records of the think-alouds and students' written comments on the questionnaires indicated that the item I thought about which ideas were most important to understand in today's lesson was confusing and not consistently understood, so this item was removed from the final version. All other items were clear and unambiguous.

\section{Fitness for purpose}

Finally, the questionnaire items needed to be a valid measure of procedural engagement. The students' responses needed to reflect their perceptions of thoughts, emotions, and behaviours that correspond to various aspects of procedural engagement. This aspect of the pilot involved analysing qualitative data as students explained their thought processes whilst completing the questionnaire. During the think-alouds students were asked to rephrase the statements and to explain why they 
chose the responses they did. Their responses reflected cognitive, emotional, and behavioural dimensions of engagement as intended, with the exception of the previously mentioned item which was removed from the final version of the questionnaire. Responses to the item I thought about how the maths I learned today relates to real life were highly congruent with the procedural component of cognitive engagement (Fredricks, et al., 2004) so it was retained because it was a substantively relevant item, despite its relatively low item total correlation. 


\section{Appendix K. Observation schedule Version 1}

Helme and Clark's (2001) list behaviours that they claim are observable signs of cognitive engagement:

1. Verbalising thinking

2. Self-monitoring

3. Asking questions

4. Completing utterances

5. Answering questions

6. Explaining reasoning

7. Resisting distractions

8. Gestures

9. Talking off-task (negative indicator)

10. Gestures of boredom (negative indicator)

11. Off-task behaviours (negative indicator)

These categories will vary in terms of their relevance in different stages of the lesson. In phases of the lesson (typically near the beginning of the lesson) when the teacher is addressing the whole class, note gestures (e.g., students who are looking at the teacher and appear to be listening), asking questions that demonstrate that students have been processing what the teacher is saying or writing, resisting distractions like other students trying to talk to them, and completing teacher utterances.

During the independent work stage of the lesson, watch for students verbalising their thinking (talking to themselves about the mathematics), self-monitoring (e.g., "that's not right" or checking their work) asking work-related questions of their peers or the teacher, completing peer or teacher utterances, answering peer or teacher questions in a way that reflects some thinking about mathematics (i.e. answering "I don't know" doesn't count), explaining their reasoning, and gestures of thought and concentration. 
Observe four students at a time for two minutes and then move on, in a systematic manner based on pre-determined positions in the class and a random starting point each lesson. Record instances of each of the behaviours listed (tagged by student) twice per lesson, once during the independent work stage and once during teacher instruction. 


\section{Appendix L. Page 1 of thematic revision sheet}

\section{Revision of Length, Midpoints and Gradient}

Some of the larger Fijian Islands are represented on this grid. One unit is about $50 \mathrm{~km}$.

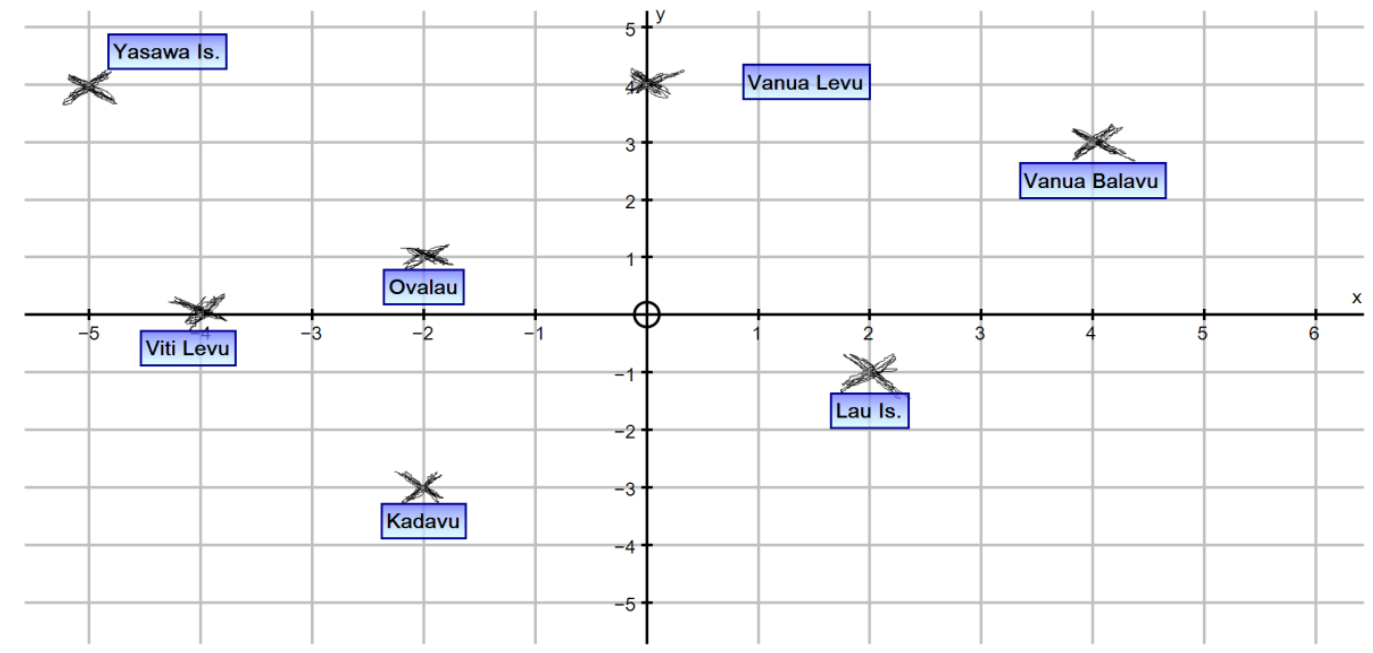

For the voyage from Yasawa Is to Ovalau:

1. Find the length of the line.

2. Find the coordinates of the midpoint.

3. Find the gradient of the line.

For the voyage from Lau Is. to Vanua Balavu:

4. Find the length of the line.

5. Find the coordinates of the midpoint.

6. Find the gradient of the line.

For the voyage from Yasawa Is. to Vanua Levu:

7. Find the length of the line.

8. Find the coordinates of the midpoint. canoe, $1830 \mathrm{~s}$

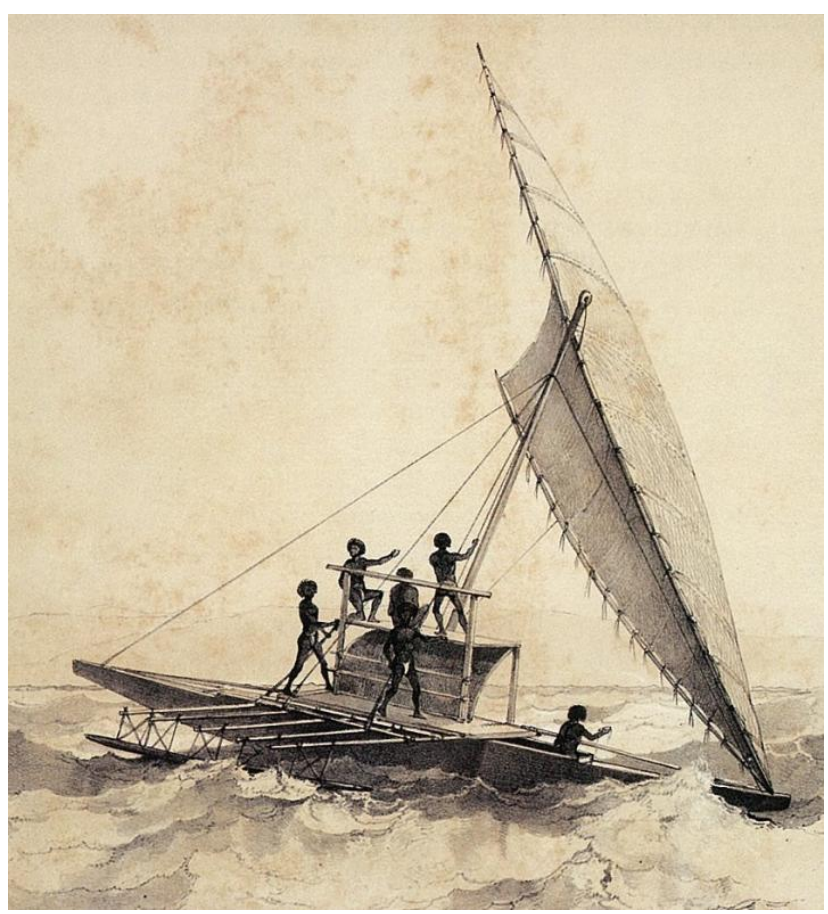

Above: Fijian camakau outrigger ${ }^{21}$

9. Find the gradient of the line.

${ }^{21}$ Image from Vaka Moana (Howe, 2006) 
Appendix M.Page 1 of non-thematic revision sheet

\section{Revision of Length, Midpoints and Gradient}

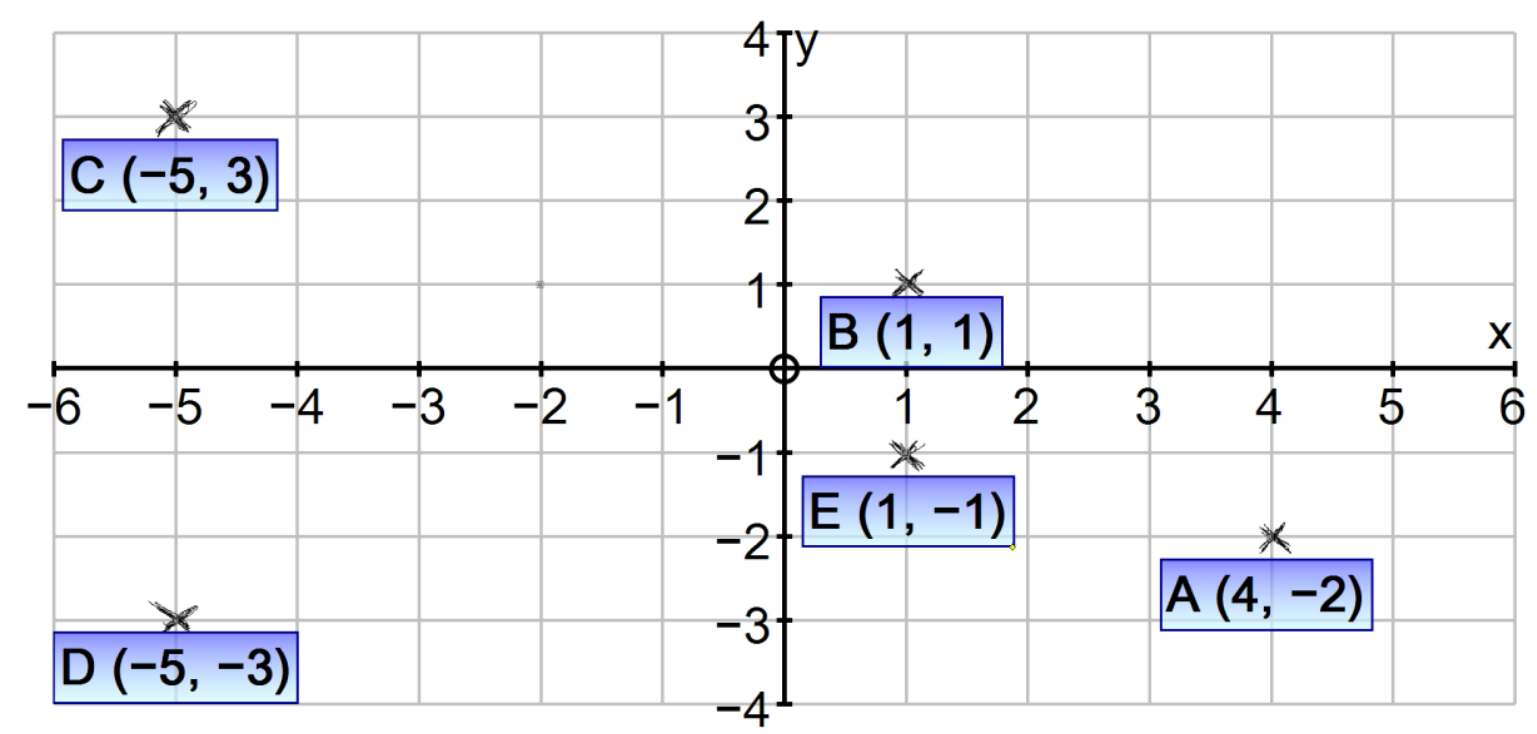

For the line $\mathbf{C B}$ :

1. Find the length of the line.

2. Find the coordinates of the midpoint.

3. Find the gradient of the line.

For the line EA:

4. Find the length of the line.

5. Find the coordinates of the midpoint.

6. Find the gradient of the line.

7. What can you tell about $\mathrm{CB}$ and EA from their gradients?

For the line CD:

8. Find the length of the line.

9. Find the coordinates of the midpoint.

10. Find the gradient of the line. 
Appendix N. Inter-item correlations for engagement questionnaire ${ }^{22}$

Inter-Item Correlation Matrix

\begin{tabular}{|c|c|c|c|c|c|c|c|}
\hline & $q 1$ & q2 & q3 & $\mathrm{q} 4$ & q5 & $q 6$ & $q 7$ \\
\hline$q 1$ & 1.000 & .428 & .571 & .650 & .658 & .772 & .729 \\
\hline q2 & & 1.000 & .339 & .472 & .456 & .413 & .368 \\
\hline q3 & & & 1.000 & .603 & .583 & .512 & .614 \\
\hline q4 & & & & 1.000 & .802 & .608 & .648 \\
\hline q5 & & & & & 1.000 & .630 & .652 \\
\hline$q 6$ & & & & & & 1.000 & .697 \\
\hline q7 & & & & & & & 1.000 \\
\hline
\end{tabular}

${ }^{22}$ For questions, see Appendix E. 
Appendix 0. Item statistics for engagement questionnaire ${ }^{23}$

Item Statistics

\begin{tabular}{|c|c|c|c|}
\hline & Mean & Std. Deviation & $\mathrm{N}$ \\
\hline$q 1$ & 3.58 & 1.000 & 300 \\
\hline$q 2$ & 2.74 & .877 & 300 \\
\hline q3 & 3.49 & .980 & 300 \\
\hline$q 4$ & 3.15 & .938 & 300 \\
\hline q5 & 3.17 & .971 & 300 \\
\hline q6 & 3.54 & 1.052 & 300 \\
\hline q7 & 3.34 & 1.114 & 300 \\
\hline
\end{tabular}

${ }^{23}$ For questions, see Appendix C. 